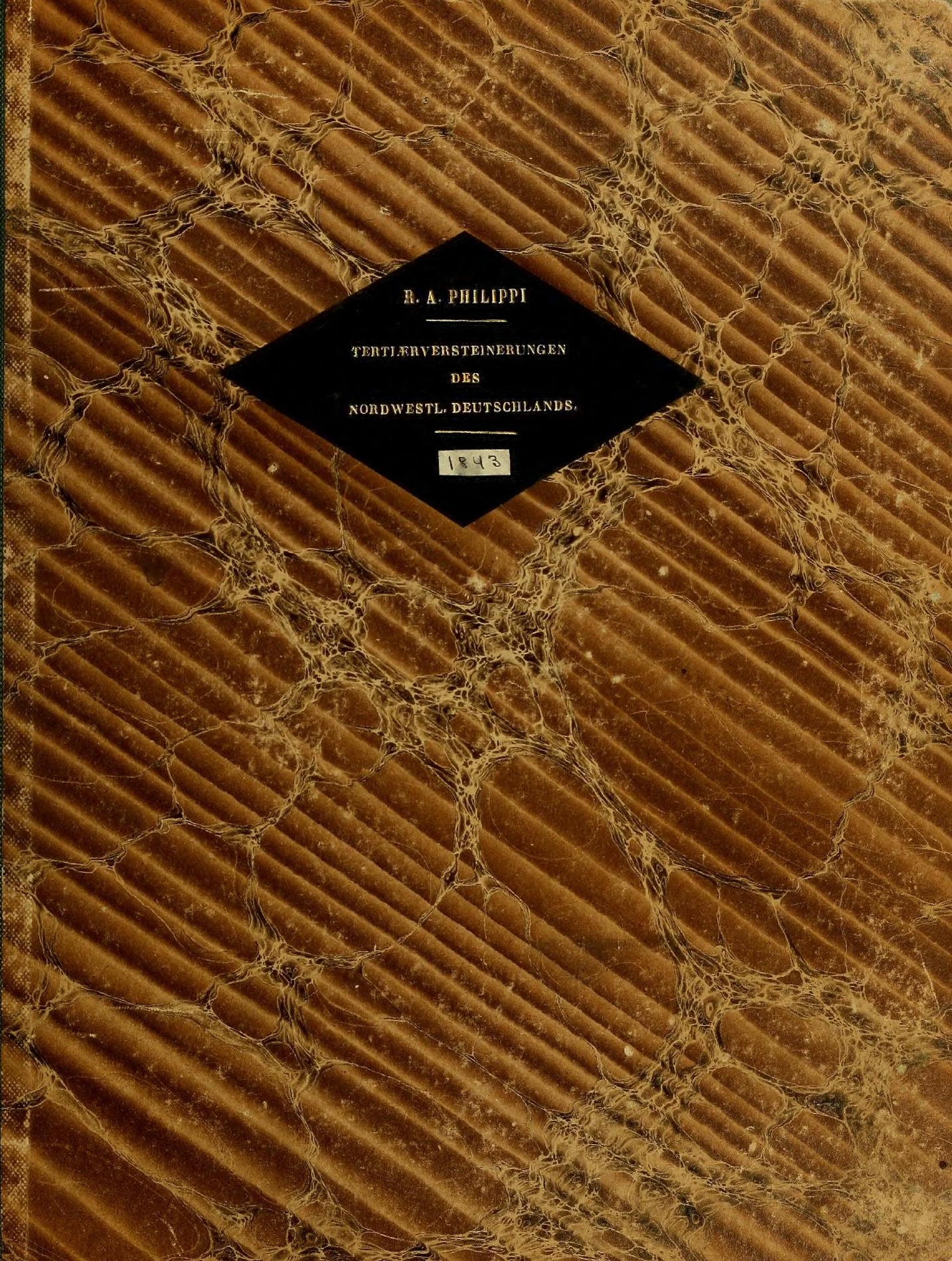


Piforary of the atturseum

oF

\section{COMPARATIVE ZOÖLOGY,}

aT IARTARd COLLEGE, CAIBRIDGE, MaSS.

foundeð by príbate subscription, ín $\mathbf{1 8 6 1}$.

DR. L. DE KONINCK'S LIBRARY.

No. 1479 


\title{
Beiträge zur Kenntniss
}

\author{
der
}

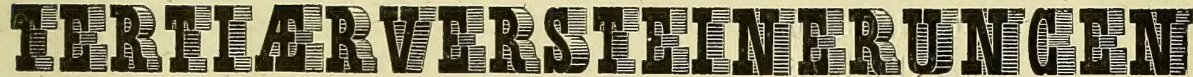

des

\section{nordwestlichen Deutschlands}

\section{DR. R. A. PHILIPPI,}

Mitglied der Königl. Academien der Wissenschaften von Neapel und Turin, der Academie Gioenia in Catania, der Academien de' Zelanti in Aci, der Academie Florimontana in Monteleone; der Gesellschaft naturforschender Freunde in Berlin und Marburg, der Wetterauischen Gesellschaft, des Rheinisehen Vereins für Naturkunde in Mainz, der Vereine für Naturkunde in Hamburg und Kassel; des Vereins für Natur und Heilkunde, für Erdkunde, für Gartenbau in Berlin.

\section{Mit Abbildungen.}

\section{IK a s e l,}

Druck und Verlag von Theodor Fischer.

$\sin 843$. 


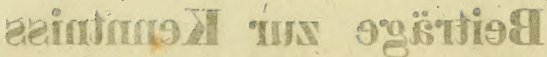

796

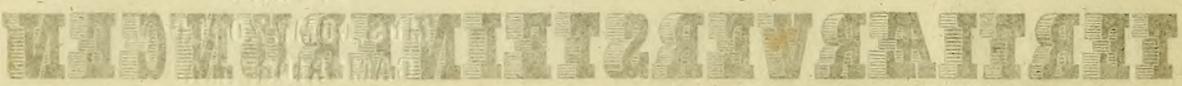

is $b$

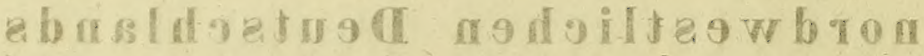

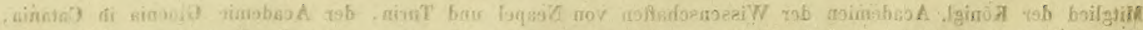

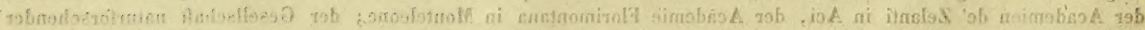

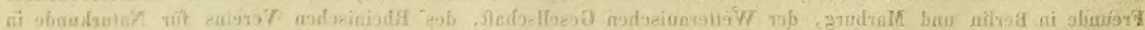

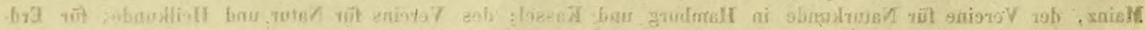

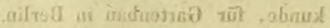

a gyabitidde tim

\section{- 1.3 a e a dis}

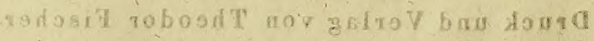

$8+81$ 


\section{y. re e e.}

Die Beiträge zur Kenntniss der Tertiärversteinerungen des nordwestlichen Deutschlands bestehen aus drei verschiedenen Theilen; einem Verzeichniss der Versteinerungen der Wilhelmshöhe bei Kassel; einem Verzeichniss der Versteinerungen der Gegend von Freden und Diekholz, und einem Verzeichniss der Versteinerungen von Luithorst, welcher Ort etwa 1 Stunde nordwestlich von Stadtoldendorf liegt. Das erstere ist bereits im August 1841 als Programm der höheren Gewerbschule in Kassel gedruckt worden. Mehrere Freunde, denen diese Arbeit bekannt wurde, munterten mich auf, sie auch auf die Tertiärversteinerungen des übrigen nordwestlichen Deutschlands auszudehnen, versahen mich mit dem nöthigen Material, und gaben so die Veranlassung zu gegenwärtiger Abhandlung. Diese stückweise Entstehung wird es, hoffe ich, entschuldigen, dass das Werk nicht aus einem Gusse erscheint, sondern manche Unbequemlichkeiten und einige Verschiedenheiten zwischen den einzelnen Abschnitten zeigt.

Bei ziemlich vielen Arten habe ich ein ? hinzusetzen müssen. Dieses werden gewiss alle diejenigen billigen, welche sich mit dem Studium der Mollusken und Versteinerungen ernstlich beschäftigt haben, und wissen, wie schwer es oft hält, eine Art mit Sicherheit zu erkennen, oder in ihr richtiges Genus zu bringen, selbst wenn wir sie ganz unversehrt und im vollen Farbenschmuck besitzen, geschweige denn, wemn wir auf der Oberflache abgeriebene oder beschädigte Exemplare vor uns haben, oder gar blosse Bruchstücke, aus deneu wir mit Mühe ein Ganzes zusammensetzen müssen; ein Fall, der leider nur zu häufig bei den untersuchten Versteinerungen eintrat. Blosse Stein-Kerne mit Sicherheit zu bestimmen, halte ich in vielen Fällen für ganz unmöglich, und habe nur in seltenen Ausnahmsfällen solche bestimmt, wo ich meiner Sache vollkommen gewiss zu sein glaubte. Die neuen Arten habe ich so kurz und deutlich, wie möglich, beschrieben; die Länge der Beschreibungeu 


\section{- II -}

ist es selten, wodurch eine Art kenntlich gemacht wird; sondern nur dadurch, dass man die unterscheidenden Kennzeichen hervorhebt. In wie fern mir dies gelungen, will ich dem Urtheil des betheiligten Publikums anheim stellen. Es war von Aufang an meine Absicht, alle neue Arten mit Abbildungen zu begleiten; da ich aber sehr wünsche dieselben selbst zu lithographiren, weil ich fürchte, dass einem mit diesen Gegenständen nicht vertrauten Lithographen die Arbeit nicht gelingen würde, und gegenwärtig noch nicht absehen kann, wann ich die nöthige Zeit dazu finden werde, so schicke ich meine Arbeit ohne dieselben in die Welt, mit dem Versprechen, die Abbildungen so bald als möglich nachzuliefern.

In Ganzen sind in dieser Abhandlung 219 Arten Mollusken aufgeführt; ich habe mich nach Kräften bemüht, dieselben sowohl mit der lebenden Molluskenfauna als mit anderen Tertiärformationen zu vergleichen, und allgemeine Resultate aus der Arbeit zu ziehen. Am genauesten ist wohl die Vergleichung mit der lebenden Molluskenfauna des Mittelmeers, wo ich meine eigenen, ziemlich vollständigen Untersuchungen benutzen konnte, so wie mit der Pariser Formation ausgefallen, die wir durch die trefiliche Arbeit von Deshayes so genau kennen. Auch die Vergleichung mit der Subappenninenformation dürfte sehr zuverlässsige Resultate gegeben haben. Weniger kann ich dies von der Vergleichung mit dem Becken von Bordeaux und mit Polen sagen: für erstere konnte ich nur die unvollständige Arbeit von Basterot und einzelne zerstreute Notizen benutzen; für letztere die Werke von Dubois und Pusch, und bekanntlich sind eine Menge der Eichwaldschen Arten noch immer problematisch. Recht sehr bedaure ich es, dass ich nicht anch die Tertiärformationen Englands in den Kreis meiner Vergleichungen ziehen kounte; Sowerby's Mineral Conchology war mir aber unzuganglich, und Flemings history of british animals, welche ich besitze, und in der die Sowerby'schen Arten aufgenommen sind, erlaubt keine Vergleichung, da dieser Schriftsteller fast alle Genera anders definirt, als man auf dem Kontinent gewohnt ist. So findet man z. B. das Pteropoden Genus Odontidium als eine Orthocera aufgeführt, Murex erinaceus als Tritonium, die kleinen Pleurotoma-Arten als Fusus, die Cerithien als Terebra, den Strombus ornatus Desh. *) als Cólumbella, die Diplodonta dilatata und den Solen strigilatus als Psammobien! - Die Zoophyten und Polythalamien erlaubten leider keine ähnliche Vergleichung, da sie im Allgemeinen wenig bearbeitet sind, und keine einigermassen vollständigen Verzeichuisse derselben für die einzelnen Formationen existiren.

Die hauptsächlichsten Resultate, welche ich durch diese Untersuchungen für sämmtliche Arten, und für die einzelnen drei Lokalitäten insbesondere gewomnen habe sind folgende:

Es ist falsch, wenn man die Tertiärformation der betrachteten Gegenden der Pariser Formation gleich stellt, und mit dem Namen Grobkalk belegt. Dieselbe zeigt vielmehr eine

*) Den Agassiz zu Tritonium (nämlich zu dem schlechten Genus Persuna) bringen will, und der ein ganz ächter Strombus ist. 


\section{- III -}

grössere Uebereinstimmung mit der Subappenninenformation, als mit irgend einer andern Tertiärbildung, indem mehr als ein Drittel ihrer Arten auch in der Subappenninenformation angeíroffen werden.

Sie hat mehr Arten mit der jetzigen Schöpfung gemein als mit den Bildungen von Paris, Bordeaux und Polen, (aber weniger als mit der Subappenninenformation); und ist daher jünger als diese Bildungen, wenn nämlich das Verhäliniss der tebenden zui den âusgestorbenen Arten ausreicht zur Bestimmung des Alters.

Von den Arten, welche die Tertiärformation von Kassel, Freden, Luithorst mit den Tertiär-Bildungen Italiens, Polens, und von Bordeaux gemein hat, sind letwas mehr als die Hälfte lebende Arten; von den Arten, welche sie mit Paris gemein hat, ist nur ein Sechstel noch lebend.

Die lebenden Arten gehören fast ganz dem Mittelmeer an sehr wenigeisinid der Nordsee eigenthümlich; in heissen Meeren kommen kaum zwei Arten vor. Das Klima in der damaligen Periode ist also höchstens ein paar Grade wärmer gewesen als gegenwärtig.

Diese Resultate ergeben sich aus folgenden Zahlen.

Es sind im Ganzen, bei Kassel, bei Freden, bei Luithorst:

lebend: $\quad 0,21 \quad 0,25 \quad 0,22 \quad 0,26$.

in der Subapp. form. $0,35 \quad 0,38 \quad 0,38 \quad 0,44$.

hei Bordeaux: 0,15 $\quad 0,19 \quad 0,15 \quad 0,15$.

bei Paris: $\quad 0,16 \quad 0,20 \quad 0,13 \quad 0,20$.

in Polen: $0,15 \quad 0,18 \quad 0,17 \quad 0,18$.

Von den 76 Arten, die auch in der Subapp. form. vorkommen, sind lebend: 40 Arten oder 0,52.

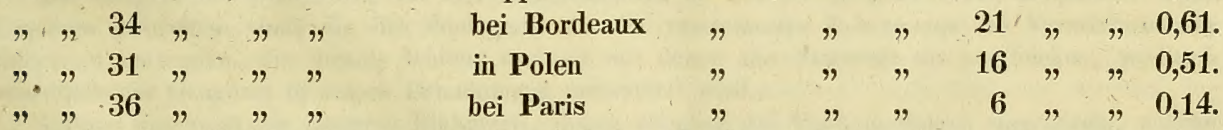

- $\quad$ - Von den 47 lebenden Arten finden sich im Mittelmeer 39

im Mittelmeer aber nicht in der Nordsee $\quad 26$

im Mittelmeer und in der Nordsee 13

in der Nordsee und nicht im Mittelmeer $5 *$ )

in heissen Meeren 2 *****)

problematisch ob lebend 1 ****; $)$.

* Cyprina islandica, Rissoa interrupta interstincta, unidentata, Natica castanea

**) Venus plicata, Turritella carinifera.

***) Dentalitim fossile $\mathbf{L}$.

Kassel, den 5. März 1843.

Dr. Plitippi. 
-

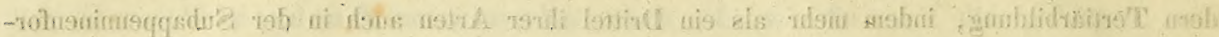

$\rightarrow$ Verzeichniss der Versteinerungen der Wilhelmshöhe bei Kassel p. 1. Verzeichniss der Versteinerungen von Freden und Diekholz $\quad$ p. 33.

- Verzeichniss der Versteinerungen von Luithorst $\quad$ p. 66.

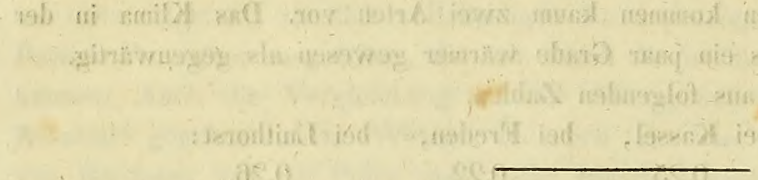




\section{Ueber die}

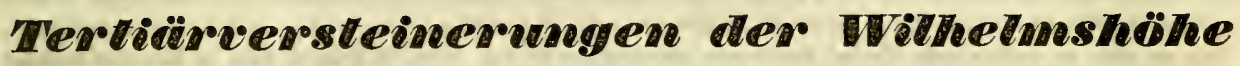 bei Kassel.}

Tu einer in geologischer Beziehung neuen Zeit hat das Meer den Boden bedeckt, auf welchem wir jetzt wandeln; grosse Flüsse haben sich hinein ergossen, Schlamm und Sand auf dessen Grunde angehäuft und namentlich auch aus den waldigen Gegenden, welche sie durchströmt, ungeheure Massen von Baumstämmen hinabgeführt. Diese sind endlich, an den Flussmündungen vermuthlich, im Schooss der Wasser begraben, ähnlich wie in dem Atchafalaya, einem Arm des Missisippi, sich eine Menge Baumstämme ansammelt, deren Inhalt im Jahr 1808 auf beinah 300 Millionen Kubikfuss geschätzt wurde; sie haben sich, mit Sehlamm und Sand bedeckt, im Laufe der Jahrtausende in Kohle vervandelt und liefern nun die für die Bewohner Kassels und der Umgegend so höchst nützlichen Braunkohlen. Aber dieses Meer blieb nicht lange in Ruhe sich selbst überlassen; die plutonischen Kräfte im Innern der Erde durchbrachen den Grund des Meeres, ergossen ihre feurig-geschmolzencn Gebirgsmassen, unsere Basalte, durch zahlreiche Oeffnungen und Spalten und hoben an vielen Stellen den Meeresboden, selbst tausend Fuss hoch empor. In einer spätern Zeit wurde der ganze Mecresgrund in Festland verwandels, und ungeachtet ein grosser Theil desselben wieder durch die neu entstandenen Flüsse hinweggeschwemmt ist, bis der darunter liegende Felsengrund zum Vorschein kam, so legen doch zahlreiche Schalen von Muscheln, zahlreiche Korallen, Zähne und Wirbel von Fischen Zeugniss von dem langen Verweilen unserer IIeimath im Grunde der See ab.

Die Aufgabe des Geognosten ist es, zu bestimmen, in welcher geognostischen Zeitperiode diese Vorgänge geschehen sind, die des Zoologen, aus den versteinerten Ueberresten das Verzeichniss der Thiere zu entwerfen, die damals lebten, und sie mit denen der Jetztwelt zu vergleichen, wodurch wesentlich der Geognost in seinen Bemühungen unterstützt wird.

Unsere Kenntniss der jüngsten Bildungen, denen offenbar die Versteinerungen angehören, welche in diesem Aufsatz untersucht werden sollen, ist sehr neu, sie schreibt sich erst von dem Erscheinen der klassischen Arbeiten von Al. Brongniart und Cuvier üßer die Ungegend von Paris im Jahr 1811 her. Eine natürliche Folge dieses V̌erkes war, dass man Anfangs alle tertiären Billungen, die an andern Orten aufgefunden wurden, mit der Tertiärformation von Paris und deren einzelnen Gliedern identificirte, und so konnte es nicht wohl anders kommen, als dass man die Braunkohlen und den Thon unserer Gegend für sogenannten ,plastischen 'Th on", den meist darüber liegenden Sanl elc. aber für, Grobkalk" erklärte, ein Name, der zwar noch jetzt häufig für diese Bildung hier in Gebrauch, aber gänzlich unpassend ist.

Späterhin, als die tertiären Bildungen in England, in der Gegend von Bordeaux, in Italien, in der Schweiz, in Polen genauer studirt wurden, erkannte man aber, dass dieselben sich zu sehr verschiedenen Zeiten abgelagert haben und sehr verschiedene Versteinerungen einschliessen, wie sie überhaupt mehr lokale Bildungen sind, und sich nie über so weile Strecken ausdehnen, wie die älteren.

In den Jahren 1833 und 1834 ist zuerst in Leonhard's Jahrbuch für Mineralogie etc. der richtige Platz der Tertiärgebilde von Niedersachsen, Kurhessen und Westphalen angegeben, und in demselhen 
Jahrbuch für 1835 hat der Graf G. zu Münster aus dieser Bildung 11 Arten Radiarien, 12 Arten Anneliden, 126 Arten zweischalige, 65 einschalige Muscheln, 18 Cirrhipeden und Crustaceen und 9 Fische namentlich angeführt, und so es fest begründet, dass diese Gebilde nicht dem Pariser Grobkalk, sondern der weit jüngeren Subappenninenformation parallel zu stellen und damit gleichaltrig sind. Unter diesen Versteinerungen sind aus der. Gegend, von Kassel: zwei Radiarien, 56 zweischalige, 32 einschalige Mollusken und 7 Fische. Man kann nicht genug die Thätigkeit und das Glück dieses gefeỉerfen Mannes bewundern, dem die Paläontologie Deutschlands' so Vieles und Grosses verdankt, dass er eine so bedeutende Menge Arten zusammengebracht hat, ohne je längere Zeit in hiesiger Gegend verweilt zu haben. Es sind darunter nicht weniger als 25 neve Arten, alle aus der Gegend von Kassel, leider aber blosse Namen ohne Beschreibung, und diesem Uebelstand ist nur theilweise dadurch abgeholfen, dass Graf Münster den grössten Theil seiner Sammlung an Goldfuss zur Abbildung und Beschreibung in dessen grossem, klassischen Petrefacten-Werk mitgetheilt hat. Mehrere der neuen Arten fehlen aber in diesem gänzlich, und sind daher vorläufig räthselhaft. In der angeführten Abhandlung ist ferner nicht bemerkt, ob die Bestimmungen sich alle auf wohlerhaltene Exemplare oder zum Theil auch auf Steinkerne gründen, die so ätsserst unsicher bestimmt werden können, so dass man über die Zuverlässigkeit der Namen oft in Zweifel ist. Einige derselben erscheinen mir unrichtig, wenn ich z. B. sehe, dass Natica glaueina und canrena als hei Kassel vorkommend angeführt werden, die ich hier nie gesehen, wogegen die sehr häufige N. castanea ausgelassen ist, und wenn Graf Münster eine Scalaria Tılesii auf die Abbildung in Tilesius Abhandlungen Tab. 1. f. 4. C. C. F. gründet, welche sehr roh ist, und jedenfalls drei vers chiede ne Arten, worunter wahrscheinlich eine Pleurotoma, vorstellt.

Ich sage dies nicht aus Tadelsucht, da jch aus eigener Erfahrung sehr wohl weiss, welche Schwierigkeiten das Bestimmen der höchst zerbrechlichen und daher meist nur in grösseren oder kleineren Bruchstücken zu erhalienden Kasseler Versteinerungen macht, sondern lediglich, um hierdurch den Vorwurf 2iitüakzuweisen, gegenwärtige Arbejt sei überflüssig. Schr unzuverlässig sind alle älteren Bestimmungen u. ich habe es daher für nothwendig gehalten, im folgenden Verzeichniss nur solche Arten aufzunehmen, die ich selbst gesehn, oder die wenigstens in dem grossen Goldfussischen Werke, als von Kassel stammend, beschrieben und abgebildet sind, indem ich dabei alle Steinkerne ausgeschlossen habe. Die Arten, weldhe ich nicht sellost gesehn habe, siml mit einem $t$ bezeichnet. Leider habe ich bei dem hier herrschenden Mangel an literarischen Itülfsmitteln, dem nur zum Theil die Liberalität der Göttinger Bibliothek abhelfen konnte, mehrere für die Bestimmung der Tertiärversteinerungen wichrige Werke mir nicht verschaffen künnen, indessen glaube ich, dass wohl nur selten der Fall vorgekommen ist, dass cine von mir als neu aufgestellte Art schon beschrieben ist. Die Werke, welche ich besonders häufig anführe von Lamarck, (xoldfuss, Deshayes, Brocchi, Sowerby, Basterol, Al. Brongniart, Pusch ete. werden auch in ihrer abgekurzten Bezeichnung dem Kundigen kenntlich sein; von mir eitire ich meine Enumeratio Molluscorum Siciliae cum viventium, tum in tellure tertiaria fossilium.

Die im Folgenden aufgeführten Verstejnerungen sind olıne Ausnahme ron Montchéri und vom Apollobcrge auf Wilhelmshöe, so wie vom Ahnethal; besonders habe ich selbst viele bei der Gelegenheit gesammelt, als im Jahr 1836 ein Versuchsschacht auf Wilhelmshöhe getrieben wurde, um den Ursprung einer eisenhaltigen Quelle aufzufinden. Sie finden sich in einem meist ockergellon oder berggrünen Sande, in dem sich häufig Eisenoxydhydrat in Menge ausgeschieden hat. Die Beschreibung: desselben, so wie genaue Nachrichten ïher das Vorkommen der obern Tertiärbildung in Kurhessen siehe in der Abhantlung vom Bergrath Schwarzenberg in den Studien des Göttingischen Vereins bergmännischer Freunde. Band 111. p 221. sq, besonders [1. 229.

Schliesslich allen denjenigen Herru, die mich durch Mittheilung ron Exemplaren und Nachrichten bei dieser Arbeit unterstïtzt haben, namentlich Ilerrn Bergrath Schwarzenberg, meinen besten Dank. 


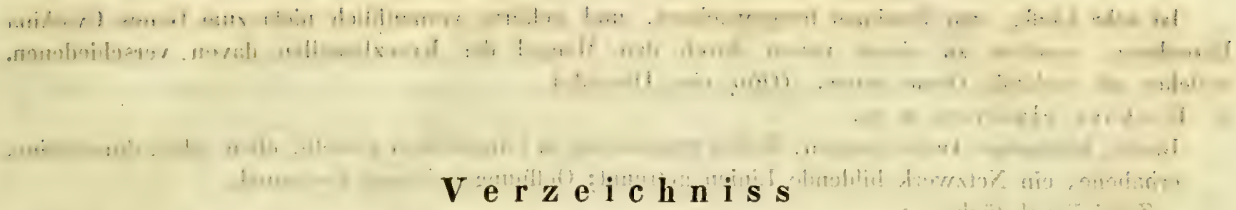

\section{aler Hei Hassel Denlogelnteten Vensteimentumgen.}

\section{zoophyten.}

1. Lunulites perforatus, Münst.

"Hochgewölbt und napförmig. Die sirahligen Furchen sind auf beiden Seiten sehr deutlich und "mit kleinen Löchern besetzt. Die von ihnen begränzten gradzeiligen Zellenreihen haben auf der "obern convexen Fläche runde Mündungen, und sind auf der innern concaven n ch ihrer "ganzen Weite geöffnet. Wạhrscheinliç. waren sie im frischen Zustande durch eine innere "Haut geschlossen. Findet sich bei Kassel," Goldf. p. 106. t. XXXVII. f. 8. Ich besize 69 Exemplare und glaube ülıerzeugt zu sein, dass Goldfuss höchst beschädigte Stücke ahgebildet und beschrieben hat. Ganz gewiss ist die untere Fläche zerstört gewesen und nur deshalb erschienen die Zellen unten nach ihrer ganzen Weite geöfhet. Wenn es ferner heisst: "hochgewölbt und "napfoürnig“ so ist zu bemerken, dass alle möglichen Grade der Wülbung und dem entsprechend alle Grade der Vertiefung auf der untern Seite vorkommen; es gibt selbst Exemplare, die auf der untern Seite vollkommen eben, ja sogar convex sind. Dies ist besonders bei kleinen jugendliçen Exemplaren. Wenn die Zellen nicht verletzt sind, so erscheinen sie oben quadratisch mit grosser eiförmiger Oeffnung und man erkennt, dass diese Art in nichts von L. radiata Lamk. verschieden ist, welche nach dem Register bei Goldfuss auch bei Kassel vorkommen soll. (Im Text wird dieser Fundert nicht angegeben).

+ 2. Lunulites rhomboidalis v. Münst.

„Beinah kreisförmig, flach, unten mit strahlenden āstigen Furchen; die Zellen beinah rautenförmig, "einander berührend, gerandet; die Mundöfrinungen oval, an Ende."

S. Goldf. f). 105. t. XXXVII. f. 7.

Ich habe diese Art nie gefunden, besitze aber 2 Exemplare von Gravina in Appulien, welche vollkoinmen wohl erhalten sind und mit der citirten Abbildung und Beschreibung genau übereinstimmen.

3. Turbinolia intermedia v. Müst.

„Keilförmig zusammengedrüekt; Seitenlamellen kurz, dick, glattkantig; Stern länglich; die abwech"selnd breiteren und schmaleren Lamellen stossen in cinem linienförmigen Mittelpunkt zusammen."

S. Goldf. p. 108. t. XXXVII. f. 19.

Ich hesitze 7 Exemplare. Schade, dass sie den Namen intermedia führt, da sie die einzige wahre Turbinolia d. h. frei, nicht angewachsen ist, die ich in Natur kenne.

4. Turbinolia granulata v. Münst.

"Verkehrt kegelförmig, an der Basis etwas gekrümmt; die Lamellen an den Kanten gekörnt; Stern "kreisrund; nur die abwechselnd breiteren Lamellen erreichen den Mittelpunkt. *

S. Goldf: p. 108. t. XXXVII. f. 20. 
Ist sehr häufig, war bestimmt festgewachsen, und gehörte vermuthlich nicht zum Genus Cyathina Ehrenberg, sondern zu einem neuen durch den Mangel der Kranzlamellen davon verschiedenen,

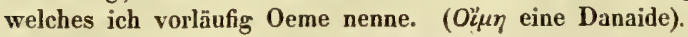

5. Eschara clathrata n. sp.

Breite, blattartige Ausbreitungen; Zellen regelmässig in Längsreihen gestellt, eben, glatt, durch feine, erhabene, ein Netzwerk bildende Linien getrennt; Oeffnungen beinah kreisrund.

Zwei Bruchstücke.

Die Ausbreitungen sind sehr breit, so dass über 12 Zellen in einer Querreihe liegen; diese sind unregelmässig, meist länglich fünfeckig. Die Oeffnungen nehmen die halbe Grösse der Zellen ein; und sind hinten etwas breiter.

6. Discopora circumcincta n. sp.

Zellen länglich, glatt, ziemlich gewölbt, durch eine doppelte Reihe grosser eingestochener Punkte von einander geschieden; Oeffnungen klein, halbinondförmig.

Zwei Bruchstücke. Nahe verwandt ist eine im Sicilischen Meer lebende Art, die ich D. suturalis nenne; sie hat weit kleinere Löcher in den Punktreihen, und eine erhabene Linie zwischen denselben, welche die einzelnen Zellen trennt.

\section{Polythalamien.}

Siehe Rōmer in Leonhard's und Bronn's Neuem Jahrbuch für Mineralogie, Geognosie etc. Jahrgang 1838 . p. 381 .

1. Nodosaria elegans vo: Münster. Römer p. 382. f. 1.

"Pfriemenförmig, stielrund, etwas gebogen, später deutlich knotig, mit 6-16 mit dem Alter an

"Zahl durch Dichotomie meist zunehmenden feinen Linien oder Rippen bedeckt." Ohne Fundort.

Ein Exemplar.

2. Nodosaria intermittens Röm. p. 382, f. 2.

„Pfriemenförmig, rund, etwas [sehr schwach] bogenförmig, mehr oder weniger knotig, nur in den „Einschnürungen längsgestreift. Ohne Fundort.

Ein Exemplar.

Frondicularia Dfr. d'Orb. *)

Wodurch unterscheidet sich Frondicularia Dfr. von Lingulina d'Orbigny? Von Frondicularia heisst es bei d'Orbigny Tableau méthodique de la classe des Céphalopodes Ann. des sciences d'hist. nat. 1826. p. 90: "loges três-déprimées sur les deux faces" von Lingulina ebendaselbst p. 91. "test déprimé sur ses faces;" von Fr. weiter: loges plus ou moins enchâssantes de chaque côté de l'axe fictif, qui est droit et central“ von Lingulina bloss: „loges recouvrantes." Von Frond. ist die Oeffnung nicht angegeben, [sie ist bei Fr. oblonga eine schmale Spalte]; bei Lingulina heisst es: "ouverture en fente et terminale." Ich glaube demnach, dass man beide Genera nicht für verschieden halten kann, sondern vereinigen muss; wobei der Name Frondicularia, als der ältere, den Vorzug verdient. Sonderbar, dass Niemand erwähnt, dass die erstern Windungen spiralförmig angeordnet sind!

3. Frondicularia oblonga v. Münst: Röm. P. 382. nr. 1. f. 4.

"Zugespitzt, eirund, glatt; Ohne Fundort.

Hãufig auf Wilhelmshöhe.

4. Frondicularia ovata v. Münst. Röm. p. 382. f. 5.

-) Es ist wohl ein Schreibfehler, wenn es bei Römer immer Frondiculina heisst. 
"Breit eirund, glatt, bisweilen concentrisch etwas gerunzelt." Ohne Fundort.

Häufig auf Wilhelmshöhe.

5. Frondicularia elongata v. Münst. Röm. p. 382. nr. 3. f. 6. *)

„Länglich keilförmig, glatt." Ohne Fundort.

Häufig:

Dicse drei Arten unterscheiden sich einzig und allein durch das Verhältniss der Länge zur Breite, welches sehr variabel erscheint; und bis bessere Unterschiede (in der Oeffnung u. s. w.) entdeckt werden, möchte ich sie alle für eine Art erklären und auch die Fr. obliqua Röm. f. 7 dahin rechnen. Als Extrem kann man noch eine Form aufstellen:

6. Frondicularia linearis n. sp.

Fast vollkommen linealisch, gerade, glatt.

Ein Exemplar. Von Fr. ensiformis Röm. f. 8 unterschieden, indem sie ganz gerade und an der Spitze nicht ungebogen ist.

7. Vaginulina laevigata. Röm. p. 383. f 11 .

"Schwertförmig, etwas gebogen, stark zusammengedrückt, glatt." Ohne Fundort.

Nicht selten.

8. Polymorphina communis d'Orb. Rōm. p. 385. nr. 9. f. 29.

„Ein gleichseitiges Dreieck mit stark abgerundeten Winkeln der Basis, unten sehr gewölbt, hinten "flach; vier Kammern sichtbar." Ohne Fundort.

Ein Exemplar.

9. Polymorphina teretiuscula Röm. p. 385. nr. 4. f. 24 ?

"Länglich spindelförmig oder erweitert, fast kreisrund und nur wenig zusammengedrückt, stumpf"spitzig; jederseits mil 4-5 Kammern." Ohne Fundort.

Ein Excmplar, welches in der Mitte zwischen P. terctiuscula und obscura steht; wegen der zusammengedrückten Schale habe ich es zu ersterer gebracht. Uebrigens stimmen Römers Worte: "fast "kreisrund" nicht mit der Figur, die eine Ellipse zeigt, deren Durchmesser sich wie 2: 1 verhalten.

10. Cristellaria subcostata v. Münst. Röm. p. 391. f. $6 \pm$ ?

"Oval his kreisrund, kleiner, gewölbter, mit etwa 8 bis zum Kiel fortsetzenden Rippen. Osnabrück.*

Ein Exemplar, nicht so gewölbt wie Römers Figur, sondern wie Cr. osnabrugensis, aber ohne den scharfen Kiel derselben.

11. Marginulina compressiuscula n. sp.

Fast linealisch, schwach zusammengedrückt im Verh. 1:3, sehr wenig aufgerollt, platt; Spitze schmaler als das Ende, Endfläche schief.

Ein Exemplar.

12. Marginulina arcuata n. sp.

Schwach gebogen, stark zusammengedrückt im Verh. 1:4-5, glatt; die Spira im Durchmesser fast so breit als der gerade Theil; Endfläche in der Sehne der Krümmung.

Ein Exemplar ausser mehreren unvollständigen.

13. Marginulina spirata $n$. sp.

Stark gekrümmt, eine volle Windung beschreibend, zusammengedrückt im Verh. $1: 4$, fast gekielt, glatt; Spira im Durchmesser zwei Mal so breit als der gerade Theil, Endfläche in der Sehne der Krümmung.

Ein Exemplar.

: .) Es ist wohl ein Druckfehler, wenn bei Römer diese Art, eben so wie nr. 1. Fr. oblonga heisst. 


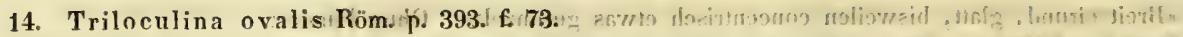
"Oval, im Durchschnitt zusammengedrückt-dreiseitig; Kammern mit stumpfem Riticken. " Ohne Fundort. Sehr hâufig; meine Exempląe scheinen etwas gröșser zu sein als die Figur von Römer..... '?

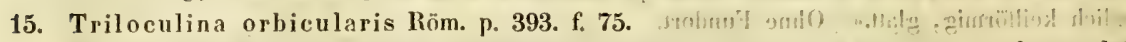
"Ziemlich kreisrund; im Durchschnitt fast ein gleichseitiges Dreieck mit efwas abgerundeten Win"keln der Basis und stumpfem Scheitel: 4 Ohne Fundort: Vier Exemplare, ein weniges kleiner als die citirte Figur.

\section{Fadiarien.}

1. Spatangus acuminatus v. Münst.

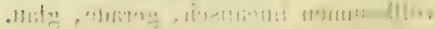

"Hinten hoch emporsteigend, scharl" gekielt, nach dem Rande schief ahgestutzt, vorn steil abschüs"sig, mit einem breiten, tiefen, nach dem Rande verschmälerten Kanal; Umfang heinah kreisförinig; „Scheitel hinter dem Centrum, Kanäle der seitlichen Ambulakra grade, die hinteren sehr:kurz, oval;

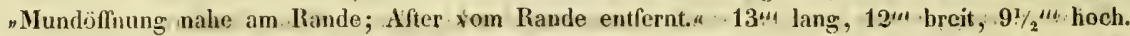

S. Goldf. p. 158. t. XLIX. f. 2. - v. Münst. in Leonhard's und Bronn's Jahrbuch etc. 1835. p. 434. nr. 9. Er gehört in das Agassizsche Geschlecht Micraster und soll anch bei. Bordeaux vorkommęn; aus der Gegend von Kassel ist Kaufungen bis jetzt der cinzige Fundort.

2. Echinoneus ovatus v. Mïnst.

Molumil mit

"Mässig gewölbt, im Umfang entweder kreisförmig oder elliptisch oder eiförmig; die Basis ganz "flach; Fühlergänge sehr kurz, Fühleröfnungen selten, entfernt" $2^{\prime \prime}$ lang.

S. Goldf. p. 136. t. XLII. f. 10. - v. Münst. l. c. p. 434 . nr.

Nur ein Exemplar; ist in der Gegend von Alfeld sehr häufig.

Apiocrinites obscurusin. sp. in

Gibt Graf Müuster. I. c. p. 434. nr. 10 an, was eine sehr sonderbare Erscheinung ist.

\section{Mollusken.}

\section{Acephalen oder Muschelthiere.}

1. Solen Ensis I. var. minor.

Schale linealisch, gekrümmt; Schloss dicht am vordern Ende, auf der einen Valve einzâhnig, auf der andern zweizähnig. $3 t^{\prime \prime \prime}$ lang, $4{ }^{\prime} / 2^{\prime \prime \prime}$ hoch.

S. Ensis L. Lamk. ex parte. - S. Iausmanni Schloth. Goldf. p. 277. t. CLIX. f. 5. (Die Enden zu rund). - Schon IIausmann sagt: Studien des Gött. Vereins III. p. 302 Note: „Mir scheint kein „so wesentlicher. Unterschied zwischen diesem Solen und der kleineren und schmaleren Varietät „des S. Ensis Statt zı finden, dass eine Trennung beider gerechtertigt werden könnte, " worin ich ihm vollkommen beistimmen muss.

Ich habe auch Bruchstücke der Schale. Das grösste Exemplar ist $3^{\prime \prime \prime}$.hoch und üher 16 ${ }^{\prime \prime \prime}$ lang. .

2.1 Solen parisiensis Desh.

Schale eiförmig länglich, beiderseits abgerundet, in der Mitte eingedrückt, mit etwa 50 schrãgen vertieften Linien.

S. parisiensis Desh. Lamk. ed. 2. V. p. 63. nr. 4. - S. strigilatus Desh. Coq. foss. 1. p. 27. t. 2. f. 22. v. Münst. p. 435. nr. 6 .

Ein Bruchstück der rechten Schale fand sick in $\Lambda$ hnegraben, an welehem man sehr gut die 
charakteristischen schiefen Streifen der Abtheilung Solecurtus erkennen kann. Wegen ihrer G'edrängt: heit, der geringen Grösse der Schale, und wegen der starken Abrundung der vordern Extremitất bringe ich dieses Bruchstück lieber zu $\mathbf{S}$. parisiensis als zu strigilatus oder gar candidus.

3. Panopaea intermedia Sow:

Schale länglich eiförnig, gewölbt, hinten etwas umgebogen; Wirbel vor der Mitte, abgestutzt, mit concentrischen unregelniässigen Rurizeln und Streifen.

P. intermedia (Sow.) Goldf. p. 275. t. CLIX. f. 6. - Mya intermedia (Sow.) v. Münst. p. 435. nr. 13, 6 .

Ein schönes, hinten etwas abgebrochenes Exemplar ist von Herrn Bergrath Schwarzenberg gefunden; es ist $30^{\prime \prime \prime}$ lang, 1 $14^{\prime \prime \prime}$ hoch, $11^{\prime \prime \prime}$ dick. Die Schale ist mit dicht gedrängten erhabenen Punkten gekörnt wie bei manchen Thracia Arten:

4. Mactra triangula Ren.

Schale klein, dreickig, beiderseits, stumpf gekielt, glänzend, glatt; beide Seiten gefurcht; die Seitenzähne des Schlosses senkrecht gestreift.

M. triangula Ren. Broc. p. 535. t. 13. f. 7. M. lactea Poli t. 28. f. 13. 14.

Vier Exemplare, die auf das genaueste mit lebenden Exemplaren des Mittelmeeres übereinstimmen.

5. Corbula nucleus Lamk.

Schale dreiseitig-kugelig, in der Quere gefurcht, die hintere Seite spitzer und eckig, der eine Wirbel weit stärker heryorragend.

C. nuclews Lamk. V. p. 496.

Ist sehr häufig. C. rotundata (Sow.) Goldf. p. 252. t. CIII. f. 3. ist wohl nichts anders als der Jugendzustand, in weldhem die Schale noch gar keine oder sehr schwache Furchen hat.

6. Corbula carinala n. sp.

Schale eiförmig-dreieckig, dünn, schr fein gestreift; die hintere Seite länger, zweiwinklig, schräg abgestutzt, gekielt.

Ich besitze eine obere und eine untere Schale, dic $2^{\prime \prime \prime}$ lang und $11^{\prime \prime \prime}$ hoch sind. Die untere Schale ist stark gewölht, beinah dreieckig; das vordere Ende ist schmaler, abgerundet; das hintere schräg alıgestutzt mit einem scharf ausgesprochenen Winkel, von welehem cin scharfer Kiel zum Wirbel verläuft. Der Zahn des Schlosses tritt mässig hervor mit einer diagonal verlaufenden Leiste. Die obere Schale ist flicher, ebenfalls gekiclt; der Schlosszahn tritt weniger hervor. C. minuta Desh. ist sehr nahe verwanil, hat aber auf der linken Schale zwei Schlosszähne.

+ 7. Corbula cuspidata Bronn.

Schale dünn, eiförmig, fein quergestreift, hinten in einen langen sclımalen Schnabel ausgehend; keine Schlosszáhine.

C. cuspidata Bronn. Phil. Enum. Moll. Sicil. p. 17. t. 1. f. 19. - Goldf. 251. t. CLII. f. 1.

+ 8. Corbula ingosa Lamk.

„Schale eiförmig bauchig, die hintere Seite gekiclt, abschüssig, beinahe schnabelartig, länger als "die Vorficrseite; ziemlich grobe regelmässige Oucrfurchen, die hinten zusammenkommen. *

C. rugosa (Lamk.) Goldf: p. 252. t. CLII. f. 3.

C. revoluta Broc. p. 516. t: XII, f, 6 .

9. Psamobia angusta n. sp.?

Die Schale länglich, schr glatt, hinten versehmälert, vorn winklig? Wirhel nach vorn liegend, spitz, klein, kaum hervorragend; die das Schlossband tragenden Wülste ragen nicht hervor.

Ps. rudis Desh.? I. p. 74. tab. X. f. 11.12 ? v: Münst. p. 436 . nr. 19.

Im Ahnegraben fand ich cine rechte vorn beschädigte Valve; sie ist $8^{\prime \prime \prime}$ lang und $4^{\prime \prime \prime}$ hoch, möchto aber, unbeschädigt, reichlich 9"' lang gewesen sein. Die kleinen schr wenig hervortretenden Wir- 
bel stehen im vorderen Dritheil. Das hintere Ende ist auffallend verschmälert aber abgerundet, das vordere breiter, winklig? Die ganze Oberfläche ist durchaus glatt, mit äusserst schwachen Spuren von Anwachssireifen. Das Schloss ist fast genau wie bei Ps. rosea Desh. (Sanguinolaria Lamk.); es besteht nämlich aus zwei kleinen Zähnchen und die kurze das Ligament tragende Wulst tritt nicht hervor. - Ps. rudis Desh. Coq. foss. I. p. 74. t. X. f. 11. 12, wofür Graf Münster l. c. p. 436. nr. 19 wahrscheinlich diese Art gehalten hat, ist sehr ährlich aber höher $\left(15^{1} / 2^{\prime \prime \prime} l a n g\right.$ und $7^{3} / 4^{\prime \prime \prime}$ hoch) und hat weit stärker hervorragende. Wirbel.

10. Tellina distorta Poli.

Schale oval-länglich, zusammengedrückt, sehr fein quergestreift, fast gleichseitig, hinten in einen spitzen Winkel auslaufend, fast schnabelförmig.

T. distorta Poli. t. 15. f. 11. - T. subcarinata (Broc.) Goldf. p. 235. t. CXLVIII. f. 2. -

Von den lebenden Exemplaren unterscheiden sich die bei Kassel fossil vorkommenden nur durch etwas kürzere Ligamentwülste, weniger hervortretende Streifung und weniger auffallende Biegung der hinteren Spitze. Sie zeigen noch abwechselnd weisse und gefärbte Zonen.

+ 11. Tellina rostralina Desh.

"Schale oval-länglich, hinten beinahe gefaltet, zusammengedrückt abschüssig, convex-plan; Wirbel

"hinter der Mitte; schr feine concentrische Linien, auf der hintern Seite lamellenartig erhaben; "Schloss einzähnig, " Goldf, 31/3" lang.

T. rostralina Desh. Goldf. p. 25̌5̆. t. CXLVIII. f. 1. v. Münst. p. 436. ni. 22.

12. Tellina tumida Broc.

"Schale oval, aufgeblasen, beinah gleichseitig, hinten winklig, in der Mitte schwach concav; dünn"wandig; drei Schlosszähne und ein Seitenzahn." Broc. 25" lang, 191/2 " hoch.

T. tumida Broc. p. 513. t. XII. f. 10. v. Münst. p. 436. nr. 20.

Ich besitze ein sehr beschädigtes Exemplar, dem ich keinen Namen zu geben gewagt hätte, wenn mir nicht Graf Münster, der wahrscheinlich ein besser erhaltenes Exemplar gehabt, darin vorangegangen wäre. - Sehr mit Unrecht vereinigt Desh. Lamk. ed. II. p. 203 diese Art mit T. Lacunosa Chemn., welche sehr ungleichseitig ist, keine Seitenzähne hat etc.

+ 13. Tellina pusilla, Ph.

Schale klein, länglich, zusammengedrückt, vorn kurz, stumpf, fast abgestutzt, kaum gebogen, mit sehr feinen aber regelmässigen Querstreifen und Seitenzähnen. 21/3"' lang $1 \frac{1}{3^{\prime \prime \prime}}$ hoch.

T. pusilla Ph. Enum. Moll. Sicil. p. 29. nr. 5. t. III. f. 9. Goldf. p. 235. 36. t. CXLVIII. f. 3.

Ich besitze diese $\mathrm{Art}$ nicht von Kassel, aber wohl aus der Gegend von $\Lambda$ lfeld; sie unterscheidet sich von meiner 'T. pusilla von Palermo nur dadurch, dass sie nicht ganz so schmal ist.

14. Lucina albella Lamk.?

"Schale kreisförmig; fast nicrenförmig, mässig zusammengedrückt, ziemlich glatt; Lunula sehr klein, "vertieft; Sehloss zweizähnig, Seitenzïhne deutlich.". Desh. 6,8" lang, $53 / 4 "$ hoch.

J. albella Lamk. Desh. coq. foss. p. 95. t. XVII. f. 1. 2.

lch besitze fünf Exemplare, welche mit der Abbildung und Beschreibung vollkommen übereinstimmen, aber nur $2^{3} /^{\prime \prime \prime}$ gross sind; bei Pezzo in Calabricn fand ich diese Art gleichfalls nur $3^{3} /{ }^{\prime \prime \prime}$ gross. L. saxorum wird $12^{\prime \prime \prime}$ gross, hat ganz schwache Seitenzähne, und auf der Hinter-Seite eine Einbiegung; könnte sonst der Form nach hicrnit verwechselt werden.

+ 15. Lucina dentata Bast.

"Schale fast kugelförmig, Wirbcl in der Mitte, Area gross, durch eine linie algesetzt; Lunula oval, "vertieft; innercr Rand gekerbt; Seitenzähne gross; häufige regelmässige Querstreifen." Goldf. ${ } 2^{1} / 3^{\prime \prime \prime}$ gross. 
L. dentata (Bast). Goldf. p. 230. t. CXLVII. f. 1. "Kassel und Bünde."

+ 16. Lucina parvula v. Münst.

nSchäle eiförmig, quer, gewölbt, Wirbel in der Mitte, spitz hervorragend; vordere Seite abschüs"sig; vorderer Schlosszahn zweispaltig; keine Seitenzähne; Area lanzettförmig; Querstreifen un"deutlich." Goldf. $2^{\prime \prime \prime}$ gross.

L. parvula v. Münst. Goldf. p. 230. t. CXLVII. f. 2. a. c. ' "Kassel und Bünde." - Der innere Rand ist ganz, die Lunula nicht vertieft.

Astarte Sow.

Nirgends finde ich bemerkt, dass in diesem Genus eine Andeutung von Seitenzähnen vorkommt; auf der rechten Valve zeigt die vordere Seite einen langen Seitenzahn, welcher mit dem Rande eine lange Furche bildet, die den hervorstehenden Rand der andern Klappe aufnimmt; auf der linken Klappe zeigt das Schloss ebenfalls einen langen Seitenzahn aber auf der hintern Seite. - Diese Seitenzähne sind bei den kleineren Arten weit aufallender als bei den grösseren, allein sie fehlen diesen nicht, und Goldfuss hat sie auch bei A. incrassata t. CXXXV. f. 2. c. sehr schön zeichnen lassen. Ebenso sind sie auf Fig. I. b. c., 3. c., 4. c., sehr gut zu sehn. In der Charakteristik des Genus und in der Beschreibung der einzelnen Arten sind diese Scitenzähne aber nirgends erwähnt.

17. Astarte laevigata v. Münst.

Schale klein, länglich, schief, glatt, hintere Seite kürzer, kreisförmig abgerundet, der innere Rand gekerbt.

Astarte laevigata v. M. Leonh. Jahrb. p. 436. nr. 31. 32. - Fehlt bei Goldfuss.

Von dieser.Art, welche auch zu Gravina in Appulien vorkommt, fand ich 11 Schalen. Sie sind nur 5/4" hoch, beinah eben so lang, und stärker gewölbt als die folgenden Arten. Die Wirbel bilden ziemlich einen rechten Winkel. Die Varietät mit glattem Rande, welche Graf Münster nr. 31 anführt, kenne ich nicht.

18. Astarte suborbicularis v. Münster.

Schale klein, rundlich dreieckig, breiter als lang, fast gleichseitig, zierlich in die Quere gefurcht; der. Rand ungekerbt.

A. suborbicularis v. Münst. Leonh. 436. nr. 28. - Goldf. t. EXXXV. f. 6.

Fünt Exemplare aus dem Ahnegraben. Sie werden $21 / 6^{\prime \prime \prime}$ lang, $2^{\prime \prime \prime}$ hoch uad sind sehr leicht durch den Mlangel der Kerben am innern Rande zu unterscheiden. Goldfuss vereinigt sie mit der folgenden Art, vielleicht mit Recht.

19. Astaite pygmaea v. Münst.

Schale klein, rundlich dreieckig, fast breiter als lang, beinah gleichseitig, zierlich in die Quere gefurcht; Rand gelsèrbt.

A. pygmaea v. Mlïnst: bei Goldf. p. 195. t. CXXXV. f. 5.

Zehn Exemplare, $1 \%^{\prime \prime \prime}$ lang, etwas weniger hoch, eben so stumpf und eben so zierlich gefurcht wie die vorhergehende Art, allein mit einem gekerbten Rande.

Alle drei Arten sind in der Gegend von Alfeld sehr häufig.

20. Astarle incrassata de la Jonk.

Schale dick, oval dreieckig, hinten etwas länger, in die Quere gerunzelt, besonders in der Wirbelgegend; Lunula eiförmig, vertieft, Area lanzetıörmig; Rand meist fein gekerbt." 11'" lang,

$9 \mathrm{~s} / 2^{\prime \prime \prime}$ hoch.
A. (Venus) incrassata Broc. p. 557 et 670, t. 14. f. 7. - Goldf. p. 194. CXXXV. f. 2. (welcher

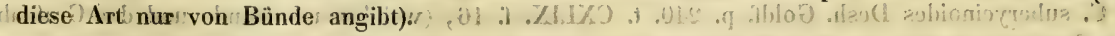

Bei Kassel finden sich nur Exemplare mit wenigen ziemlich feinen Runzeln in der Gegend der Wirbel. 


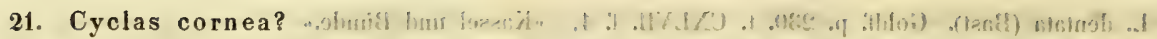

In der Gegend von $Z$ wehren hat Herr Philipp Schwarzenberg in einem hellaschgrauen : séhr.nérí; geligen: Kalkstein nebst Paludinen verstënerte Schalen gefunden, welche: mit Gycłas cornea' in Grösse, Gestalt und Wölbung vollkommen übereinstimmen, die calcinirte Schale ist jedoch dicker: und das Schloss nicht sichtbar.

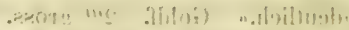

Derselbe hat ebenfalls in dem dort häufig vorkommenden Sandstein, und zwar in einer ziemlich lockeren graulich weissen Varietüt, lierne von Bivalven gefunden, welche man wegen des glèichzètigen Vorkommens von vegetabilischen Resten, Stengelstücken u. s. w. für Süsswassermuscheln ansprechen möchte. Sie sind $10^{\prime \prime \prime}$ lang, 11/2"' hoch aber nur etwa $5^{\prime \prime \prime}$ dick und beinah gleichseitig. Das Genus, dem sie zuzuschreiben sind, wage ich nicht zu bezeichnen.

22. Cyprina is landica Lamk.

Schale eiförmig, fast herzförmig, fein und unregelmässig quer gestreift; vordere Seite sehr kurz; keine Lunula und keine Einbiegung des Manteleindruckes.

C. (Venus) islandica L. ete. Cyprina aequalis Ph. En. M. Sicil. Goldf. p. 236: t. CXVIII. f. 5 (welcher' nur Bünde und den Grafenberg als Fundorte angibt). C. islandicoides v. Münst. p. 437. nr. 34 und Lamk. nr. 7. zum Theil.

Ich bin nicht im Stande anzugeben, wodurch sich diese Art äusserlich von der folgenden unterscheidet; Schloss und Manteleindruck sind sehr verschieden. . Ist bestimmt von der lebenden Art nicht verschieden.

23. Cytherea inflata Goldf:

„Schale gross, rundlich-ciförmig, aufgeblasen, vorn sehr kurz, mit grosser herzförmiger, ebener, von "einer doppelten Furche umgebenen Lunula, und häufigen Querstreifen, die hinten blättrig werden

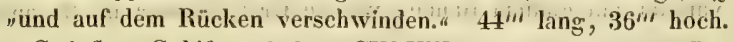

C. inflata Goldf. p. 239. t. CXLVIII. f. 6, (es sind nur Bünde, Alzei und Piacenza als Fundorte angegeben).

Sie wird $25^{\prime \prime \prime} \mathrm{lang}, 22^{\prime \prime \prime}$ hoch, $14^{\prime \prime \prime}$ dick, doch ist auch hier das Verhältniss der Dimensionen etwas schwankend. Die Gestalt ist genau wie bei Cyprina islandica, die Oberlläche, ebenfalls durch scharfe Anwachsstreifen, zicmlich rituh. Das Schloss zeigt auf der rechten Valve zwei vordere sehr schiefe Zähne, die nur schmal und schwach sind, der erste ist nicht gespalten, der zweite durch eine tiefe und breite Grube vom hintern dritten doppelten Zahn geschieden. (Bei Cyprina isl. ist der erste Zahn dick, fast gerade, durch eine dem Rande parallele Furche in zwei getheilt, dann folgt eine grosse tiefe Grube, und der zweite Zahn, welcher sehr stark und hoch ist, ist mit dem dritten beinah verwachsen). Auf der linken Valve hat Cyprina isl. zuerst vorn eineu vollkommen quer gestellten Zahn, in der Mitte einen sehr starken senkrechten Zahn, und hinten, durch einen sehr breiten Zwischenraum getrennt, einen schmalen lamellenförmigen Zahn. Bei unserer Cytherea infl. dagegen ist vorn gar kein quer gestellter Zahn vorhanden; der erste Zahn steht senkrecht, weit nach vorn; darauf folgt ein mässig starker, schräg nach hinten verlaufender Zahn, welcher durch einen sehr schmalen Zwischenraum vom letzten getrennt ist. - Die Grube am Anfang des Ligaments, welche man früher für ein charakteristisches Kennzeichen der Gattung Cyprina hiclt, ist hicr auch vorhanden, allein auch eine deutliche Einbiegung des Manteleindrucks, welche bei Cyprina nicht vorkommen kann.

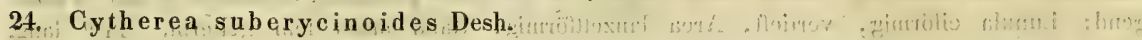

Schale quer oval, mässig gewölbt, vorn kürzer, mit zahlreichen ziemlich regelmässigen concentrischen Rippen (der vielmehr Furchen); Lunula herzförmig-lanzettlich.

C. suberycinoides Desh. Goldf. p. 240. t. CXLIX. f. 16, (welcher nur Bünde und den Grafenberg als Fundorte angibt): 


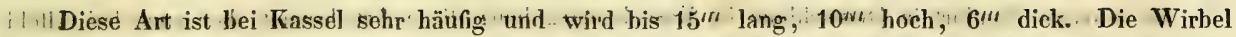
liegen zwischen dem dritten und vierten Theil der Läng'e. In der äusseri Gestalt und Beschaffenheit der Furchen kommt sie sehr mit Venus vetula Bast. überein, nur ist. das hintere! Ende schmaler und der stumpfe Winkel hinten ạm Ende des Rückenrandes fehlt, auch ist das Schloss ein ganz anderes.

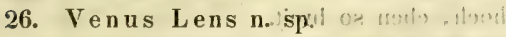

Schale linsenförmig, fast kreisförmig, etwas länger als hoch, fast gleichseitig, schwach gewölbt, quer 'gestreift; Rückenrand beiderseits gewölbt; keine Lunula; Ligament äusserlich nicht sichtbar.

Drei Exemplare. $11^{\prime \prime \prime}$ lang, 91/2"' hoch, $4 \frac{1}{2}{ }^{\prime \prime \prime}$ dick. Sie haben ganz das Ansehn von Lucira. z. B. Lucina lactea. Dic Wirlel liegen in der Mitte und ragen nur wenig hervor; der vordere Rückenrand ist schwach gewölbt, und zeigtikeine Lunula, wenn gleich eine feine linie einen breit lanzettförmigen Raum einschliesst. Eben so weng ist eine Area vorhanden, doch ist die Schale an deren Stelle etwas glatter. Die drei.Sclilosszähne (der linken Valve) divergiren sehr stark und sind sehr dünn, der vorderste ist an seinem innern Rande schwach gespalten. - Mit V. incompta Ph. sehr nahe verwandt, welche aber ein äusserlich sich(bares Ligament und auf der linken Valve einen grossen tief zweispaltigen Mittelzahn hat.

27. +. Venus plicata Lamk.

„Schale oval dreieckign, gewölbt, vorn sehr kurz, hinten beinah kielförmig abschüssig; Lunula herz"förmig: vertieft; Area breit lanzelförmig, unglejehseitig; Schlossrand gebogen; innerer Rand gekerbt; "Lamellen, concentrisch aufrecht, mehr oder weniger entfernt und regelmässig."

Goldf. p. 278. t. CLI. f. 9. 28"' lang', 23"' hoch.

"Wien, Kassel, Dax, Piacenza."

28. Venus? decipiens n. sp.

Schale fast kreisförmig, linsenförmig, ungleichseitig, mässig gewölbt, glatt; Lunula herzförmig länglich, chen, glatt; Ligament von aussen sichtbar; Schloss . .

Ein Exemplar, 12//" lang, 11/2"' hoch, $6^{\prime \prime \prime}$ dick, hält in der Gestalt genau das Mittel zwischen Venus Lens und Cytherea lincta. Die Wirbel liegen beinah in dritten Theil der Länge; der hintere Rückenrand ist mässig convex, der vordere anfangs etwas concav. Von der V. Lens und von Cy: therea lincta verschieden durch die äusserlich sich(baren Wülste, welche das Ligament tragen, so wie durch die Beschaffenheil der Lunula, welche bei V. Lens fehlt, bei C. lincta von einër tief eingedrückten Linie umgeben ist.

29. Cardium striatulum Broc.

Schale beinah kreisförmig, convex, gleichseitig, mit zahlreichen erhabenen Längsstreifen, und breiteren punktirten Zwischenräumen. $4^{1 / 2} 2^{\prime \prime \prime}$ lang, eben so hoch.

C. striatulum Broc. p. 507. t. 13. f. 5. - Goldf. p. 223. t. CXLV. f. 5."

Dìe Exemplare von Kassel sind beinah $5^{\prime \prime \prime}$ gross. Die Zahl der Rippen beträgt etwa 50 .

30. Cardium turgidum Brander.

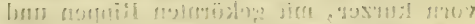

Schale fast kreisförmig, gewölbt, mit zahlreichen Längsstreifen und sehr feínen Querstreifen; Wirbel in der Mitte stehend dick. $8^{\prime \prime \prime}$ lang, $7^{3} / 4^{\prime \prime \prime}$ hoch.

C. turgidulum Brand. Sow. Goldf. p. 222. t. CXLV. f: 3., welcher als einzigen deutschen Fundort $\therefore$.., Sternberg angibt.

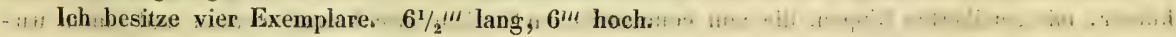

31. Cardium papillosum Poli.

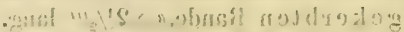

Schale fast kreislörmig, stark gewölbt, $\cdots$ mit 24 fáchen Rippen, die mit kurzen Papillen besetzt sind, und schmalen punktirten Zwischenräumen.

C. papillosum Poli tab. 16. f. 2. 3. 4. Goldf. p. 223. t. CXLV. f. 7. 
Als einziger Fundort in Deutschland ist Kassel angegeben; diese Art kommt aber auch bei Alfeld vor. Von Kassel besitze ich nur eine Schale.

32. Cardium multicostatum Broc:

Schale schief herzförmig, mit zahlreichen, (etwa 55) flachen Rippen, die vorn und hinten höckerige Lamcllen tragen; Rand tief gekerbt, vorn gesägt. $27{ }^{\prime \prime \prime}$ hoch, eben so breit.

C. multicostatum Broc. p. 506. t. 13. f. 2. Goldfuss hat diese Art nicht.

Ich besitze ziemlich zahlreiche Fragmente, die aber bei dieser sehr charakteristischen Art keinen Zwieifel über die richtige Bestimmung der Art erlauben.

33. Cardita scalaris Goldf.

Schale beinah kreisförmig, mässig convex, gleichseitig, mit lanzettförmiger Lunula und zwvanzig convexen Rippen, mit schmalen Zwischenräumen und ziemlich entfernten conceutrischèn Streifen.

Venericardia scalaris Sow. Cardita sc. Goldf. p. 188. t. CXXIV. f. 2.

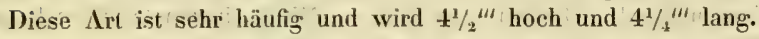

34. Cardita tuberculata v. Münst.

Schale beinah kreisförmig, mässig convex, gleichseitig, mit herz-lanzettförmiger Lunula und 16-18 convexen Rippen, mit schmaleren Zwischenräumen und tiefen entfernten regelmässigen Querstreifen.

C. tuberculata v. Münster Goldf. p. 188, t. CXXIV. f: 3.

Ich halie diese Art, welche seltener ist als die vorhergehende, für eine blosse Varietät derselben, zumal da die Zwischenräume der Rippen nicht immer schinaler, sondern bisweilen auch breiter sind, in welchem Fall der einzige Unterschied der in der Zahl der Rippen bleibt.

35. Is o c a rdia Cor. Lank.

„Schale eiförmig kugelig; Wirbel dick, spitz, nach vorn eingerollt; Schlossrand vorn horizontal, "hinten abschüssig mit einer oberllächlichen Furche; Anwachsstreifen unregelmässig."

Goldf. p. 211. t. CXLI. f: 2.

Ich habe vier Exemplare gesehn, keines grösser als $15^{\prime \prime \prime}$ lang und $13^{\prime \prime \prime}$ hoch, sonst in nichts von den lebenden verschieden.

736. Area diluvii Lank.

"Schale oval-trapezförmig, bauchig; Wirbel nach vorn gestellt, entfernt; hintere Seite abgerundet, "gewölbt; 28-30 strahlende elbene Rippen, die nebst den ebenen Zwischenräumen quer gefurcht "sind. " $17^{\prime \prime}$ lang, $10^{1 / 2}$ " hoch.

A. diluvii Lamk. ed. II. vol. VI. p. 476. note. - Goldf. p. 143. t. CXXII. f. 2. "Kassel, Weinheim, Wien. “

37. Arca didyma Broc.

Schale oval, trapezförmig, gewölbt, beiderseits abgerundet, in der Mitte buchtig eingedrückt, vorn kürzer, mit gekörnten Rippen und gekerbte m Rande. $2{ }^{1} / 2{ }^{\prime \prime \prime}$ lang.

A. didyma Broc. p. 479. t. 11. f. 2. - Goldf. p. 144. t. CXXII. f. 4. a. b. Sehr häufig.

+ 38. Arca quadrilatera Lamk.

„Schale oval, trapezförmig, bciderseits convex abschüssig, in der Mitte buchtig eingedrückt, vorn kürzer, mit genäherten Rippen, die von concentrischen Streifen durchkreuzt werden und einem ungekerbten Rande. " $21 / 2^{\prime \prime \prime}$ lang.

A. quadrilatera Lamk. Goldf. p. 144, t. CXXII. f, 5. "Kassel, Grignon.“

39. Area barbatula Lanik. 
Schale ziemlich oval länglich, gewölbt, beiderseits abgcerundet, .vorn kürzer; Wirbel genähert; die zahlreichen ausstrahlenden erhabenen Linien; sind vorn zweitheilig und werden von häufigen concentrischen Streifen durchkreuzt. 16" lang, $8^{\prime \prime \prime}$ hoch

A. barbatula Lamk. .Goldf. p. 144. t. CXXII. f. 6, welcher Baden bei Wien und Piacenza als Fundorte angibt.

Ein Exemplar im Besitz des Ilerrn Bergraths Schwarzenberg ist etwas höher, sonst stimmt es ganz mit der Abbildung und Beschreibung von Goldfuss überein. Uebrigens finde ich keinen hinreichenden Grund, diese Art von A. barbata zu trennen.

40. Pectunculus crassus Ph.

Schale ziemlich kreisförmig, fast gleichseitig, unregelmässig quer gestreift, erstaunlich dickwandig; die Wirbel abstehend; ein hohes Feld für das, Ligament.

P. polyodontus Goldf. p. 161. t. CXXVI. f. 6. 7. excl. synonym.

Diese bei Kassel sehr häufige Art, welche ausserder noch bei Ortenburg, Alzei, Weinheim, Osnabrück, Lemgo, Osterweddingen bei Magdeburg, Dësseldlorf, Alfeld ete. vorkommt, ist meiner Meinung nach sehr mit Unrecht für die Arca polyodonta Brocchi gehalten. Brocchi sagt p. 490 seines klassischen Werkes: "Das Individuum welches ich vor Augen halse, hat eine Höhe von $4 \mathrm{Zoll} 2^{\prime \prime}$ von der "Spitze des Wirbels bis zum Rande, und ist nur $4^{\prime \prime \prime}$ breiter etc. Die äussere Oberfäche ist mit groben „concentrischen Furchen bezeichnet und nur auf der Wölbung der Spize bemerkt man einige Längs"streifen. von haarartiger Feinheit، Dagegen sagt Goldfuss: Dic äussere Fläche ist mit einer dünnen Oberhaut überzogen, welche durch zarte gedrängte Streiien gegittert ist. - Brocchi fälirt fort: "Die "Schlosszähne sind gross vorstchend, vertikal gestreift; ihre Zahl beträgt [bei einem 4 Zoll grossen "Exemplar!] 14 auf einer Seite und 12 auf der andern, und es ist zu bemerken, dass sie sich ohne "Unterbrechung durch die ganze Linie des Schlosses erstrecken, obgleich die in der Mitte kleiner "sind als die seillichen. Dieser Lmstand kommt zwar gewöhnlich bei allen Pectunculus vor, wenn sie „klein und von mittlerer Grösse sind, aber er findet sich nicht bei den voluminösen Individuen der "andern Aiten." - Ganz das Gegentheil ist bei unserer Art der Fall und es sagt auch Goldfuss: "Die Schale hat im Schloss 10-20 starke, lange seitlich mit senkrechten Linien besetzte Zähne. "Das Bandfeld erweitert sich mit dem Alter, wobei es die mittleren Zähne überdeckt, so "dass öfters nur noch die zwei äussersten übrig bleiben." Ein sehr grosser Irrthum ist es ferner, wenn Goldfuss diese $\Lambda$ rt mit dem lebenden $\mathbf{P}$. pilosus vereingt.

Schon bei den kleinsten Exemplaren fälle die Dicke der Schalen schr auf. Bei einem $21^{\prime \prime}$ hohen Excmplar ist z. B. die Entfernung vom Schlossrand bis zum Manteleindruck am Bauchrande nur 12" die IIöhe des Bandfeldes 2 $\frac{1}{2} 2^{\prime \prime \prime}$; bei einem $21^{\prime \prime \prime} \mathrm{P}$. pilosus sind beide Grössen: $16^{1} / 2^{\prime \prime \prime}$ und $1^{\prime \prime \prime}$. Die Schlosszähne sind bei P. crassus sehr stark, wohl dreimal so stark, als bei pilosus, und ebenso sind auch die Zähne des Randes doppelt so gross und daher weniger zahlreich. Der P. terebratularis Lamk. Desh. coq. foss. p. 221. 1. XXXV. f. 10. 11. ist unserer Art sehr ähnlich und nur die flachen Rippen der Oberfläche unterseheiden ihn, die innere Seite zeigt keinen Unterschied.

41. Pectunculus pulvinatus Desh.?

Schale kreisförmig, etwas schief, bauchig, fein gekreuzt und punktirt, undeutlich in der Länge gerippt; Schloss schmal; Rand fein gekerbt, mit kurzen Kerben; Bandleld sehr schmal.

P. pulvinatus Lamk. Ann. d. Mus. Desh. coq. foss. p. 219. t. XXXV. f. 15. 16. 17. hl.

Diese Art, von welcher ich nur wenige Exemplare gesehen hahe, stimmt fast in allen Dingen, Gestalt, Grösse, Sculptur, Schloss, Bandfeld mit der vortreffichen Beschreibung von Deshayes und mit Pariser Exemplaren; allein die Kerben des Randes sind zahlreicher, länger und gefurchty und es ist daher vielleicht die in der Touraine vorkommende Art, welche Desh. p. 220 erwähnt. Die Exemplare von Kassel sind $13^{\prime \prime \prime}$ hoch, $14^{1} /^{\prime \prime \prime}$ breit. 


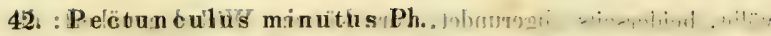

- Schâle klein, schief, eiförníg, fast geöhrt, in deri@uere gestreift gekördelt; Bandfèld mit ciner Längsgrube; Rand gekerbt. $2^{3} /{ }^{\prime \prime \prime}$ hoch, eben so Jreit.

- mP. minutus Ph. Enum. p.' 63. t. V. f. 3. - Goldf. p. 163. 1.. CXXVII. f. 1.

Ist bei Cassel sehr gemein.

43. Nucula plácentina Lamk.

- Schale qutir eilörinig, hinten weit länger und breiter, mit schwachen Längs- und Querstreifen; Lunula herzförmig von einer Grube umgeben; Rand gekerbt. $15 \frac{1}{2}$ "w lang, 11 wr hoch:

N. placentina Lamk. Phil. Enum. M. S. p. 65. t. V. f. 7. - N. loevigata Sow. Goldf. p. 157. t. CXXV. f. 19.

Nicht eben häufig; die Kasselschen Exemplare entsprechen der kleineren Varietät aus Sicilien.

44. Nucula sulcata Bronn.

Schale quer lä́nglich, beinah dreieckig in der Quere gefurchi, in der Länge schwächer gestreift;

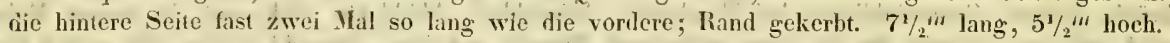

N. sulcata Jironn. Reise 2. p. 617. Italiens Tertiärgebilde p. 109. N. Polii Ph. En. M. S. p. 63 . V. f. 10 . N. compta Goldf. p. 158 . t. CXXV. f. 20.

Ziemlich selten.

45. Nucula margaritacea Lamk.

Schale schief eiformig, dreieckig, glait oder undeutlich gestreift; die Hinterseite $1 \frac{1}{2}$ Mal so lang wie die Vorderseite; Rand gekerbt. 6 $6^{\prime \prime \prime}$ lang, $5^{\prime \prime \prime}$ hoch.

N. marganitacea Lamk. Phil. En. p. 64. t. V. f. 8. - Goldf. p. 158. t. CXXV. f. 21 ? $9^{\prime \prime \prime}$ lang, 7 hoch.

Ebenfalls ziemlich selien.

46. Nucula minuta. Bronn.

Schale eiförmig, vorn abgerundet, fast gleichseitig, hinten in einen Schnabel verlängert, in der Qucre runzeliggefurcht; Area länglich von erhabenen Kielen eingefasst; Rand ungekerbt. $5^{\prime \prime \prime}$ lang, $3^{\prime \prime \prime}$ hoch.

Area minuta L. Broe: p. 482. t. Il, f, 4 - Nucula m. Bronn. - Goldf. p. 158. t. CXXV. f. 22. Ich besitze zwei Exemplare; sie sind stärker zusammengedrückt als die von Palermo.

† 47. Nucula nitida Drr.

Schale eiförnig, gewölbt, etwas ungleichseitig, vorn spitz, in die Quere dicht gestreift; Lunula lanzettörmig von einer Furche umgeben; Schlosswinkel síumpf; Rand ungekerbt, 41/2"' lang,

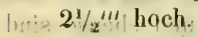

N. (Arca) nitida Broc, p. 482, t. 11. f. 3. - Goldf. p. 158. t. CXXV. f. 37.

48. Modiola serice aronn.

Schale elliptiscl eiförmig, schief, aufgeblasen, der Länge nach schr dicht und fein gestreift; die Spitzen aufgeblasen, gekrümmt. 10 $\frac{1}{2 \prime \prime \prime ~ l a n g, ~} 7 \frac{1}{2} "$ ' hoch, leben so dick

yerrib MI sericela Bronn. Ital Tert. Geb. p. 112 - Ph. En. p. 71. tab. V. f. 14. - Goldf. p. 179.

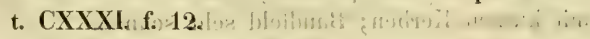

Nicht sehir selten!

49. Modibilaricari nata Broc.

ปirs ISchale, klein', trąuezförimig, gewölbt; auf den. Sciten gekielt, mit concentrișchen sich deckenden

:- Furchen; Schlossrand graile verlängert; untere Seite vorn in einen Winkel vorgezogen, ": hinten

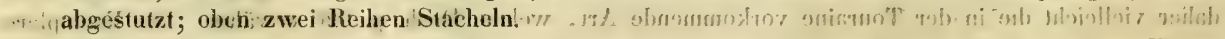

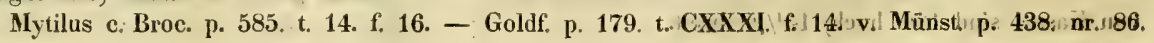




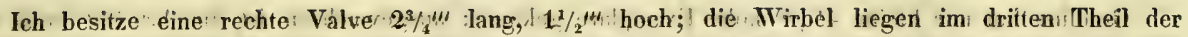
Länge; die vordere Extremität ist nicht ganz so spitzlals in der'Figur von' Goldfuss: aDie Beschaffenheit des.Schlosses, wulohe sehr abwëicht, ist bei Goldfussı eben so wenig wie bei Brocchi erwăhnt; dè Rückenrand tritt näılich, wenn die. Schale auf der Wölłung liegt, sehr weit hervor und läғst einen breiten drejeckigen Ausschnitt unter den Wirbeln; unmittclbar dahintep, zeight er, zwei von de,n. W Wirbeln ausstrahlende Leistchen, so dass ich vermuihe, es sei ein inneres Ligament vorhanden und die linke Schale liege mit ihrem.Schlossrande auf dem ausspringenden Schlossrande der rechten. In diesem Falle müsste diese Art ein eigenes Genus bilden.

50. Modiola py.gmaea Ph. . f yijic.

Schale klein und dünn, eiförmigdreiekig; die Wirbel nahe dem vorderen Ende; die hintere Seite sehr breit, abgerundet.

Vier Exemplare ạs dem Ahnegraben 21/4"' lang, hịten beinạh $2^{\prime \prime \prime}$ hoch. Der Rückenrand ist gerade, ziemlich lang; auch der Bauchrand ist gerade; die vordere Extremität ist ahgerundet, die hintere Seite ist sehr breit und beinah von einem Kreishogen begräızt. Die Wirbel stehen nahe an der vordern Extremität. Die Schale ist gleichmäsșig geẉölbt; ohne Kiel, sehr. dünn und sehr glatt. Kommt auch bei Palermo vor.

51. Pecten bifidus v. Münst.

Schale kreisförmig mit zahlreichen gewöhnlich zweispaltigen, mehr oder weniger knotigen Rippeu, dic untere Schale mässig gewölbt, die obere fast: flach; die Ohren beinah rhombisch, ungleich gẹippt und von Querlinien durchkreuzt.

P. bifidus v. Münst., Goldf, p. 69. t, XCYII. f. 10.

Der einzige Fundort ist Wilhelmshöhe [und der Ahnegraben] bei Kạssel. Goldfuss sagt: "Kreis"förmig, flach convex gleichschalig [!], mit zahlreichen gespaltenen Rippen, welche durch Hervortreten "concentrischer Linien mehr oder weniger knotig erscheinen. Die ungleichen in wenig schiefer paraleller "Richtung abgeschnittenen Ohren zeigen einige kleine Rippen, wclche mit scharfen conceitrischen "Linien durchkreuzt werden." - Es ist ein Irrthum, dass beide Schalen gleich sind, die linke ist weit flacher, beinahe eben. Die Rippen etwa 23 , sind bald glint, bald mit kleinen Spizchen besetzt, bald einfach, bald zweispaltig und es lassen sich folgende Varietäten unterscheiden:

a) Rippen einfach glatt, nur die mittleren zuletzt zweispaltig.

P. Hausmanni Goldf. p. 69. nr. 92. t. XCVII. f. 8.

b) Die mituleren Rippen cinfach, aber die Seitenrippen zweispaltig.

P. lucidus Goldf. p. 69. nr. 95, t. XCVII. f. 11. *)

c) Die Rippen fast alle zweispaltig.

P. bifidus, bei Kassel die gewöhnlichste Form.

d) Rippen fast alle einfach, gegen den Bauchrand verflacht und verschwindend. - Nur eine Schale. Bei Bünde sind die Formen a und b, bei Kassel die Form c häufiger.

52. Pecten decussatus v. Münst.

Schale oval kreisförmig, ungleichklappig, beinahe flach, sehr fein concentrisch gestreift und mit zahlreichen feinen Längsrippen, die schmaler sind als die Zwischenräume; Ohren ungleich, gefaltet, liniirt.

P. decussatus v. Münst. Goldf. p. 65. t. XCVI. f. 5. v. Münst't. I. c. p. 449. nr. 100.

") Dass die Rippen bei P. IIausmanni breiter als die Zwischenrâume, bei P. Iucidus schmaler und häher, sind, wie Goldfuss angibt, ist rein individuell; meiue Excmplare habeu Rippen und Z $Z$ wischenräume gleich. 
" 'Goldfuss liat nur kleine $4^{1 / 3} 3^{4 \prime \prime}$ hohe Exemplare gekannt; ausgewachsen ist die Art 11"', hooh und 10 die Qucrlinien verschwinden und nur zahlreiche erhabene Längslinien ! übrig bleiben (die ich nicht Rippen nennen möchte) zeigt die linke nur zahlreiche tiefe Querfurchen.

53. Pecten àsperulus v. Münst.

Schale klein, ungleichklappig, flach, convex, kreisförmig mit $25-30$ Rippen, die auf der rechten

thi Schale breiter und knotign, auf der linken schmaler und kantig sind; Ohren ungleich, gerippt. $3^{3} / 4^{\prime \prime \prime}$ hoch, $3^{1 / 2}{ }^{\prime \prime \prime}$ lang.

P. asperulus (v. Münst.) Goldf. p. 62. t. XCV. f. 8. v. Münst. p. 439. nr. 93.

Weit sidteiler dils die vorhergehenden Arten:

54. Pecten pygmaeus v. Münst.

Schale sehr klein und dünn, oval-kreisförmig, gleichklappigg, flachconvex, aussen glatt, innen [zuweilen] mit zwanzig erlabenen Linien; Ohren gross, das vordere verlängert und ein wenig: ausgebuclitet. $3^{\prime \prime \prime}$ hoch, $3 \frac{1}{3^{\prime \prime}}$ lang.

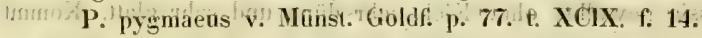

Diese Art, als deren einzigen Fundort Goldfuss Bünde in Westphalen angiebt, ist bei Kassel selten; sie kommt ausserdem bei Palermo und bei Gravina in Appulien vor.

+ 55. Pecten limatus v. Münst.

Schale elliptisch zugespitzt, flach convex, mit zahlreichen zu je dreien gestellten Rippen und ungleichen gerippt knotigen Ohren. 10 $10^{\prime \prime \prime}$ hoch, $7 \frac{1}{2} " \prime$ lang.

P. limatus Goldf. p. 59. t. XCIY. f. 9, der ausser Wilhelmshöhe noch Angers in Frankreich als Fundort angibt! v. Münst. p. 439. nr. 91 .

56. Ostrea deltoidea (Lamk.?) Goldf.

Schale gross, flach convex, beinah dreieckig oder rhomboidisch, blättrig, fast wellenförmig; die obere Schale am innern Rande mít Knötehen besetzt.

O. deltoidea Lamk. ? Goldf, p. 27. t. LXXXIII, f. 1. bene. *)

Diese Art ist bei Kassel nicht eben hạufig; ich habe fünf Schalen gesehn, die $5 \frac{1}{2}$ Zoll hoch und $4^{3 / 4}$ Zoll breit sind und mit der Beschreibung und Abbildung von Goldfuss gut übereinstimmen.

57. Ostrea caudata v. Münst. Goldf.

„Schale mässig gewöllıt, deltoidisch oder halbmondförmig; obere Valve concentrisch gestreift, untere "gefaltet; Falien divergirend, entfernt, convex, schindelartig, blätrig." $15^{\prime \prime \prime}$ lang, $13^{\prime \prime \prime}$ hoch.

Ostrea caudata v. M. Goldf. p. 17. t. LXXVII. f. 7. (von Dischingen und Ortenburg).

Ich besitze mehrere Exemplare, welche mit der Baschreibung und Figur von Goldfuss gut übereinstimmen. Das grösste ist zwar nur $9^{\prime \prime \prime}$ lang, während die Figur $16^{\prime \prime \prime}$ lang ișt, indessen beweisen einzelne Bruchsiücke, dass auch bei Kassel diese $\Lambda \mathrm{rt}$ zu bedeutenderen Dimensionen heranwuchs. Die erhabenen Punkte des innern Randes der oberen Schale, welche den vertieften Punkten auf der untern Schale entsprechen, ziehen sich sehr weit nach vorn fort.

58. Ostrea bullata n. sp.

Schale sehr klein, sehr dünn, glat, aufgeblasen, fast kugelig.

Ich besize sechs obere Scha'el, welche in ihren Kennzeichen eine so grosse Uebereinstimmung zeigen und so auffallend gebildet sind, dass ich sie durchaus für eine neue Art halten muss. - Das

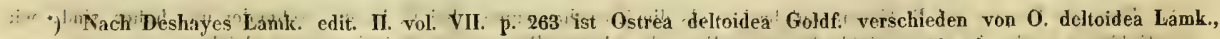
welche wiedérún 'eine ganz' andere" 


\section{$-17-$}

grösste Exemplar ist 31/"' gross; die Gestalt ist bei vier Exempl. beinah kreisförnnig, bei den beiden andern mehr queroval, bei allen sehr aufgeblasen, fast halbkugelförmig. Die Wirbel sind sehr klein und spitz und treten kaum über den Rand hervor. Die ganze Schale ist weit glatter als es bei Austern der Fall zu sein pflegt und erstaunlich dünn. Die Schlossfurche ist daher sehr klein; der Rand daneben ist ungezähnt.

59. Anomia.

Bekanntlich ist es bei den Anomien äusserst schwer zu sagen, was Art sei, da ihre Gestalt mehr als bei irgend einem andern Genus der aufgewachsenen Muscheln vor dem Körper abhängt, auf welchem sie grade festsitzen. Dieselbe Art kann gewölbt oder concav, ganz glatt, mit wenigen oder zahlreichen Längsrippen oder auch mit Querrippen versehen sein, je nachlem sie auf einer glatten Muschel, auf einem Pecten, einem Dolium, einem Cardium aufsitzt. Ich bin daher in Verlegenheit, welchen Namen ich der Art geben soll, die bei Kassel vorkommt. Ich besitze mehrere Exemplare der obern Schale, welche $3 \frac{1}{2}$ "' lang und $2^{3} /{ }_{4}^{\prime \prime \prime}$ hoch sind; am meisten stimmen sie mit der Figur von Goldfuss t. LXXXVIII. f. 7, welche er p. $40 \mathrm{\Lambda}$. squamula L. (squamosa ist wohl nur Druckfehler) nennt und von Bünde erhalten hat, weit weniger die Fig. 8, welche er A. Lens Lamk. nennt, und die Graf Münster auf der Wilhelmshöhe gefunden hat. Uebrigens muss ich offen bekennen, dass ich keinen irgend erheblichen Unterschied zwischen Fig. 6, 7 und 8 finde, und alle diese drei Formen, als einer einzigen Art angehörig, betrachten muss, welche sich von A. Ephippium, wozu Goldfuss die Fig. 6 rechnet, durch constant geringere Grösse wesentlich zu unterscheiden scheint.

\section{Brachiopoden oder Armfüsser.}

60. Terebratula pusilla n. sp.

Schale klein, fast kreisförmig, flach gedrückt, glatt, unter der Lupe sehr zierlich eingestochen punktirt; Schlossfeld gross, Oeffnung gross, dreieckig.

Im Ahnegraben fand ich ein wohlerhaltenes Exemplar 21/s"' lang, $2^{1 /}{ }_{6}^{\prime \prime \prime}$ breit, 5/6 hoch. Die Gestalt is fast kreisförmig, kaum tritt der Schnabelwinkel hervor; die Stirn sehr breit. Die Rückenschale ist mässig gewölbt ohne alle Spur des Kieles, den man immer bei T. truncata noch erkennt. Die Bauchschale ist flacher mit gradem Schlossrande, der in der Mitte, wo er die Schnabelöfnung bilden hilft, schwach ausgeschnitten ist. Die Oberfläche ist ohne alle Spur von Rippen oder Reihen erhabener Punkte, ganz glatt, mit feinen im Quincunx gestellten eingestochenen Punkten, die mit der Lupe erkannt werden müssen. Das Schlossfeld ist $11^{\prime \prime \prime}$ lang, $1 / 2^{\prime \prime \prime}$ hoch; die Schnabelöfnung gross, indem sie den dritten Theil der Area einnimmt, mit schmalen getrennten Deltidien. - Sehr nahe verwandt sind T. Iruncata und T. eusticta Ph.; erstere ist stets breiter als lang, selbst im frühesten Jugendzustand; letztere stärker gewölbt; beide sind deutlicher gekielt und mit Längsrippen oder Längsreihen erhabener Punkte versehn.

\section{Gasteropoden oder Bauchfüsser.}

61. Calyptraea vulgaris $\mathrm{Ph}$.

Schale ziemlich kreisförmig, kegelförmig, mehr oder weniger flachgedrückt, sehr dünn, glatt oder mit kleinen erhabenen Schüppchen besetzt; innere Lamelle flach und einfach. $10^{\prime \prime \prime} \mathrm{im}$ Durchmesser. S. Ph. Enum. p. 119.

Ich besitze drei Fragmente, die jedoch keinen Zweifel an der richtigen Bestimmung der Art erlauben. 
62. Bulla lineata n. sp.

Schale zwischen eiförmig und walzenförmig, tief und dicht in die Quere gestreift, an der Spitze genabelt; Oeffnung linearisch, unten plötzlich erweitert.

B.' linearis v. Münst. p. 442. $\mathrm{nr} .14$ ?

Ich besitze ein Exemplar 4"' lang, 21/“" breit. Diese Art ist sehr bestimmt von B. lignaria verschieden, mit der die Streifung úbereinstimmt. Die Gestalt ist beinahe walzenförmig, oben nicht viel schmaler als unten, der Rücken jedoch etwas bauchig, die äussere Lippe ist fast grade. Die obere Extremität ist weit und ziemlich tief genabelt.

60. Bulla Utriculus Brocc.

Schale eiförmig, dickschalig, beiderseits genabelt, quer gestreift, die Streifen punktirt, die in der Mitte oft verwischt, die an den Extremitäten tiefer. $3^{3} /{ }_{4}^{\prime \prime \prime}$ lang, $2^{1} /{ }_{2}{ }^{\prime \prime}$ dick.

Brocc. p. 633. t. I. f. 6. (Bulla striata ibid. p. 276).

Ich besize ein wohlerhaltenes Exemplar.

64. Bulla ovulata Broce.

Schale länglich-walzenförmig, mit äusserst feinen Querstreifen, (die mit blossem Auge nicht sichtbar sind); Spitze stumpf, genabelt; Columelle unten mit einer schwachen Falte. $5^{\prime \prime \prime}$ lang, $2^{\prime \prime \prime}$ dick.

Brocc. p. 277 . t. I. f. 8 . a.

Ich fand 6 Exempl, an denen zwar die feine Sculptur, so wie die schwache Falte am Grunde der Iündung nicht zu sehn ist, die aber sonst auf das Genaueste mit den lebenden übereinstimmen.

65. Bulla intermedia n. sp.

Schale länglich, walzenförmig, mit tiefen entfernten Querstreifen, an der Spitze genabelt, die Oeffnung schmal, am Grunde erweitert, die Columelle schief rechts gezogen.

Drei Exemplare, $31^{\prime \prime \prime \prime}$ lang, $1^{2}{ }^{\prime \prime \prime}$ lreit, walzenfürmig, unten und oben abgerundet, unten kaum breiter als oben. Am nächsten verwandt ist B. cylindroides Desh. coq. foss. II. p. 40. t. V. f. 22. 23. 24. allein noch schmaler, sehr fein und nur an der Basis gestreift.

66. Bulla retusa n. sp.

Schale länglich, genau walzenförmig, an der Spitze abgestutzt und in der Mitte genabelt mit deutlicher Spira; unten abgerundet, Oeffnung oben sehr eng, unten erweitert.

Ein Exemplar, 13/4"' lang, $1^{\prime \prime \prime}$ breit; oben gerade alggestutzt; eben, nur in der Mitte mit einem kleinen Nabel, so dass die $3 \frac{1}{2}$ Winlungen ganz deullich erscheinen. Die Oberfläehe ist etwas angegriffen, scheint aber weder Querstreifen noch Falten gehaht zu haben. - B. minuta Desh. 1. c. p. 43. t. V. f. 16.17. 21. ist sehr nahe verwandt, läuft aber unten spitz zu, der obere liand ist vorgezogen, die Spitze daher trichterförmig vertieft, die Oeflnung oben ziemlich weit. Die Beschreibung gibt auch nur $3^{1 / 2}$ Windungen an, die Abbildung zeigt aber deren 5!

66. Bulla (Bullina) Lajonkeireiana Bast.

Schale beinah walzenförmig, glatt, oben mit einem spitzigen Gewinde, welches den vierten Theil der Länge etwa einnimmt.

B. Lajonkeireiana Bast. p. 22. t. I. f. 25 .

Drei Ezemplare, $2^{\prime \prime \prime}$ lang, wenig über $1^{\prime \prime \prime}$ breit, zeichnen sich von den Formen dieser wandelbaren Art dadurch aus, dass das Gewinde ganz allmählig spitz zuläuft; doch sind die einzelnen Windungen durch eine tiefe Nath geschieden.

67. Bulla terebelloides n. sp.

Schale verlängert, spindelförmig - walzenförmig, fein in die Quere gestreift, das Gewinde weit länger als die halbe Oeffnung; diese ist oben äusserst eng, unten erweitert. 
Zwei Exemplare, welche in der äussern Gestalt ganz abweichen und eher an Terebellum erinnern, deren Mündung aber genau die von Bulla ist. Sie sind $4^{\prime \prime \prime}$ lang, fast $1 \frac{1 / 2}{\prime \prime \prime}$ breit, das Gewinde etwas lānger als die halbe Oeffnung, lang kegelförmig, aus fünf Windungen zusammengesetzt. Die letzte Windung ist in der Mitte walzenförmig oben und unten verschmälert. Die ganze Oberfläche ist mit ziemlich feinen Querstreifen bedeckt, die unten am Grunde entfernter und tiefer werden.

68. Limnaeus?

In einem graulich gelben, ziemlich thonigen Kalksteine, aus der Gegend von Zwehren, welcher ausserdem noch mehrere unbestimmbare Reste von Muscheln enthält, so wie eine wahrscheinlich von einem Pflanzenstengel entstandene Röhre, findet sich ein $7^{\prime \prime \prime}$ langer, $3^{1 / 2^{\prime \prime \prime}}$ breiter Kern von einem Limnaeus. Derselbe zeichnet sich zwar durch seine olivenförmige Gestalt vor allen mir bekannten Arten aus, erlaubt jedoch keine genauere Beschreibung. Von Herrn Bergrath Schwarzenberg aufgefunden.

69. Paludina.

In demselben Stück, welches die oben erwähnte Cyclas enthält, findet sich ein Abdruck einer Paludina, welche mit P. acuta Desh. (Cyclostoma acutum Drap. Paludina pusilla Bast. Desh.) überein zu kommen scheint.

70. Rissoa varicosa Bast. *)

Schale thurmförmig, quer gestreift, loisweilen in der Länge gerippt, mit (9) schwach gewölbten Windungen; Mündung einfach, rundlich eiförmig, den vierten Theil der Länge einnehmend.

Basterot. p. 37. t. 1. f. 2.

Ich besitze 21 Exemplare, $1^{2} / 3^{\prime \prime}$ lang. Auf jeder Windung sind $4-5$ vertiefte Querlinien; die Längsfalten sind sehr veränderlich, meist gedränģt, bisweilen fast gänzlich fehlend. - Die gezähnte Lippe, die Baslerot in der Diagnnse angibt, kann ich an keinem Exemplare sehen, sie fehlt aber auch auf Basterót's Figur, die sonst genau übereinstimmt.

71. Melania quadristriata n. sp.?

Schale klein, pfriemenförmig, Windungen eben, mit vier vertieften Querlinien, durch tiefe Näthe getrennt; Oefnnung eiförmig am Grunde nicht buchtig.

Ein vollständiges und drei beschädigte Exemplare liegen vor. Bei einer Länge von $3^{\prime \prime \prime}$ sind 9 Windungen vorhanden, ganz flach durch eine tiefe Nath geschieden, glänzend, mit vier vertieften gleich weit von cinander entfernten Querstreifen; die obern zeigen undeutliche Spuren von Längsfalten. Die Oeffnung ist klein, eiförmig, mit cinem undeutlichen stumpfen Winkel, da wo die Columella von der letzten Windung alggeht. - Sollte diese Art eine Varietät von M. hordeacea Lamk. sein? welche nach Desh. coq. foss. p. 108 bald schmaler, bald breiter, bald mit zahlreichen Querstreifen, bald mit wenigen, f. 23., bald ganz glatt vorkommt, und von der ich II. canicularis nicht zu unterscheiden vermag.

72. Melania secalina Ph.

Schale klein, pfriemenförmig, Windungen schwach gewölbt, mit zahlreichen Querstreifen, und zahlreichen undeutlichen Längsfalten; Oeffnung rundlich eiförmig.

Ein Exemplar ohne Spitze, etwas kleiner als die vorige Art mil stärker gewölbten dicht gestreiften Windungen. Es sind 6-7 Streifen auf jeder Windung. Die Längsrippen sind weit deutlicher, zumal oben an der Nath; die Mündung ist runder, und die Columella nicht gerade, sondern concav.

Bemerkung. Dass dic beiden vorhergehenden Arten keine ächten Melanien sind, bedarf keiner Auseinandersetzung, allein sie passen in keins der bisher aufgestellten Genera, namentlich auch nicht

") Der Name ist sehr zu tadeln, und noch mehr, dass Basterot die schwachen Längsfalten in der Diagnose varices nennt; eine Verwechselung der Begriffe, die auch von Gray und andern gemacht wird. 
in Eulima und Rissoa. Am nächsten verwandt scheinen sie mit den von mir En. moll. Sicil. p. 156 unter dem Namen Melania Campanellae, rufa, scalaris, pallida beschriebenen lebenden Arten, für welche ich ein eigenes Genus Pyrgiscus vorschlage.

73. Eulima subulata (Donov.) Desh.

Schale pfriemenförmig, sehr glänzend, Windungen vollkommen eben, durch eine kaum merkliche Nath geschieden (im Leben mit 2 braunen Querbinden verziert); Mündung länglich.

S. Desh. ined. 2. Lamk. VIII. p. 456. - Broc. p. 305. t. 3. f. 5.

Ich besitze 6 Exemplare, von denen zwei vollkommen wohl erhalten sind:

74. Natica castanea Lamk.

Schale kein, kugelig, glat, mit spitzem Gewinde, welches die halbe Iöhe der Mundöflnung erreicht; Nabel kaum durch die schwielige linke Lippe etwas verdeckt. Ilöhe $5^{1 / 2}{ }^{\prime \prime}$.

N. castanea Lamk. hist. nat. etc. VI. 2. nr. 24. *) $81 / 2 . " \prime$

Die bei Kassel so häufig vorkommente Natica, welche nie grösser als $5^{1} / 2^{\prime \prime \prime}$ wird, kann ich von der lebenden N. castanea nicht unterscheiden. N. eximia Eichwald nach einem, wenn ich nicht irre, vom Grafen Münster herstammenden Exemplar aus Wien ist auch nicht davon verschieden, und wahrscheinlich gilt dasselbe ron N. hemiclausa Sow., deren Figur ich nicht nachsehen kann. Uebrigens ist bekanntlich die Unterscheidung der fossilen Natica-Arten erstaunlich schwierig, indem sie sich gewiss oft, gleich den Iebenden, nur durch die Farbe in ihrem früheren Zustand unterschieden haben.

75. Natica dilatata n. sp.

Schale kugelig, weit breiter als hoch, glatt, Nabel ziemlich weit offen, nur wenig dureh die schwielige linke Lippe verdeckt; Gewinde mehr als von der halben IIöhe der Mundöflnung.

Ich besitze nur ein Exemplar, welches $5^{1} / 2^{\prime \prime \prime}$ hoch ist, aber $6^{\prime \prime \prime}$ im Durchmesser hat, allein weit breiter erscheint, weil die Windungen weniger schief verlaufen, der Nabel ist grösser, die Mündung: breiter im Verhältniss zur IIöhe als bei der vorigen Art.

76. Cryptostoma elegans Ph.

Schale oval, flach-convex, mit gedrängten erhabenen Querstreifen; Gewinde spitz, mässig hervorstehend, Nabel mässig, offen.

Ein wohlerhaltenes Exemplar hat IIerr Bergrath Schwarzenberg gefunden. Es ist $6^{\prime \prime \prime}$ hoch, $5^{1 / 2}{ }^{\prime \prime \prime}$ breit, fast genau von der Gestalt wie Sigaretus perspicuus Ph. und besteht aus $33^{1 / 2}$ Windung. Dic Spira ist etwa den dritten Theil so lang wie die Mundöfnung. Die Beschaffenheit der innern Lippe lässt sich nicht erkennen. - Cryptostoma (Sigaretus) canaliculatum Sow. Desh. coq. foss. p. 182 t. XXI. f. 13. 14, unterscheidet sich durch ein ganz flaches Gewinde.

77. Tornatella punctato-sulcata n. sp.

Gehäuse eiförmig, spitz, quer gestreift; die Streifen grubig punktirt; das Gewinde länger als die halbe Mündung.

Vier Exemplare, etwas über $3^{\prime \prime \prime}$ lang, $2^{\prime \prime \prime}$ breit. Die Gestalt ist eiförmig, spitz, und das Gewinde, welches beinahe zwei Fünftel der ganzen Länge einnimmt, zcigt fünf Umgänge, die schwach gewölbt sind. Die regelmässigen Querfurchen erscheinen bei genauerer Betrachtung als Reihen ziemlich grosser runder Grübchen. Hierdurch unterscheidet sich diese Art von der sehr ähnlichen 'T'. inflata Fér. Desh.

") Dechayes erklärt 2te Ausg. von Lamk. VIII. p. 639. Note oben: Die N. castanea für den Jngendznstand der monilifera. Für die. N. castanea halte ich die Art, welche in Holland so gemein ist, und zu den aus Muscheln verfertigten Puppen so häufig verwendet wird; sie scheint von monilifera wesentlich verschieden durch constant geringere Grösse, höheres und spitzeres Gervinde, Mangel der braunen Flecke an der Nath - die von Desh. zu N. castanea citirte Fig. von Blainville Malacologie t, 36 . bis f 4 . gehört aber zu N. monilifera. 
coq. p. 188. t. 24. f. 4. 5. 6., denn diese ist nach Basterot "transversim sulcata, striis longitudinalibus exiguis clathrata. - T. truncatula Bronn. Ital. Tertiärg. p. 69., ist bei $2^{\prime \prime \prime}$ Breite $4 \frac{1}{2}{ }^{\prime \prime \prime}$ hoch.

78. Scalaria decussata Lamk.

Schale klein, beinah pfriemenförmig, quergestreift, mit gedrängten dünnen Längslamellen; die Basis mit einer ebenen sehr fein gestreiften Scheibe gekrönt; Oeffnung rund mit scharfen Rändern. $11^{1} / 2^{\prime \prime \prime}$ lang.

Desh. coq. foss. II. p. 197. t. XXIII. f. 1. 2.

Ich besitze ein ganzes aber nur $3^{2} / 3^{\prime \prime \prime}$ langes Exemplar und 4 Bruchstücke. Jede Windung hat etwa 15 Längsfalten und 5-6 mehr oder weniger hervortretende Querlinien. Die platte Lamelle der Basis tritt am Rande wulstig hervor.

79. Scalaria rudis n. sp.

Schale lang thurmförmig, dicht und fein quergestreift, mit stumpfen gebogenen Längsrippen; Windungen mässig gewölbt, Basis mit einer ebenen, fein gestreiften Scheibe gekrönt.

Ein Exemplar $10^{1} / 2^{\prime \prime}$ hoch, etwas über $4^{\prime \prime \prime}$ breit. Die Rippen sind etwa 14 auf jeder Windung, schwach gebogen, hier und da ist eine grösser, wulstig. Auch die mit ihrem Rande kielartig hervortretende Scheibe der Basis ist fein gestreift. - Von Sc. torulosa Brocchi p. 377. t. VII. f. 4., welche am nächsten verwandt ist, unterschieden durch die mässig gewöllbten, nicht flachen Windungen und den Kiel der Basis.

80. Delphinula dubia n. sp.

Schale klein, niedergedrückt, weit genabelt, unten flach, quer gestreift; Windungen rasch zunehmend; Oeffnung oval-kreisförmig, breiter als hoch, sehr schief.

Ein Exemplar von $1^{3} \varsigma_{\ddagger}^{\prime \prime \prime}$ im Durchmesser, flach gedrückt, oben schwach gewölbt, unten fast eben, wegen der raschen Zunahme der Windungen, deren ich nur vier zähle, beinahe eiförmig. Diese sind oben nur wenig algesetzt, ziemlich dicht in der Quere gestreift; die letzte an der Peripherie und wo sie in den weiten Nabel übergeht, wohl gerundet. Der Durchmesser des Nabels beträgt ungefähr den dritten Theil vom Durchmesser des ganzen Gehäuses.

81. Delphinula carinata n. sp.

Schale klein, flach kegelförmig, weit genabelt, die letzte Windung mit drei Kielen von denen der oberste undeutlich ist.

Fün Exemplare, alle mehr oder weniger beschädigt, von $1 \frac{11}{21}$ im Durchmesser, mit $5-5^{1 / 2}$ Windungen, welche mässig gewölbt sind. Der obere Kiel der letzten Windung ist sehr schwach und stumpf und auf den vorhergehenden Windungen ganz verwischt; der zweite Kiel dagegen, weleher die Peripherie bildet, und der dritte, in der Mitte zwischen der Peripherie und dem Nabel, sind sehr deutlich und scharf. Der Nabel nimmt nur den vierten Theil der untern Scite ein, ist concentrisch gestreift und hat einen abgerundeten Rand. Sonst ist die Schale glatt, und nur in der Nähe der Kiele sieht man hie und da einen Querstreifen. - Diese Art hat viel Aehnlichkeit mit D. trigonostoma Bast. p. 28. t. IV. f. 10. ab. (nicht mit D. trigonostoma Lamk. jetzt Cancellaria zu verwechscln), allein Basterot gibt den ausgezeichneten Kiel der Peripherie gar nicht an, quch stimmt die Gestalt des Nabels nicht.

82. Delphinula urispula n. sp.

Schale klein, kegelförmig, weit und tief genabelt; Windungen gerundet mit krausen Querleisten; Mundöffnung kreisförmig.

Ich habe nur ein einziges Exemplar, welchem noch dazu die Spitze fehlt, so dass nur 3 Windungen übrig sind. Der Durchmesser beträgt $2^{1} /_{2}^{\prime \prime \prime}$, die Höhe kann $1^{2} /{ }^{\prime \prime \prime}$ nicht überstiegen haben. Die Gestalt ist vollkommen kegelförmig, die einzelnen Windungen sind stark abgerundet; die vorletzte hat 4-5, die letzte bis zum Anfang des Nabels etwa 13-14 Gürtel, die von der Breite der Zwischen- 
räume sind, und von den darüber hinweglaufenden regelmässigen erhabenen Anwachsstreifen kraus gemacht werden. Des Nabel nimmt beinah den dritten Theil der Unterseite ein, und geht ganz allmählig in die untere Fläche üher. Die (beschädigte) Oeffnung ist kreisrund; die ganze Schale perlmutterartig. 83. Trochus scrutarius Ph.

Schale flach kegelförmig, an der Peripherie ausgebreitet, schneidend; die Windungen eben, Bruchstücke von Muscheln etc. anklebend; Basis flach-concav, weit genabelt, mit erhabenen concentrischen linien.

Diese Art ist häufig genug, aber meist nur in Fragmenten. Mein grösstes Exemplar hat $8^{\prime \prime \prime}$ im Durchmesser und das Verhältniss der IIöhe zum Durchmesser ist etwa 1:1,7. Die obere Fläche zeigt, wo die aufklebenden Bruchstücke von Muschelschalen sie erkennen lassen, der Quere nach verlaufende wellenförmige erhabene Streifen, die auf der untern Seite stärker und durch drei- his viermal breitere Zwischenräume geschieden sind. - Am nächsten verwandt sind Tr. plicomphalus Pusch. Polens Paläontologie p. 110. t. X. f. 7. a. b., der sich durch die Falten des Nabels unterscheidet, und Tr. agglutinans Lamk., bei welchem die untere Fläche ganz glatt ist.

84. Trochus elegantulus n. sp.

Schale ziemlich hoch kegelförmig, undurchbohrt; Windungen eben, fast geschindelt, mit sieben Querreihen dornenförmiger Knötchen, die abwechselnd kleiner sind; die letzte Windung scharfkantig.

Ein vom Herrn Bergrath Schwarzenberg gefundenes Exemplar ist $4^{1 / 4}$, hoch und hat $33_{4}^{\prime \prime \prime}$ in Durchmesser; es zeigt 7 Windungen und $2-3$ an der Spitze mögen fehlen. Dieselben sind fast eben und ragen unten etwas über die folgenden hervor. Die zweite, vierte und namentlich die sechste Querreihe der dornenförmigen Knötchen sind weit schwächer als die übrigen, die fünfte ragt dagegen stärker hervor. An beschädigten Stellen erscheinen die kleinen Dornen wie runde Körnchen. Die untere Seite ist ziemlich eben mit zahlreichen, scharfen, glatten Querleisten. Die Oeffnung ist viereckig, etwas breiter als hoch mit einer senkrechten Spindel.

85. Turbo.

Ich habe einen schön erhaltenen Deckel gefunden, der oval, in der einen Richtung 4 in der andern $3^{1} / \mathrm{s}^{\prime \prime \prime}$ gross ist; die innere Seite ist eben und zeigt vier Windungen, die äussere ziemlich stark gewölbt, im Centrum etwas vertieft mit zimmlich starken Runzeln und Gruben.

86. Turritella communis Risso.

Schale mittelgross, verlängert thurmförmig; Windungen schwach und gleichmässig gewölbt, mit $8-10$ scharfen, gleichen oder ungleichen erhabenen Querlinien. $19^{\prime \prime \prime}$ lang, $4^{1 / 2}{ }^{\prime \prime}$ breit.

T. communis Risso hist. nat. de l'Eur. mérid. IV. p. 106. f. 37., (welcher aber noch eine T. Terebra und ein Dutzend anderer Arten davon trennt). 'T. Terebra der meisten auct. z. Theil, namentlich Broc. 374. t. 6. f. 8. Den Namen Terebra muss man wohl der grossen chinesischen Art lassen.

Diese in den europäischen Meeren sehr gemeine Muschel ist auch unter den Kasselschen Versteinerungen sehr häufig.

87. Cerithium vulgatum Brug.?

Ich besize nur eine Spitze von 5 Windungen, welche ich nicht von dem lebenden $\mathbf{C}$. vulgatum unterscheiden kann.

88. Cerithium Lima Brg.

Schale klein, pfriemenförmig; Windungen eben, oft wulstig mit 4 oder 5 Querreihen von Knötchen; Lippe etwas vorgezogen; kein Kanal.

C. Lima Lamk. VII. p. 77. - Murex scaber Broc. p. 448. t. 9. f. 17. 
Von dieser sehr häufigen und ziemlich veränderlichen Art habe ich nur, ein jugendlichcs, wenig über 1"' langes Excmplar gefunden, welches 7 Windungen zeigt, und in nichts von den gleich grossen lebenden Exemplaren abweicht.

89. Cerithium perversum Lamk.

Schale klein, pfriemenförmig, links gewunden; Windungen eben, mit 3 Querreihen von Knötchen;

Kanal klein, gekrümmt, beinah geschlossen.

C. perversum Lamk. VII. p. 77. - Murex granulosus Broc. p. 449. t. 9. f. 18.

Dieses Cerithium ist sehr veränderlich und mit Unrecht in mehrere Arten zerspalten.

90. Cerithium trilineatum Ph.

Schale klein, pfriemenförmig; Windungen eben, mit drei glatten stumpfen Kielen, in den Zwischenräumen mit feinen Längslinien verziert; Kanal sehr kurz.

S. Ph. Enum: p.' 195. t. XI: f. 13.

Ein vollständiges Exemplar und zwei Bruchstücke stimmen auf das Genaueste mit der im Sicilischen Meere lebenden Art; sie findet sich auch bei Freden.

91. Cerithium melanoides Lamk.

Schale schr klein, verlängert-thurmförmig, mit sehr feinen beinah gleichen erhabenen Querstreifen;

Windungen mässig gevölbt; die letzte abgerundet, am Grunde gestreift; Mündung oval-rund, schief, vorn in einen sehr breiten Kanal endigend; Lippe einfach. $3^{\prime \prime \prime}$.

S. Desh. coq. foss, II. p. 384. t. 55. f. 15. 16. 17.

Ein 2"' langes Exemplar mit 7-8 Windungen, an welchem die Mündung beschädigt ist, stimmt ganz vollkommen mit der citirten Abbildung und Beschreibung.

92. Cerithium bitorquatum n. sp. _ - an clavus Lamk.?

Schale sehr verlängert pfriemenförmig; Windungen eben, mit zwei perlschnurförmigen Knotenreihen; die Knötchen laufen in Jäingsfalten aus.

Ich besitze nur ein Bruchstück von $2^{1 / 2}$ Windungen, welches auf ein $11^{\prime \prime \prime \prime}$ breites, $7-8^{\prime \prime \prime}$ langes Gehäuse schliessen lässt, welches sich demnach durch seine lange, schlanke Gestalt sehr auszeichnet. Die einzelnen Windungen sind vollkommen flach, zweimal so breit als hoch und haben fast dieselbe Skulptur als C. clavus Lamk. S. Desh. p. 391. t. 58. f. 4. 5. 6. und f. 14. 15. 17., so dass gegenwärtige Art vielleicht nur eine Varietät des C. clavus ist. - Fig. 14. 15. 17. hat namentlich auch nur 2 Reihen Knötchen, allein weit stärkere Längsstreifen und ist nicht so schlank.

93. Pleurotoma belgica v. Münst.

„SSchale spindelförmig glatt; die $(6-7)$ Windungen beinah eben, in der Mitte mit einer oberfläch„lichen Furche; die letzte in einen graden schlanken Schnabel auslaufend.“

Goldfuss. Petref. III. p. 20. t. CXX1. f. 2. (Klein Spauwen).

Bei- Kassel nicht selten, ein fast vollständiges Exemplar ist $11^{\prime \prime}$ lang, Bruchstücke Iassen auf die doppelte Grösse schliessen. Die Windungen sind oben dicht an der Nath oft etwas angeschwollen, dann breit und seicht ausgehöhlt unten wieder etwas gewölbt. - Pl. transversaria Lamk. Desh. II. p. 450. t. 62, f. 1. 2, ist sehr nahe verwandt, und vielleicht müssen heide Arten zusammenfallen.

94. Pleurotoma curvicosta Lamk.

,Schale verlängert spindelförmig, fein in die Quere gestreift, mit kleinen zahlreichen, gebogenen ,'ängsrippen; Windungen mässig gewölbt, dic letzte kürzer als die Spira; rechte Lippe sehr dünn, ;,stark gebogen; Einschnitt kurz, breit." $9^{1 / 4^{\prime \prime \prime}}$ lang, $3^{\prime \prime \prime}$ breit.

Deșh. coq. foss. II. p. 460 . t. 63 . f. 4. 5. 6.

Neun mehr oder weniger beschädigte Exemplare stimmen mit der Abbildung und Beschreibung wohl überein. - Deshayes sagt: diese Art sei Pleur. undata und bicatena sehr ähnlich, und man 
müsste vielleicht späterhin, wenn mehr Beobachtungen vorlägen, diese drei Arten in eine vereinigen. Ich würde dieses unbedenklich thun, und auch Pl. propinqua dahin rechnen.

Pleurotoma undatella n. sp.

Schale klein, lang spindelförmig, fein in die Quere gestreift von noch feineren Anwachsstreifen durchkreuzt; Windungen mässig gewölbt, die oberen mit Längsrippen, die untere ungerippt; die Oeffnung mit dem Kanal so lang wie die Spira.

Ich besize 19 mehr oder weniger beschädigte Exemplare, $5^{\frac{1}{2}}{ }^{\prime \prime \prime}$ lang, $1^{2} / 3^{\prime \prime}$ breit, mit 9 Windungen. Diese sind mässig gewölbt, oben etwas concav, an der Nath gerandet und mit $10-12$ erhabenen Querlinien besetzt. Die oberen Windungen (bald 4 , bald 5, bald 6) sind mit mehr oder weniger hervorragenden, unten und oben mehr oder weniger abgekürzten lippen versehn, welche oft nur als kleine Knötchen hervortreten. Ihre verschiedene Entwickelung gibt den cinzelnen Individuen ein sehr verschiedenes Ansehen. Die Anwachsstreifen beweisen, dass der Einschnit in der Lippe ziemlich hoch oben sass und sehr breit war.

96. Pleurotoma acutangularis Desh.?

,Schale verlängert spindelförmig, spitz, quergestreift, mit unregelmässigen Längsstreifen durchkreuzt; „Windungen in der Mitte scharf, kantig, die ersten gekerbt, an der Nath gerandet, die letzte kürzer "als die Spira; Lippe sehr dünn zerbrechlich; Einschniti kurz und eng." $12 \frac{1}{2}{ }^{\prime \prime}$ lang, $4^{\prime \prime \prime}$ breit.

Desh. II. po, 459. t. 64. f. 24.25.

Ich besitze nur 2 Spizen, die mit der Abbildung bei Desh. ziemlich gut übereinstimmen.

97. Chen opus paradoxus n. sp.

Schale thurmförmig, fein durchbohrt, sehr fein quergestreift, mit gerundeten Windungen, von denen die oberen gedrängte, gebogene Rippen, die letzte aber eine doppelte Querreihe von spitzen Kinoten zeigt. Gegenwärtige Art, welche ich nicht allein von Kassel sondern auch von Freden und Luithorst in melireren Exemplaren besitze, habe ich lange für ein eigenes Genus gehalten, indem ich an keincm meiner ziemlich zahlreichen Exemplare eine Syur von der erweiterten Aussenlippe finden konnte, welche das Genus Chenopus rharakterisirt. Dazu kam der zwar sehr enge, aher bis zur Spitze gehende, in allen Bruchstücken deutlich zu verfolgende Nabel, von welchem ich an Chenopus pes pelecani, welchen ich in jedem Alterszustande besitze, keine Spur antreflen konnte. Erst späterhin fand jch an einer ähnlichen Art vom südlichen Calabrien, die ich wegen des Nabels und der Skulptur in dasselbe vermeintlich neue Genus bringen wollte, an einem Exemplar den Rest der erweiterten Aussenlippe, und als ich hierauf meine fossilen Chenopus Arten untersuchte, fand sich auch der enge durchgehende Nabel an Ch. pes graculi Bronn. - Die bekannte Rostellaria pes pelecani habe ich unter dem Namen Chenopus von Rostellaria abtrennen müssen, weil die Thiere beider sehr verschieden sind. Während nämlich das Thier von Rostellaria sich von Strombus nicht unterscheidet, (die Augen auf einem dicken Stiel hat, von dem seitlich kleine Fühler abgehen etc.) ist das Thier von Chenopus, um es kurz zu sagen, ein Cerithium, mit langer Schnauze zwischen den Fühlern, Augen am Grunde der Fühler etc., gehört also in eine ganz andere Abtheilung der Kammkiemer. - Den Namen Aporrhaïs Dillwyn habe ich deshalb nicht annelmen können, weil 1) Dillwyn aus einem hypothetischen und falschen Grunde diese Sonderung vornahm, indem er glaulste, dicjenigen liostcllaria-Arten, welche wie li, pes pelecani keinen wirklichen Kanal an der Basis hätten, besässen auch Këinen liüssèl zun Anbohren lebender Mollusken, vermögten sich mithin nur yon todten Thieren zu nähren und kämen als die einzigen Zoophagen mil den Phytophagen schon in secundären Bildungen vor, 2) weil den Namen Aporrhaïs die ältern Conchyliologen den Pterocera. Artèn gegèben liaben.

Ch. paradoxus ist bei Kassel nicht selten. Die vollständige Länge mag $14^{\prime \prime \prime}$ die Breite $6^{\prime \prime \prime}$ ohne deu Flügel betragen haben. Es sind wenigstens $10 \mathrm{~W}$ indungen vorhanden gewesen. Diese sind gleichmässig gewülbt, gerundet, sämmtlich fein in die Quere gestreift, die obern mit $20-22$ gebogeñe Längsrippen. 
versehn, die sich auf der letzten Windung verlieren, und durch zwei Querreihèn von Knötchen ersetzt werden, die denen von Chenopus pes pelecani täuschend ähnlich sehn, aber nicht durch Kiele verbunden sind. Die zweite Reihe findet sich etwas unterhalb der Mitte der letzten Windung, die erste zwịschen dieser und der Nath in der Mitte. Bei grossen Exemplaren gesellt sich noch wie bei Chenopus p. p. eine dritte Reihe schwach entwickelter Knötchen in geringer Entfernung unterhalb der zweiten hinzu. - Ein Schnabel ist nicht vorhanden. Die Oeffnung nimmt kaum den dritten Theil der ganzen Länge ein, ist länglich und läuft oben in cinen offneren, unten in einen engeren Winkel aus, ohne Spur von Ausschnitt oder Kanal. Der Spindelrand ist gerade; die Innenlippe dick, besonders nach unten, die Aussenlippe fehlt an allen Bruchstücken, scheint aber nicht flügelartig erweitert und auf den vorhergehenden Windungen festgewachsen gewesen zu sein. Eine zweite Art besitze ich aus Calabrien.

98. Faściolaria Fusus n. sp.

Schale länglich, spindelförmig; Windungen eben, glatt; Spitze stumpf; Schnabel verlängert, sehr schlank.

Ich besitze zwei Spitzenstücke von 5 Windungen und vier Stücke der Basis, an denen die scharf charakterisirte Art vollständig erkannt werden kann. Sie zeichnet sich selır aus, durch die stark ausgeprägte Spindelgestalt, den schlanken schmalen stark verlängerten Schnabel, die Flachheit der Windungen und die stumpfe abgerundete Spitze. Es sind auf der Columella drei sehr schiefe und sehr stark hervortretende Falten vorhanden, von denen die oberste auf den obern Windungen verschwindet. Diese Art mag eine Höhe von $20^{\prime \prime \prime}$ bei einem Durchmesser von $8^{\prime \prime \prime}$ erreicht haben.

99. Fusus rugosus (Murex) Parkinson.

Schale länglich-spindelförmig, spitz; etwa 6 höckerige Windungen mit ungefähr $10 \mathrm{~J}$ ängsrippen, die von vielen tiefen Querstreifen durchsetzt werden; Schnabel gerade; Mundränder dick; Kanal ziemlich breit. $21^{\prime \prime \prime}$ hoch, $10^{\prime \prime \prime}$ breit.

Sow. Min. Conch. I. t. 34. f. 1. 2.

Ich besitze kein vollständiges Exemplar, aber zahlreiche charakteristische Bruchstücke.

\section{Fusus striatus (Murex) Sow.}

Schale breit spindelförmig, bauchig, Windungen gewölbt, mit entfernten tiefen Ouerstreifen; Mundöffnung eiförmig, mit dem kurzen weiten Kanal so lang wie die Spira. 46"' lang, $28^{\prime \prime \prime}$ breit.

Sow. Min. Conch. I. t. 22.

IIäufig, aber verdrückt oder sonst beschädigt und nur $10-11^{\prime \prime \prime}$ lang und $6^{\prime \prime \prime}$ dick, aber wohl sicher dieselbe Art.

101. Fusus tenuis Desh.?

Schale verlängert spindelförmig, ziemlich bauchig, fein in die Quere gestreift; Windungen gewölbt, die letzte länger als die Spira; Basis in einen kurzen Kanal auslaufend; Mündung eiförmig; Lippe dünn, einfach. - $3^{1} / 2^{\prime \prime \prime}$ lang.

Desh. coq. foss. p. 555 . i. 76 . f. 19. 20.21.

Ich besitze die untere Hälfte, die stärker erhabene Querstreifen hat in der Gegend wo die Oeffnung: in den Kanal übergeht; auch tritt diese Stelle stärker hervor, indem der Kanal unter einem deutlichéren Winkel abgeht. Die Breite beträgt $2^{1 / 2}{ }^{\prime \prime \prime}$, die Fiöhe mag $5^{\prime \prime \prime}$ gewesen sein.

102. Fusus exilis n. sp.

Gehäuse sehr klein, länglich spindelförmig; Windungen gewölbt, beinah kantíg, der Länge nach gefaltet mit erhabenen Querlinien, Mündung länglich eiförmig, so lang wie die Spira; Kanal sehr kurz, kaum zu unterseheiden.

Vier vollständige Exemplare $2^{1 / 4^{\prime \prime \prime}}$ lang, $1^{\prime \prime \prime}$ breit, mit 7 Windungen. Diese sind ziemlich stark gewölbt, in der Mitte mehr oder weniger kantig mit ungefähr 11 faltenartigen Längsrippen und $6-7$ 
feinen erhabenen Querlinien; die letzte Windung hat 11-12 Querlinien und geht ganz allmählig in den sehr kurzen Kanal über. Die Columella ist vollkommen grade.

103. 'Fusus costulatus Jamk.' var.

"Schale länglich eiförmig, huccinumähnlich *), quer gefurcht, mit [10-12] Längsrippen; Win"dungen kurz, gewölbt; die letzte bauchig, kürzer als die Spira, in einen kurzen Kanal auslau"fend; Mündung eiförmig; Lippe verdickt, innen gezảhnelt." $16^{1 / 2}$ " $^{\prime \prime}$ lang, $9^{\prime \prime \prime}$ breit.

S. Desh. coq. foss. II. p. 562. t. LXXV. f. 16. 17.

Ein Exemplar $12^{1} /{ }^{\prime \prime \prime}$ lang, $7^{\prime \prime \prime}$ breit mit $7-8$ Windungen, und mit 8 nicht $10-12$ Längsrippen. Am Grunde der Columella, wo sie in den Kanal übergeht, sind ein paur schwache Knötchen.

104. Pyrula elathrata Lamk.?

„Schale verkehrt eiförmig, keulenförmig, gegittert; die erhabenen Streifen abwechselnd kleiner. *

Lamk. Ann. d. Mus. vol. II. p. 391. nr. 5 (kann ich nicht nachschn) An. s. vert. VII. p. 572. „Fossile de Grignon. Cab. de feu Mr. Richard. - v. Münst. 1. c. p. 444. nr. 60.

Ich besitze kein ganz vollständiges Excmplar und alle mcine Bruchstücke haben gleiche Querstreifen. Ich bin daher über die richtige Bestimmung der Art zweifelhaft. Ueberhaupt ist diese Species sehr prohlematisch, da Deshayes in seiner Deser. des coq. foss. de Paris sie gar nicht erwähnt, wohl aber p. 583 sagt, er habe nie das fragliche Individuum geschn (von dem er sonderbarer Weise behauptet, Lamarck habe es Pyrula ficus benarint).

105. Pyrula megacephala n. sp.

Schale birnförmig, oben spizzlich, glatt; die oberen Windungen in der Mitte kantig und knotig, die letzte sehr bauchig, mit ciner dreifachen oder vierfachen Knotenreihe; Oeffnung länglich eiförmig; Columella fast gerade; Schnabel ....

Zwei Exemplare, beide unten beschädigt, $13^{\prime \prime \prime}$ hoch, 14"' breil, die Spira ist $3-4^{\prime \prime \prime}$ hoch, spitzlich. Diese Art gehört in die Abtheilung der Feigen, jst dünnschalig, und durch die an Cassidaria echinophora erinnernden Kroten sehr ausgezeichnet. Die Columella ist fast ganz gerade und setzt sehr stark von der letzten Windung ab.

106. Murex vaginatus de: Crist. et Jan.

Schale lang spindelförmig, ğlatt, Vindungen in der Mitte gekielt, unten und oben eben; die Varices auf dem Kiel in zusammengedrückte nach oben gebogene Dornen verlängert; Schnabel gerade, sehr schlank.

S. Ph. Enum. p. 211: t. XI. f. 27.

Sechs beschädigte Exemplare liegen vor. - Kiener bildet gegenwärtige Art t. 2. f. 2. als Fusus echinatus ab, und sagt p. 20, er komme lebend bei Sicilien vor. Ich glaube, er hat die vom Meer aus dem Thon ausgewaschenen fossilen Exemplare, die sehr wohl erhalten sind, und nicht selten Paguren beherbergen, für lebend gehalten. Wenn er aber diese Art zu Fusus bringt, so weiss ich nicht, wie er dies verantworten will, da er noch dazu selbst sagt: "ses épines se terminent en varices" und die Varices es gerade sind, wodureh sich Murex von Fusus unterscheidet. Der Name F. echinatus ist zum Ueberfluss auch schon vergeben.

107. Murex (Typhis) simplex n. sp.

Schale länglich spindelförmig, glatt, mit 6 schmalen einfachen Varicen, und 6 mit den Varicen abwechselnden einfachen Rippen, die oben in eine kurze Röhre auslaufen.

-) Was soll das heissen? gibt es denn eine bestimuite (iestalt für Buccinam? 
Ich besitze ein vollstândiges Exemplar und mehrere charakteristische Bruchstücke dicser sehr ausgezeichneten Art, welche auch bei Alfeld vorkommt. Sie scheint $10^{1} /{ }^{\prime \prime \prime}$ hoch und $5 /_{4}^{\prime \prime \prime}$ dick zu werden. Die Varices sind ganz schmal, einfach, ganzrandig, die Rippen gerundet, der mässig lange Schnabel stark abgesetzt. Die Oeffnung ist rundlich-eiförmig, so lang wie der Kanal, der vermuthlich auch geschlossen war.

108. Tritonium rugosum n. sp.

Schale eiförmig länglich; Windungen der Länge nach faltig gerippt, quer gestreift, die letzte bauchig, undeutlich gegürtelt; die Oeffnung rundlich eiförmig, nicht verenģt (mit dem Kanal) kürzer als die Spira.

Ein sehr vollkommen erhaltenes Exemplar, dem nur die ätusserste Spitze fehlt, hat Herr Bergrath Schwarzenberg auf Montchéri gefunden; es ist $21^{1 / 2} 2^{\prime \prime \prime} \operatorname{lang}, 11^{\prime \prime \prime}$ breit. Es ist nahe verwandt mit Tr. corrugatum, jedoch mehr thurmförmig als spindelförmig, der Schnabel liürzer, deutlicher algesetzt, es fehlen die ausgezeichneten Querleisten, und die Mündung ist nicht verengt, indem die äussere Lippe inwendig kaum die schwachen Spuren von 7 Zähnen zeiggt. Die innere Lippe hat oben einen starken Zahn, und unten in der Nähe des Kanals die schwachen Spuren von drei andern Zähnen.

109. Cassidaria carinata Lamk.

Schale eiförmig aufgeblasen, fein in die Quere gestreif, mit etwa 5 scharfen, kielförmigen Leisten, von denen die obern höckerig sind; Windungen oben flach; Schnabel ziemlich lang, aufsteigend. $22^{\prime \prime \prime}$ hoch, $14^{1 / 3}{ }^{\prime \prime \prime}$ breit.

Desh. p. 634. t. 85. f. 8. 9. - t. 86. f. 7 .

Ich besitze nur Bruchstücke, welche jedoch auf das Genauste mit einem Pariser Exemplar dieser Art übercinstimmen.

110. Cassis Rondeleti Basterot.

Schale eiförmig, aufgeblasen, spitz; die vorletzte Windung mit zwei Reihen, die lctzte mit 7 Reihen Knoten, die aul" erhabenen Gürteln stehn, und mit elwa 5 Querleisten ohne Knoten. $24^{\prime \prime \prime}$ hoch, $17^{\prime \prime \prime}$ breit.

Bast. p. 51. tab. IV. f. 13. - tab. III. f. 22. (ein jugendliches Exemp.) v. Münst. p. 444. nr. 59.

Ich habe nur 3 Bruchstücke, die aber an der charakteristischen Knotenbildung nicht zu verkennen sind.

111. Buccinum Macula Montag.

Schale länglich, fast thurmförmig, scharf quer gestreift, der Länge nach deutlich gerippt; Windungen stark gewölbt; Oeffnung beinah kreisrund; Columella runzelich gekörnt. 61/2 ${ }^{\prime \prime}$ lang, $3 \frac{1}{4}$ "' breit.

Fossil Broc. p. 339. t. 5. f. 8. unter dem Namen B. asperulum. v. Münst. p. 444. nr. 64 .

Ziemlich häufig, doch besitze ich kein einziges vollständig erhaltencs Exemplar.

112. Buccinum semicostatum Brocchi p. 654. t. $\mathrm{XV}$. f. 19. v. Münst. nr. 63.

Noch immer wird diese Form, welche ganz offenbar ein jugendliches, unentwickeltes Individuum von einer andern Art (wahrscheinlich von B. variabile Ph.) vorstellt, hin und wieder als Art citirt. Bei Kassel kommen ebenfalls junge, mit der citirten Figur übereinstimmende Exemplare vor, die der vorigen Art nicht angehören, aber keine genauere Bestimmung erlauben.

113. Terebra plicatula Lamk.?

Schale pfriemenförmig; Windungen eben, mit feinen dichten Längsfaltẹ, die auf den untern Windungen sich verlieren; Oeffnung schmal oval, schief; Lippe dünn, einfach, gerade....19"' lang, $4^{\prime \prime \prime}$ breit.

S. Desh. p. 660. t. 87. f. 25.26.

Ich besitze 13 Bruchstücke, welche noch etwas schlanker als die angeführte Abbildung sind. 
114. Mitra plicatula (Voluta) Broc.

${ }_{n}$ Schale spindelförmig, glatt; Windungen undeutlich gefaltet; Basis ziemlich gerade; Columella mit

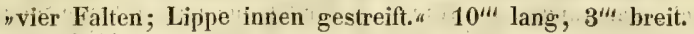

S. Broc. p. 318. t. IV. f. 7 .

Ich besitze zwei wohlerhaltene nicht ausgewachsene Exemplare von $2^{\prime \prime \prime}$ Länge. Uebrigens kann ich sie nur für Abart einer sehr wandelbaren, im Mittelmeer nicht selten lebenden Art anselin. S. Enum. p. 229.

115. Voluta harpula Lamk.

Schale eiförmig spindelförmig, lāngsgerippt; Windungen oben gekerbt, fast rinnenartig; Columella mit vielen Falten, von denen die drei untersten grösser sind, die vorletzfe am stärksten vorsteht. $14^{\prime \prime \prime}$ lang.

S. Desh. p. 702. t. 91. f. 10. 11.

Ich besitze 2 kleine, fast vollständige Exemplare, das grösste $5^{1 / 2}{ }^{\prime \prime \prime}$ lang mit 6 Windungen.

116. Ringicula striata n. sp.

Schale länglich eiförmig, tief quer gestreift; Spira so lang wie die Mündung; Aussenlippe innen glatt.

Auricula ringens var. v. Münst: in Leonh. Jahrb. 1835. p. 442. nr. 17.

Diese $\Lambda \mathrm{rt}$, welche läufig genug ist, wird nur $1^{1 / 2^{\prime \prime \prime}}$ lang und $1^{\prime \prime \prime}$ breit, und zeichnet sich durch ihre schlanke Form und die beträchtliche Länge der Spira vor den andern Arten aus. Auf der vorletzten Windung zähle ich etwa 5, auf der letzten 10-12 Querstreifen. - Ring. ringens, welche ebenfalls eine sehr stark gestreifte Oljerläche hat, ist $3^{\prime \prime \prime}$ gross und hat eine gezăhnelte Aussenlippe.

117. Cypraea inflata Lamk.

„Schale eiförmig aufgeblasen, vorn spitz verschmälert, hinten stumpf, glatt; Oeffnung verlängert, „schmal, am Grunde erweitert; Columella schwach fallig-gezähnt, Aussenlippe verdickt, aussen "beinah gerandet, innen regelmässig gezähnt, Enden der Oeffnung kaum ausgerandet.“ $15{ }^{1} / 2^{\prime \prime}$ lang, $11^{\prime \prime}$ breit.

S. Desh. p. 724. to 97. f. 7.8 .

Ein etwas kleineres Exemplar hat einer meiner Schüler, IIerr Würtemberger, im Ahnegraben gefunden.

118. Ancillaria glandiformis Lamk.

„Schale [länglich-] eiförmig, ziemlich bauchig und ziemlich spitz, unten schwielig; die Nãthe be"deckt..." $18^{1 / 2} /{ }^{\prime \prime}$.

S. Lamk. VII. p. 414. - Enc. meth. t. 393. f. 7. a. b. und Varietät Brongniart. Vicent. p. 63. t. 4. f. 12. unter dem Namen $\boldsymbol{A}$. inflata, was nicht mit $\mathbf{A}$. inflata Desh. zu verwechseln ist. $-\mathbf{A}$, conflata Boué nach v. Münst. p. 444. nr. 65 .

Nicht selten, in der Gestalt sehr veränderlich, indem dip jungen Individuen weit schmaler und spitzer sind. Mein grösstes Exemplar misst $14^{\prime \prime \prime}$ in der Länge und $7^{1} / 2^{\prime \prime \prime}$ in der Breite. - A. coniformis Pusch Polens Paläontologie p. 116. t. XI. f. 1, ist noch stumpfer, 20"1 lang, $12^{1 / 2}{ }^{\prime \prime}$ breit.

\section{Conus Brocehii Bronn.}

Schale verkehrt kreiselförmig, glatt; Spira etwa $2 / 7$ der Länge einnchmend, concav kegelförmig, mit rinnenförmigen Windungen; letzte Windung oben kantig. $19^{1 / 2}{ }^{\prime \prime}$ lang, $8^{3} /{ }_{4}^{\prime \prime \prime}$ breit.

C. Brocchii Bronn. in Leonh. Zeitschrift für Mineralogie. 1827 etc. C. deperditus Broc. p. 292. t. III. f. 2.

Ein bis auf die/Spitze der Basis sehr wohI erhaltenes Exemplar. 
120. Dentalium strangulatum Desh.

Schale drehrund, schwach gekrümmt, matt; vordere Oeffnung verengert, mit etwas eingebogenem abgerundeten dicken Rande. Bis $14^{\prime \prime \prime}$ lang und $5 / 4^{\prime \prime \prime}$ dick.

D. strangulatum Desh. Mem. d. 1. Soc. d'hist. nat. II. p. 372. t. 16. f. 28. - D. coarctatum Brocc. p. 264. t. I. f. 4 .

Ich habe 13 Stück gefunden, deren Durchmesser höchstens $5 / 6$ " beträgt, die aber übrigens wohl übereinstimmen. Die Einschnürungen der Schale sind zwar häufig aber nur zufällig.

\section{Dentalium fossile $\mathbf{L}$.}

Schale sehr schwach gekrümmt, mit häufigen, regelmässigen, stumpfen und gleichen Längsstreifen.

S. Desh: Mem. etc. p. 355. t. 17. f. $12 .-$ v. Münst. p. 441 . nr. 5 .

Ist sehr häufig. - D. Bouéi Desh. 1. c. p. 355. t. 18. f. 8. von Baden bei Wien ist wohl damit zu vercinigen. Der einzige Unterschied besteht nach der Diagnose darin, dass D. Bouéi stärkere Anwachsstreifen hat, allein Exemplare von Baden sellsst, die von dem Grafen von Münster herrühren, haben ebenfalls nur schr schwache Anwachsstreifen. Auch ist die Zahl der Längsstreifen dieselbe, bei D. Boući an der Spize 20; bei den Kasseler Exemplaren 16-18; am Ende die doppelte.

\section{Crustaceen.}

Ich besitze den Daumen einer Kirebsscheere, nur wenig beschâdight, der dem Genus Xantho oder Platycarcinus angehört haben mag.

\section{Hische.}

Zu den häufigsten Versteinerungen der Wilhelmshöhe gehören Haifischzähne, da aber von dem klassischen Werke von Agassiz über die fossilen Fische noch nicht alle hierher gehörenden Tafeln erschienen sind, und noch mehr vom Texte fehlt, bin jch nicht im Stande gewesen, alle zu bestimmen. Nach einer früheren Bestimmung von Agassiz siehe v. Münst. I. c. p. $\mathbf{4 6}$, haben sich bei Kassel folgende Arten gefunden, die fast sämmtlich in Wolfart's historia naturalis Ilassiae inferioris etc. Kassel 1719 folio tab. XXI. abgebildet sind.

1. (nr. 3.) Lamna denticulata Ag. Ist dies Galeus denticulatus Agass. III. t. 26. f. 1?

2. (nr. 4.) Notidanus primigenius Ag. III. t. 27. f. 2-17. Sehr selten.

3. (nr. 5.) Sphæerodus parvus Ag. Wolfart f. $21-25$. Hāufig.

4. (nr. 6.) - n. sp. Ag.

5. 6. 7. (nr. 7. 8. 9.) Myliobates n. sp.

IJierzu kommen:

8. Galeus minor Ag. III. t. 26. f. 15-21. Wolfart f. 16. 20?

Ich selbst besitze 5 Stück, die besonders mit Figur 18 und 20 genau übereinstimmen.

9. Carcharias megalodon Ag. III. t. 29. Bronn. Lethaea. p. 1163. t. XLIII. f. 1.

Ich habe 5 Zähne gesehn, von denen besonders der im Besitz des Herrn Bergraths Schwarzenbergo ganz genau mit der Figur von Bronn. übereinstimmt.

10. Otodus?

11. Fischwirbel von verschiedener Grösse:

12. Gehörknöchelchen verschiedener Art, nicht seIten. 
Nur die versteinerten Molluskengehäuse sind zahlreich genug, um eine erfolgreiche: Vergleichung: mit der Bevölkerung des jetzigen Meeres und derjenigen Meere zu erlauben, aus denen sich die Tertiärformationen von Paris, Bordeaux, der Subappenninen, Polens u. s. w. niedersehlugen. Ich bedaure recht sehr, dass mir weder Dujardin's Werk über die Versteinerungen der Touraine noch Sowerby's Mineral-Conchology zu Gebote standen, und dass ich daher eine Vergleichung mit der Fauna der Falun's und mit dem Englichen Crag unterlassen muss.

Von den bei Kassel von mir, heobachteten Molluskenarten finden sich:

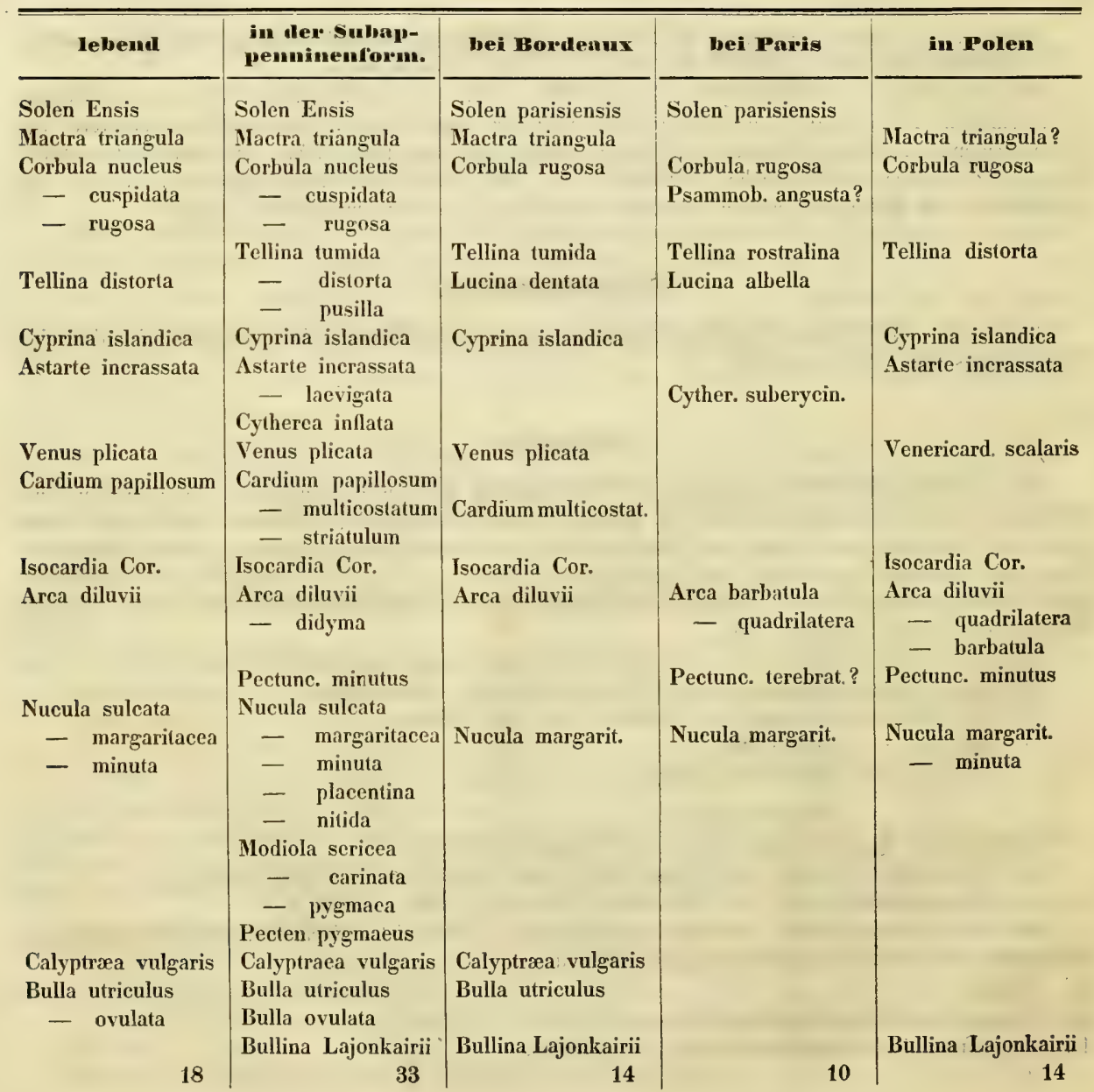




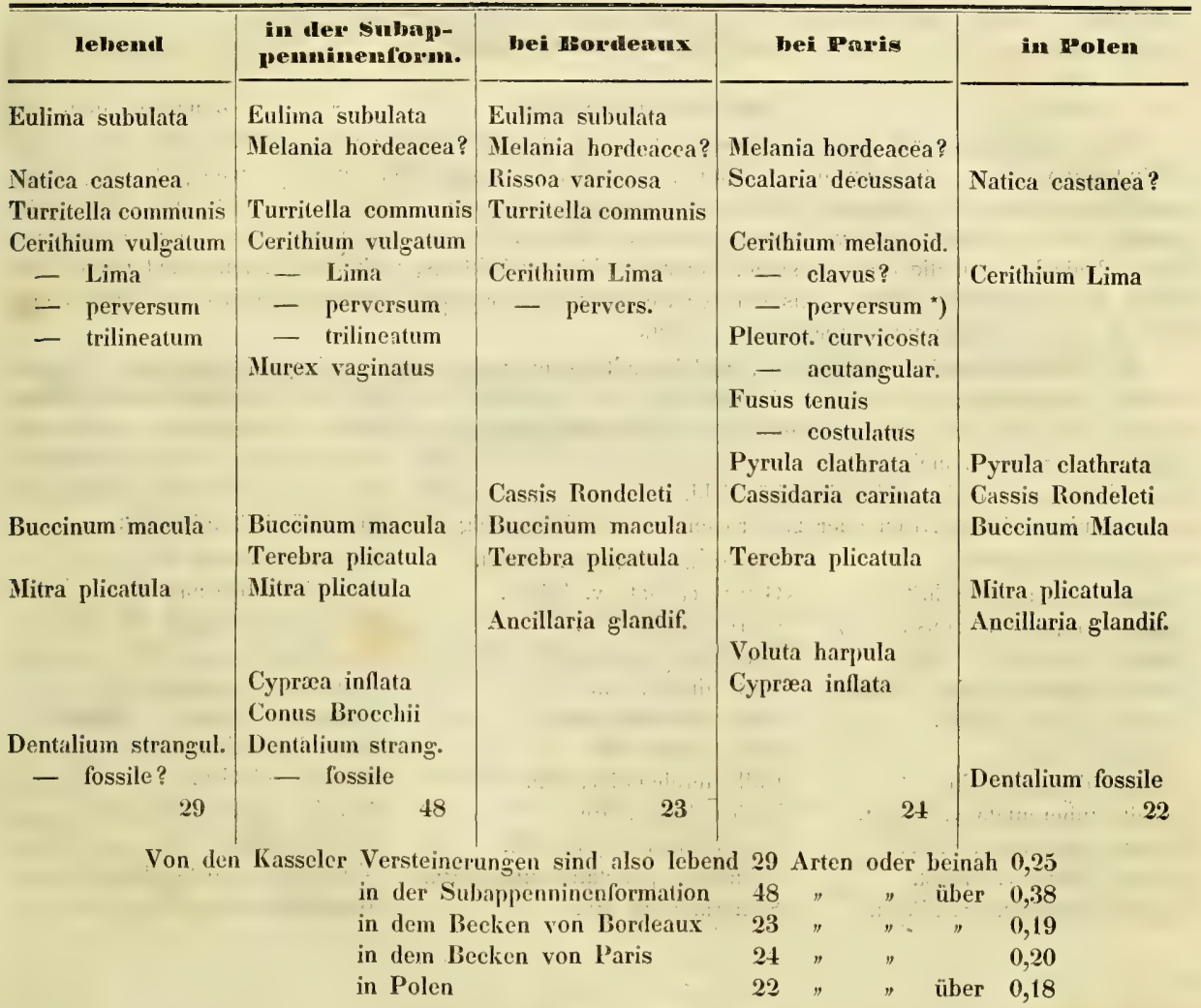

Aus dem Englischen Crag sind etwa 13 Arten auch in der Kasselsehen Tertiärbildung zu finden.

Betrachten wir die Acephalen oder Bivalven und die Gasteropoden oder Univalven gesondert, so finden sich:

Bivalven

15 Arten oder 0,27

in der Subappenninenformation $29 . "$ " " 0,48

bei Bordeaux

in Polen

bei Paris
$10 "$ " 0,17

13 " " 0,22

10 " " 0,17
Univalsen

14 Arten oder 0,23

19 " " 0,31

13 " " 0,21

9 " " 0,15

14 , " 0,23

Es hat also die Gegend von Kassel mit der jetzigen Schöpfung, mit der Subappenninenformation, und mit Polen verhältnissmässig mehr Bivalven; mit den Becken von Bordeaux und von Paris mehr Univalven gemein.

") Wenn, wie ich überzeugt zu sein glaube, C. inversum davon nicht getrennt zu werden verdient. 
Von den 48 Arten, die Kassel mit der Subappenninenformation gemein hat, sind 28 lebend, d. i. 0,61 " в. 23: " " " " dem Becken von Bordeaux

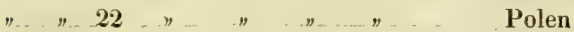

" 24 " " " dem Becken von Paris

$\begin{array}{ll}" & n \\ \prime & n\end{array}$

14 lebend, d: i. 0,61

14 lebend, d. i. 0,63

Sehr bemerkenswerth ist der Umstand, dass von den 29 lebend vorkommenden Arten 26 im Mittelländischen lleere, dagegen nur 7 Arten in der Nordsee angetroflen werden, während eine einzige Art Venus plicata in wärmeren Meeren, am Senegal vorkommt. Letztere Art habe ich nicht selbst gesehn. Es hat daher die Bevölkerung desjenigen Meeres, welches zur Tertiärperiode die Gegend von Kassel bedeckte und die Schalen seiner Bewohner hier zurückliess, weit mehr Aehnlichkeit mit der des fernen Mittelländischen Meeres, als mit der Bevölkerung der nahen Nordsee und fast gar keine Aehnlichkeit mit der Faunà wärmerer Meere gehabt.

Die Tertiärformation von Kassel, welche mit denen von Bünde, Astrupp, Düsseldorf, Grossen Freden, Osterweddingen u. s. w. eine Bildung, ein sogenanntes Becken für sich auszumachen scheint, stimmt nach den, durch unsere Untersuchungen übereinstimmend mit früheren Forschungen gewonnenen Resultaten zwar am meisten mit der Subappeninenformation überein, allein sie zeigt auch wiederum in ihrer Fauna sehr bedeutende Eigenthümlichkeiten, und von den blos bei Kassel beobachteten Arten sind nicht weniger als 35 Arten oder 29 Procent dieser Bildung eigenthümlich, nämlich folgende:

Corbula carinata $\mathrm{Ph}$.

Psammobia angusta Ph.?

Lucina parvula v. Münst.

Astarte pygrmaea v. Münst.

Astarte suborbicularis v. Münst.

Cytherea inflata Goldf.

Venus Lens $\mathrm{Ph}$.

Venus? decipiens $\mathbf{P h}$.

Cárdita tuberculata v. Münst.

Pectunculus crassus Ph.?

Pecten bifidus v. Münst.

Pecten decussatus r. Münst.
Pecten asperulus v. Münst.

Ostrea caudata v. Münst.

Ostrea bullata $\mathrm{Ph}$.

Terebratula pusilla Ph.

Bulla lineata Ph.

Bulla intermedia $\mathrm{Ph}$.

Bulla retusa Ph.

Bulla terebelloides Ph.

Natica dilatata Ph.

Crypiostoma elegans Ph.

Tornatella punctato-sulcata $\mathbf{P h}$.

Scalaria rudis $\mathbf{P h}$.
Delphinula dubia $\mathrm{Ph}$.

Delphinula carinata $\mathbf{P h}$.

Delphinula crispula $\mathrm{Ph}$.

Trochus scrutarius $\mathrm{Ph}$.

Trochus elegantulus $\mathrm{Ph}$.

Pleurotoma belgica v. Münst.

Fasciolaria Fusus $\mathbf{P h}$.

Fusus exilis $\mathrm{Ph}$.

Pyrula megacephala Ph.

Typhis simplex Ph.

Tritonium rugosum $\mathrm{Ph}$.

Ringicula striata $\mathbf{P h}$. 


\section{V e r z e i c h is s \\ aller bei Freallen and Dield

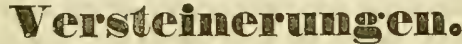

Die Fundorte der jetzt zu beschreihenden Versteinerungen kenne ich nicht aus eigener Anschauung; sie liegen beide im Ilitlesheimischen, und ich labe ihre Petrefakten nicht von einander trennen wollen, weil sie an heiden Orten fast ganz diesellen sind. Doch scheint es, als ob bei Diekholz mehr Korallen, mehr Steinkerne in festeren Massen gelagert vorkïmen, ein grösserer Reichthum an Arten jerloch die Gegend von Freden auszeichne. Den bei weitem grössten Theil der Versteinerungen verdanke ich IIerrn Prof. Lcunis in Ilildesheim, welcher dieselben mit einem unendlichen Eifer gesammelt und mir fast sämmtlich, von einigen Arten vielleicht funfzig lois liundert Exemplare, zur Ansicht nach und nach mitgecheilt hat. Fruher latte ich bereits eine ziemliche Anzahl derselben von IIerrn Bergrath Koch in Grüncnplan erhalten, und um gegenwïrtige Arbeit zu vervollständigen, hat auch IIerr Amtsassessor Römer, jetzt in Bovenden, die Güte gehabt, mir melrere seltenere Arten zur Ansicht mitzutheilen. Diesen Freunten verdanke ich allein die Möglichkeit, gegenwärtige Arbeit ausgeführt zu haben, und ich halte es daher für Pflicht ihnen öffentlich dafür zu danken.

Ueher die gengnostischen Verhältnisse, unter welehen diese Versteinerungen vorkommen, hat hauptsächlich Herr Ilofrath Hausmann in den Studien des Götting ischen Vereins hergmännischer Freunde, Band III. einige Nachricht megehen. Er sagt daselhst pag. 161: "Eine ähnliche, nschon lange bekannte, zuerst von Cramer ausfulirlich beschriebene, dureh den Reichthum ihrer Schal"thierreste besonders ausgezeichnete Allagerung, findet sich an der von Alfeld nach Ilildeshoim führenden "Strasse, eine Stunde südlich von letzterer Stadt, bei dem Dorfe Dickholzen und dem IIeidkruge," und ebendasellst: "In den Gegenden der Leine habe ich nur eine einzige, sehr kleine, kalkig san„dige mit Conchylienresten erfüllte Grobkalkmasse aufgefunden, die im Amie Winzenlurg, in der Nähe "von Kleinenfreden, an der rechten Seite der Leine, an einem nach Schildhorst führev:len Fahr"wege zu. Tage ausgeht."

Die Conchylien dieser beiden Lokalitäten sind fastebenso zerbrechlich, wie die der Wilhelmshöhe, und von den grösseren Arten finden sich fast allein Fragmente; sie sind in dem thonigen Sande so häufig enthalten, dass sie den dritten Theil, ja selbst bisweilen die Hälfte desselben an Gewicht betragen, und am besten durch Schlämmen und Siében zu erhalten. 


\section{$-34-$ \\ Zop the}

1. Turbinolia initermedia v. Münst. S. p. 3.

Nicht eben häufigg.

2. Turbinolia sulcata Lamk.?

Verkehrt kegelfïrmig, mit dichotomischen Furchen, welche vertiefte Punkte in doppelten Reihen zeigen; die erhabenen Zwisehenräume gekörnt, nicht flïgelartg erweitert. Ph. S. Goldf. p.5t. tab. XV. f. 3. - Bronn Lathaca. p. 889 . t. 36 f. 4. Ziemlich häufig bei Freden, $3^{3} / 4^{\prime \prime \prime}$ lang, oben fast $2^{\prime \prime \prime}$ in Durchmesser haltend, vollkommen kegelförmig, unten abgestutzt. Die Oberfläche ist wahrhaft gefurcht, und zwar theilen sich die Furchen nach oben dichotomisch; die erhabenen Zwischenräume sind nicht flügelartig erweitert, nicht lamellenartìg dünn, sondern mässig erhahen, so hreit wie die Furchen, auf dem Rücken al,gerundet, schwach gekörnt oder gekerbt. Unten stossen etwa acht zusammen und bilden cine kleine Vertiefung; durch Zwischenschieben neuer Leisten wächst ihre Zahl zuletzt auf etwa 48 bis 52 , von denen nur die Hälfte in Lamellen des Sterns übergeht. Dieser ist bei allen Exemplaren beschälligt, scheint aber einen Kranz von 6 griffelförmigen Lamellen und zwei einzeln stehende, elenfalls griffellörmige Centrallamellen gehabt zu haben. Es ist kaum glaublich, dass diese Bildung sich in cinen einfachen, zusammengedrückten Centralzapf, $n$ verwandle, wie ihn die citirten Figuren zeigen. - Ist dieses die Lamarcksche Art? die Figur der T. sulcata hei Blainville Manuel d'Actin. t. LVII. f. 2 stellt jedenfalls etwas ganz Anderes, unserm Genus nicht Angehöriges dar, und von Paris besitze ich durch Herrn Bergrath Koch eine verschiedene Art Turbiuolia, welche ich alata nennen möchte, wenn nicht etwa sie die Lamarlische sulcata ist, in welehem Fall unsere deutsche Art einen andern Namen erhalten muss. Sie ist bei $3 \%^{\prime \prime \prime}$ Länge olien $2 \frac{1}{3}^{\prime \prime}$ breit, der Stern zeigt etwa 20 Randlamellen, gar keine Kranzlamellen, und in der Mitte einen zusammengrdrückten zungenförmigen Zapfen, der nicht aus dem Stern hervorragt. Die äussere Fläche zeigt nur etwa 24 sehr dünne, flügelartig erweiterte Lamellen, die nach unten immer höher werden, und durch breite Zwischenräume getrennt worden, welche nach olien noch durch kleine, kaum hervorragende Leistchen getheilt werden. - Zu den Turbinolien darf man nur die wirklich freien Arten rechnen. Man kann sehr wohl an der Spitze sehen, ob sie festgewachsen gewrsen ist, oder nicht. Im letzien Fall stossen die Leistchen der Oberfäche in cinem Punkt zusammen, im entgegengesetzten Fall breitet sich der Mantel des Thieres noch etwas auf den Gegenstand aus, auf' dem es festgewachsen ist, wie bei den Gorgonien etc. unl man erblickt eine kalkige Ausbreitung des P'olypenstocks oder eine Bruchfläche. Eine solcho wurzclartige Ausbreitung fehlt bestimmt den Turbinolien, und wenn auch dann und wann ein Sandknrn an der Spitze festsitzt, so ist dies ein ganz anderes Verhältniss. Möglich dass die Brut der Turlinolien festsizt, die erwachsenen Individuen sind jedenfalls frei. Aehnlich verhält es sich ja mit den Fungien, welche nach den Beobachtungen von Stutchbury in der Jugend festgewachsen sind. S. Trans. Linn. Soc. XVi. p. 493 u. Müll. Arch. f. Phys. 1834. p. 77.

3. Flabellum Roemeri n. sp.

Zusammengedrückt-kreisellörmig, scharf zweikantig, mit breiter Spitze angewachsen; nur zwölf Hauptlamellen im Stern.

Ilerr A. A. Römer hat mir cin Exemplar mitgetheilt. Es ist $31_{2}^{\prime \prime \prime}$ hoch, oben $3 \frac{1}{2}{ }^{\prime \prime \prime}$ breit und $21 / 2^{\prime \prime \prime}$ dick; der Stern, stark beschäiligt, zeigt genau dieselbe Beschaffenheit wie Turbinolia cuneata Goldf. t. XV., f. 9 nur dass nicht mehr als 12 lluuptamellen sind. Die äussere Fläche ist ziemlich glatt, mit schwach vertieften Linien; die ehemalige Auhefungsstelle ist eine Linie breit, glatt; es ist keine frische 
Bruchfläche, sondern scheint bereits durch den herübergewachsenen Mantel des Thieres mit eincr glatten Schicht, bedeckt, zu sin.

Anmerk. Ich hahe zu wenig Erfalirungen, nm beurtheilen zur können, ol, Bronn Recht hat, wenn er Lethaca p. 897 die 'Turbinolia siauosa, cuncata, anceps, appendiculata für Varietäton cincr A't crklärt, in wel. chem Fall woh! auch gegenwārtign Form nur als Varietät auzuschn wăre. Uchrigens hin ich der Ansicht, dass man die turbinolienähulichen Korallen, ,.welche stark zusammengedrückt sind, unten in eine ,feine Spitze auslaufen und infernt sichende, ahwechselud grössere und kleinere Sicrulamellen haben, „Yon denen nur etwa $\mathbf{j}$ de vierte his gesen die Ni le ri ht, wo dio Wärzchen der Iamellen in cine ,dopjelte Querwand zusammenfliessen, die so tiel' lixgt, dass man sie hei unloschäligtem Stern nicht sehen kann," wie dies bei den crwähnten Arten der Fall ìt, ị ein besolderes Gents vereinigen muss, welches Lesson unter dem Namen Flabelium aufigestellt hat, und wonit vielleicht Goldfussens Diploctenium zusammenfallt. Unstreit,g muss die Verschiedenheit in Ban des Sternes wesentlich zur Begründung der Gentra benuzt werdın, und es kann uns hiervon der üble Umstand nicht abhalten, dass wir bei fossilen Arten so oft die urşrüngliche Beschafinheit des Sternes wicht sehen künnen.

4. Cyathina (orler Oeme?) granulata v. Nünst. S. p. 4.

Nicht selten.

5. Cyathin a (oder Oeme?) Münsteri Römer.

Verkehrt kegelförnig, an der Basis rtwas gekrümmt, mit stark erhabenen, gewundenen und hökerichen, aher glatten Längsleisten, und etwa zwanzig Sternlamellen.

Ein Exemplar von II'rrn A. A. Römer mitgetheilt, $2^{\prime \prime}$ hoch, der Stern hat 11/2"' im Durchmesser, ist vielleicht nur Varietät der vorigen Art.

6. Lunulites radiata Lamk.

Flach convex, heiderseits durch Furchen strahlig.

S. p. 3. nr. 1. und Bronn Lethacea p. 889. sq.

IJ̈ufig. Diese Art habe ich auch als L. perforita v. Münst. erhalten, jedoch ein vollkommen wohl erhaltenes, unten nicht perforirles Excmplar.

7. Millepora truncata L. Myriapnra Blainv.

Aestig, dichtomisch; die $\Lambda$ este sticlrunt, am Ende oft zusammengerlrückt; die Nündungen der Zellen gross, kreisrund, an den untern Theilen des Stammes virleckt; die Zwischemrätune grlatt.

Bei Freden und Diekholz selten, ven der Jebenden Art in nichts versebieden. Was ich bisher als M. malriporacea Goldf. von Bünde unl Astrupp geselın, siml W/usse Stammstücke dieser Art mit oblitterirten Zellen; ob die Art aus Iem Krejderuf von Mastricht versehieden ist, kann ich nicht sagen. Die Endspitzen der Aeste habe ich auch unter dem Namen Lschara porosa whalten.

8. Retepora cellulosá Lamk.

Ein berherförmiges, faltiges Netz mit rhombischen Maschen; auf der inneren Seite zahlreiche hervorstchende Zelleumündungen, auf' der äussern erhahenen Querstriemen.

Sehr selten, bei Luithorst gemein. L. vibicata Goldf. p. 10:3. t. 36. f. 13 ist nicht veschieden; alle von Goldfuss als unterscheidend angegebenen Kennzeichen heobachtet man auch bei der lelvenden Art, so namentlich die erhabenen Querstriemen, welche nichts auderes sind als die Gränzen der einzelnen Zellen. Um diese zu sehen, muss man ein lebendes Exemplar vergleichen, welches durch langes Liegen im Meer die thierische Substanz verloren hat.

\section{Hornera gracilis n. sp.}

Baumartig, sehr stark verästelt, mit schlanken schwach zusammengedrückten Aestcn; die Zellenmündungen zerstreut, nicht hervorragend, dazwischen kleine poren. 
Selten, bei Luithorst häufig. Dic Verästelung, Grösse, das äusscre Ansehn sind ganz wie bei H. frondiculaia, und der einzige Unterschied ist, dass die Zellenmündungen nicht hervorragen. Ausserdem bemerkt man noch zwischen je zwei Zellenmündungen zwei kleinere Poren. Dieser Umstand machte mich Anfangs geneigt diese Koralle für ein anderes Genus, für eine Heteropora zu halten, weil ich bei der lebenden Hornera frondiculata solche Poren nicht fand, nachdem ich aber durch Aetzkalilauge von dieser die thierische Substanz entfernt hatte, fand ich ebenfalls Poren zwischen den Zellenmündungen.

10. Hornera biseriata n. sp.

Baumartig, sehr stark verästelt, mit schwach zusammengedrückten Aesten; die Zellenmündungen nicht hervorragend, auf der innern Seite zweifach in Querreihen gestelli; die Poren in regelmässige Längsreihen gestellt.

Bei Freden selten, bei Luithorst gemein.

Die Querreihen der Zcllenmündungen stehen etwas schief und greifen in der Mittellinie über einander; dazwischen finden sich kleine längliche Poren in Vertiefungen, so dass eine grosse Aehnlichkeit mit der innern Fläche einer Baumrinde entstcht. Auf der hintern Seite sinl die Poren mehr kreisrund und stehen regelnässiger in Längsreihen, die durch erhalıene Zwischenrüume getrennt werden. Die Verästelung ist ganz wie bei der vorigen Art; die grösseren $\Lambda$ este sind kaum $1 / 2^{\prime \prime \prime}$ dick. Die Annäherung an ldmonea fällt in die Augen.

11. Hornera subannulata n. sp.

Baumartig verïstelt, mit schwach zusammengedrückten Aesten; die Zellenmündungen hervorragend, in zweifuche Querreihen gestellt.

Sehr selten, schlanker als die vorhergehende Art, sehr ausgezeichnet durch die stark hervorragenden, unvollkommene Ringe bildenden Zellenmündungen. Die dazwischen befindlichen Poren stehen sehr regelmässig.

12. Ceriopora variabilis v. Münst. (nach mitgeth. Exempl.)

Mit walzenförmigen Aesten und lireisrunden Zellenmündungen, welche ziemlich regelmässig in Längsreihen stehen, und durch erhabene Zwischenräume getrennt werden.

Bei Freden selten, bei Luthorst häufig. Die einzelnen Aeste haben einen Durchmesser von $13 /{ }_{4}{ }^{\prime \prime}$ und sind walzenfömig. Die kreisrunden Zellenmündungen stehen im Durchschnitt in 20 - 30 Längsreihen, oft äusserst regelmässig, in welchem Fall die erhabenen Zwischenrüume, welche die einzelnen Zellen trennen, ein zierliches Tetzwerk von regulären Sechsecken bilden. Häufig aber, besonders wo die Aeste sich (gahbelförmig) theilen, wird die Stellung der Zellenmündungen unregelmässig, ihre Gestalt verzogen und eckig. Aufrallend ist es, dass viele Endungen der Aeste trichterförmig vertieft sind, was seinen Grund in der Richtung und Lage der Zellen in bezichung zur Axe zu haben scheint. Die sehr grosse Achnlichlieit mit C. milleporacea Goldf: P, 34. X. f. 10. aus der Kreide von Mastricht, und mit C. gracilis Goldf. p. 35. 1. X. f. 11 aus dem Grünsand von Essen springt bein ersten Anblick in die Augen; allein bei C. milleporacea stehen die Zellen in Quincunx etc., bei C. gracilis in Querreihen.

13. Ceriopora stellata Goldf.

Incrustirend, oder cylinderförmig; die Oberfäche überall porös, mit strahlenden, mehr oder weniger devitichen Rippen.

S. Goldf. p. 39. t. XI. f. 11. tab. XXX: f. 12.

Bei Freden sehr selten, bei Luithorst desto gemeiner. - Ich habe kein Exemplar gesehn, welches grösser als $2^{\prime \prime \prime}$ gewesen wäre. Die häufigste Form scheint die cylindrische zu sein, mit gewölbter, fast halbkugelförmiger Endfläche. In diesem Zustand sind die Seiten glatt, mit einer kalkigen 
Haut geschlossen. Stumpfe, strahlende, nicht im Mittelpunkt zusammen kommende Rippen zeigen die meisten, es kommen aber auch viele unregelmässige, zum Theil wohl abgerollte Formen vor; sprossend sah ich sie nie. Die ganze Masse besteht aus verwachsenen, ursprünglich wohl 'cylindrischen, áber durch das Zusammenliegen unregelmässig und kantig gewordenen Röhren, deren Zwischenwände weit schmaler sind als ihr Durchmesser, was auf den Goldfussischen Figuren nicht gut wiedergegeben ist. Durch den geringeren Durchmesser der Mündungen unterscheidet sich diese Art vornämlich von C. Diadema Goldf.

14. Ceriopora spiralis Goldf. „Gabelförmig verästelt, walzenförmig, spiralförmig gewunden, mit ovalen in spiralförmigen Bän"dern gestellten Zellenöfinungen."

S. Goldf. 1. p. 36. tab. X!. f. 2.

Ich hahe drei Exemplare von Diekholz gesehen; kommt nach Goldfuss in der Kreideformation von Mastricht vor.

15. Ceriopora minuta n. sp.

Mit schmalen cylindrischen Aesten und ovalen Zellenmündungen, welche regelmässig in Längsreihen stehen, und durch schmale erhabene Zwischenwände getrennt werden.

Neunzehn Exemplare, höchstens $3 / 4^{\prime \prime \prime}$ in Durehmesser haltend, von C. variabilis durch geringere Grösse, kleinere, längere noch weit regelmässiger in Längsreihen gestelle Zellenmündungen verschieden. Dies ist vermuthlich nur der abgeriebene Zustand, denn ein Exemplar ist mit einer kalkigen Iaut überzogen, welche kleine, kreislörmige Zellenmündungen zeigt, die fast um das Zweifache ihres Durchmessers von einander abstehen, und hier und da von einem schwachen wulstigen Ring umgeben zu sein scheinen.

16. Cellaria hexagona (Glauconome) v. Münst.

Sechs- (oder acht-) kantig; die Oberfläche der Zellen von eiförmiger, unten durch die Spitze der nächstuntern Zelle abgeschnittener Gestalt, mit einer erhabenen Linie eingefasst.

S. Goldf. p. 101. tab. XXXVI. f. 8.

Bei Freden selı selten. Die Anzahl der in einer Ebene liegenden Zellen, und was davon bedingt wird, der Kanten des Stämmchens ist nicht durchaus beständig; man findet bisweilen Bruchstücke, die auf der untern Häfte weniger Zellen in einer Ouerreihe und weniger Kanten haben als auf der oberen.

17. Cellaria tetragona (Glauconome) v. Münst.

Vierkantig, je zwei Zellen abwechselnd cinander gegenüher gestellt, welche äusserlich eine länglich sechseckige Fläche zeigen; die Zellenmündungen oberhalb der Mitte.

S. Goldf. p. 100. t. XXXVI. f. 7.

Sehr selien, bei Freden von Herrn Römer aufgefunden.

18. Cellaria marginata (Glauconome) v. Münst.

Ziemlich walzenförmig; die Zellen auf der Oberfläche sechsseitig mit einem erhabenen Rande; die

Zellenöflinung quer eiförmig, central, of gedoppelt.

S. Goldf. p. 100. t. XXXVI. f: 5 .

Sehr selten, bei Freden von Herrn Römer, bei Diekholz von Herrn Leunis gefunden.

19. Cellaria rhombifer a (Glauconome) v. Münst.

Ziemlich walzenförmig, die Zellen auf der Obernäche rhombisch-elliptisch mit erhabenen, fortlaufenden Rändern, die Zellenöffnungen fast kreisrund, excentrisch.

Bei Freden, sehr selten. 
20. Cellaria gracilis n. sp.

Walzenfürmig, sehr schlank urd dünn, aus sechs Jängsseihen von Zellen hestchend, mit länglichen eingestochenen P'unkten; die Zellen ohne erhalune Känder, init kreisförmigen, sehr entfernten Mündunæren.

Ein Exemplar 5/4"' lang, 1/3"' dick von IJern Prof. Leunis eshalten. Der Mangel der erhabenen, die Zellen hegränzenden Linien, die eingestochene Punkte der Oberfläche, zeichnen diose Art sehr aus. Die Entfernung der Zellenmündungen von einander in senkrecliter lielitung ist viermal so gross, als ihr Durchmesser.

Anmerk. Dass Glanconome v. Mūnster, Vincularia Defrance und Cellaria Lamarck, Lamouroux ctc. ein Genus sind, bedarf woll jetzt keines weiteren beweises.

21. Eschara glabra n. sp.

Mit last stielrumien, schwach zusammengedrückien Aesten, die Oberflāche vollkommen glatt, die

Zellenmünilungen eiförmig.

Selien.

Die A'ste sind etwa 1 "' hreit und $2 / 3$ "' dirk, auf der Oherfläche vollkommen eben und glatt. Es sind fünf Lïngsreihen Zellen auf jetler Seite, die im frischen Zustanle dureh crhabene Zwischenräume getrennt werden, bisweilen jerloch liegen die Zwischenrïume in einer Ebene mit den Münlungen, und man erblickt nur mu llülfe der Lupe äusserst foine Linien, wolche die cinzelnen Zellen ahgränzen und langgezogene Scchsecke bilden. Die Oeffhungen stehon regahmässig im Ouincunx, sind grenau clliptisch und nur weniges liürzer als die Zwischentiume zvischen $\mathrm{j}$ : zwei derschllhen. - Am nächsten verwandt ist E. teretiuscula n. sp. von Palermo, bei welcher die Oeffnungen in Vertiefungen liegen, und wo die Oberfläche fein grubig punktirt ist.

22. Eschara punctata n. sp.

In schmale zusammengedrürkte Aeste getheilt, anf der Oberfläche porös punktirt; die Mündungen der Zellen klein, kreisförmig, im Quincunx gestellt.

Ein Fragment von Ilerrn Leunis gefunden. Die Aeste sind kaum $1^{\prime \prime \prime}$ breit und 5/12"'dik, von vier längsreihen von Zellen grebildet. Die Oeflunngen derselhen sind nur den vierten Theil so gross, wie der Zwischenraum bis zur senkrech darauf folgemlen. Unter jeder Zellenmündung steht seitlich ein kleines Loch, und noch kleincre Punkte sind überall eingestuchen.

23. Eschara porosa n. sp.

In ziemlieh breite blattartige Aeste getheilt, die Zellen ziemlich regelmässig im Quincunx gestellt, durch eine doppelte lieilie eckiger Poren gescheden; die Mündungen der Zellen gross, fast kreisförmig.

Ein drei Linien breites Bruchstück, bei Luihorst häufiger. Die einzelnen Zellen sinil schwach gुewölh, aul' ('ine ähnliche Weise durch eingestodlene Punkte geschieden wic Discnpora circumeincta p. 4, diese Punlite sind jedoch grüssır, eckig, durch schr schmale Zwischenräume geschicden. Die Hündungen der Zellen wie bei E. glalira.

24. Eschara clathrata Pl.s. s. 4.

Ein Lxemplar ist vom $11 \mathrm{~m}$. Prof. Leunis bei Diekholz gefunden.

25. Eschara diplostoma n. sp.

In schmale, stark zusanmm ngedrückte Aeste getheilt; die Zellen lïnglich, durch cine einfache Reihe eingestochener Punkte geschieden, mit einer kleincn kreisrunden Mlündung und einer zweiten kleincren, tbenlalls lireisunden Oefhung unterholb derselhen.

Bei Dickholz sehr selten, bei Luithorst häufig. Die Atste sind nicht breiter als cine Linie, und 


\section{$-39$}

oft nur 1/3"' dick, mit ctwa siehen Reihen Zellen, welche, in sehr schräge Reihen gestellt, einen unregelmässigen Ouincunx bikłen. Dieselben sind sehr verlängert, flach, und durch die eingestochenen sehr kleinen Punkte geschieden.

26. Eschara celleporacéa v. Münst.

In ziemlich schmale zusammengedıükte Aeste getheilt; die Zellen eiförmig, stark hervorragend, ohne Ordnung gestellı; die Mündungël rundlich eiförmig.

S. Goldf. 1. p. 101. lab. XXXV'. f. 10.

27. Cellepora.

Ein Excmplar, bei Luithorst häufig, immer so abgerieben, dass an eine genate Bestimmung der Art nicht zu denken ist.

28. Discopora circumeincta Ph. S. p. 4.

Ein Exemplar auf Dentalium strangulatum, mit ziemlich stark hervortretenden Rippen der Mundoffnung.

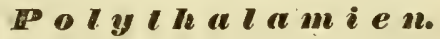

1. Nodosaria elegans v. Münst. S. p. 4.

Nicht selten.

2. Nodosaria intermittens liöm. S. p. 4.

Iläufig. Sehr verinterlich, oft fist gar nicht cingeschnürt, in welchem Fall die Streifung nicht selten fist vollständig verschwindet.

3. Nodosaria radicularis v. Münst.

„Pfriemenförmig, meist etwas loggenförmig, und perlenschnurartig knotig, mit (4-7) tiefen Ein"sclinürungen, glaıt."6

S. Römer in Leonh. und Bronn N. Jahrb. 1838. p. 382. nr. 3.

Nicht selten.

4. Nodosaria acicula n. sp.

Sehr fein pfriemenförmig, perlschnurartig knotig, mit zahlreichen feinen Längslinien oder Rippen bedeckt.

Zwei Exemplare, 11/2"' lang,, aus acht, durch starke Einschnürungen getrennten Gliedern bestehend, noch ein Mal so dünn wie $\mathbf{N}$. elegans, mit etwa 16 scharfen Rippenstreifen.

5. Frondicularia? lancea n. sp.

Beinah ellịtisch-eiföruig, nach der Mündung zugespitzt, in der Mitte der Länge nach stumpl' aber deutlich gekielt, an der Spitze schwach ausgerandet**).

Ein Exemplar bei Freden von Ilerrn Prof. Leunis gefunden, leider aufgeklebt, und dic Mundöff-

*) Einer brieflichen Mitthcilung des IIrn. A. A. Römer zufolge ist Frondieulina v. Münst. kein Schreihfrhler, soadern bezeichnet ein neues Genus, welches durch eine Iä ngliche M und a palte von Frondicularia schr verschie. den ist, wo wir eine runde I Indïfinung antrefen. Allein es ist, kein wesentlicher Unterschied zwischen Fronảiculina v. Münst, und Lingulina d'Orb,; und Lingulina Suldanii z. B. ist von Frondiculina ovata nur dadurch 
nung nicht zu sehen. Sie scheint aber kreisförmig gewesen zu sein. Ich zähle neun Kammern; die Spitze scheint nicht spiralförmig angeordncte Kammern zu haben, wie sie bei Lingulina vorkommen.

6. Lingulina oblonga v. Münst. S. p. 4.

Häufig.

7. Lingulina ovata v. Münst. S. p. 4.

Hãufig.

8. Lingulina elongata v. Münst. S. p. 5 .

Häufig.

9. Lingulina linearis $\mathbf{P h}$. S. p. 5 .

Häufig.

10. Lingulina obliqua v. Münst.

„2Länglich eirund bis keilfürmig, concentrisch schwach gerurzelt, glatt, die Spitze spiralförmig um,gebogen."

S.' Römer a. a. 0. p. 382. nr. 4 fig. 7.

Nicht selten.

11. Lingulina ensiformis Röm.

„Fist linealisch, Anfangs etwas umgebogen, concentrisch tief gerunzelt, glatt; Oeffnung etwas ,gseitlich. 66

S. Römer a. a. O. p. 381. nr. 5. f. 8.

12. Lingulina striata v. Münst.

„Spitz eirund, unten mit convergirenden, vor der Mitte verschwindenden Längslinien."

S. Römer a. a. 0. p. 382. nr. 6. fig. 9.

13. Lingulina cuneata v. Münst.

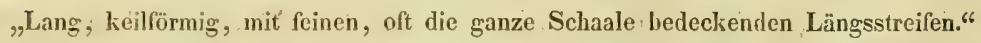

S. Römer a. a. O. p. 383. nr. 7. f. 10.

Alle diese Arten sind nicht selten.

14. Marginulina Gladius n. sp.

Linealisch, schwach gebogen, stark zusammengedrückt.

Bei Freden gemein, $2^{\prime \prime \prime}$ lang, $2 / 3^{\prime \prime \prime}$ breit, ${ }^{1} / 3^{\prime \prime \prime}$ dick. Diese Art geht durch ihre Form in Vaginula über, wohin man sie rechnen müsste, wenn die Kammern der Spitze nicht spiralförmig angeordnet wären. Von Lingulina entfernt sic die Stellung der Mundöffuung, welche nicht in der Mitte der letzten Zelle, sondern an dem seitlichen, vorspringenden Winkel ist. Sollte es dennoch Lingulina (Frondiculina) ensiformis Röm. 1. c. fig. 8 sein? Geht in Planularia über.

15. Planularia intermedia n. sp.

Länglich, mässig gebogen, die Scheidewände der Zellen erhaben, die Spițe beiderseits gekielt; die Spira kürzer als der grade Theil.

Drei Exemplare, $1{ }^{3} / 4^{\prime \prime \prime}$ lang; über $3 / 4^{\prime \prime \prime}$ breit, $1 / 3^{\prime \prime \prime}$ dick; stelt in der Gestalt zwischen der vorhergehenden Art und Pl. areuata (Marginulina) p. 5.

unterschciden, dass die Querwände der Kammern in der Mitte eingebogen sind. Man vergleiche auch die-Charakteristik des Genus Linģulina, wie sie d'Orbigny gibt, mit der von Römer a. 3. O. aufgestellten Charakteristik von Frondiculina, wie ich beide p. 4 nebeneinander gestellt habe. 


\section{$-41-$}

16. Planularia oblonga n. sp.

Stark zusammengedrückt, länglich, auf der cinen Seite gradelinigt, auf der andern gebogen.

Ein Exemplar, $12 / 3^{\prime \prime \prime}$ lang, $5 / 6 "$ breit, $1 / 4$ "' dick.

17. Planularia semicircularis n. sp.

Fast genau hallkreisförmig, flach, die Seitenwand vollkommen abgerundet.

Zwei Exemplare 21/"' lang, 11/"' hreit, 1/"' dick, durch den Mlangel des Kieles sogleich von

Pl. auricula zu unterscheiden. Die Scheidewände stehen nicht hervor.

18. Polymorphina regularis v. Münst.

„Breit lanzettlich, ungleichseitig, unten spitz, oben erweitert, in der Mitte der Breite mit deutli,chem Rücken, glatt, mit jelerseits 6 - 9 Kammern. ${ }^{66}$

S. Röniner a. a. 0 . etc. 385. f: 21.

Bei Diekholz namentlich äusserst gemein.

19. Polymorphina anceps n. sp.

Eiförmig, unten (wo die Münlung) spitz, in der Mittellinie gewölbt, an den Seiten stark zusammengedrückt, zweischneidig; jederseits vier bis fünf Kammern.

Gemein bei Freden und Dickholz.

Diese sehr ausgezeichnete Art ist fast eine Linie lang.

20. Polymorphina olscura Röm.

„,Lang elliptisch, etwas spindelförmig, schwach gehngen, wenig zusammengedrückt, stumpf„spitzigt in Durchschnitt fast kreisrund, mit jederseits vier bis fünf, aussen wenig sichtbaren „Kammern.6

S. Röiner a. a. 0. p. 385. f. 23.

Zwei Exemplare.

21. Poły morphin a Ligua Röm. (ob Lingua?)

وLang zungenfürmig, stark zusammengedrückt, stumpf zweischneidig, mit jederseits $4-5$ „Kamunern。6

S. Römer p. 385. f. 25.

Fünf Exeinplare, meist von Diekholz.

22. Polymorphina cylindroides Röm.

„Fast walzenförmig, oberhalb etwas verdickt, jederseits mit zwei, etwas gewölbten, sehr langen ,Kammern.“

Ein Exemplar, an dem ich fünf Kammern zähle. S. Römer p. 385. f. 26.

23. Polymorphina subdepressa v. Münst.

"Oval, dick, etwas zusammengedrückt, jederseits mit zwei bis drei Kammern, die meist schwer „zu erkennen sind."

S. liömer p. 385 . f. 26.

Sieben Exemplare.

24. Polymorphina communis d'Orbig. S. p. 5.

Nicht selten.

25. Polymorphina crassatina v. Münst.

„Varkchıt eirund, glatt, stark gewölbt, mit fünf aufgeblasenen, dickwandigen Kammern.“

S. Römer p. 385 . f. 30 .

Nicht häufig. 
26. Polymorphina gibba d'Orb.

„, Verkehrt eirund, oben (wo die Oefnung) zugespitzt, unten stark gewölbt, Kammern wenig "vortretend. ${ }^{66}$

S. Römer p. 386. f. 32.

Selten.

27. Polymorphina globosa v. Münst.

„Fast kugelförmig, glatt; Kammern kaum zu unterscheiden."

S. Römer p. 286 . f. 33.

Ein Exemplar.

28. Polymorphina minuta Röm.

„Verkehrt cirund, oben etwas zugespitzt, wenig zusammengedrückt; Kammern wenig gewölbt."*

S. Riömer p. 386. f. 35 .

Zwei Exemplare.

29. Polymorphina oblonga Röm.

„Eirundlich, unten stumpfer, etwas ungleichseitig, zusammengedrückt; Kammern gewölbt.6

S. Römcr p. 386 . f. 37.

Ein Exemplar.

30. Rotalia discifera n. sp.

Beillerseiis stark gewölbt, am Rande deuilich gekielt, auf der untern Seite eine. grosse Scheibe, welche von den acht Kammern durcli eine vertiefte linie getrennt ist.

Ein Exemplar, die obere Fläche ist alggerieben, die untere sehr ausgezeichnet durch die angegehene Bildung, so dass diese Art sehr leicht zu erkenuen ist. lhr Durchmesser beträgt $\mathbf{3} / \mathbf{2}^{\prime \prime \prime}$.

31. Truncatulina communis d'Orb.

„Aeusserst fein punktirt, meist eirund; die gewölbte Seite in der Mitte oft scbwach genabelt, mit „,vier his sechs tiefen oder undeutlichen ausstrahlenden Furchen; Rücken scharf; unere Seite mit $1 \frac{1}{2}$ Winlungen, flach oder flach concav."6

S. lłömer a. a. O. p. 389. f. 56.

Ein Exemplar.

32. Robulina subnodosa v. Münst.

„Kreisrund, scharf gekielt, mit 12-15 von der Nabelscheibe ausstrahlenden, fast geraden Furchen, "und meist gewölbten Zivischenräumen."

S. Römer p. 391. f. 61.

Selar gemein.

33. Cristellaria osnabrugensis v. Münst.

„Gross, runit, sehr zusammengedrückt, mit etwa zehn, am scharfen Kiel rückwärts gebogenen, „schmalen lippen, deren Zwischenräume breit und flach sind."6

S. Kömer p. 391. f. 62.

Sehr liäufig.

34. Cristellaria subcostata vo Münst. S. p. 5.

Selten.

35. Trilnculina oblonga d'Orb.

"Lïnglich-uval, stumpf, mit schmalen, zugerundeten Kammern."

S. liömer p. 393. f. 70.

Seiten. 
36. Triloculina inflata d'Orb.

„Fast kreisrund; gross; Kammern nach dem schmalen, stumpfen Rücken hin zusammengedrückt, "breit; die cingeschlossene dritte rechts etwas vorstehend und geliantet; ebenso die ziveite „Kammer.6

S. Rōmer J. 393. f. 72.

Sehr häufig, sie hat nichts Aufgetricbenes an sich.

37. Triloculina ovalis Röm. S. p. 6.

Häufig.

38. Triloculina orbicularis Röm. S. p. 6.

Häufig.

39. Triloculina carinata n. sp.

Länglich-ciförmig, stark zusammengedrückt; die cinzclnen Kammern auf dem Rücken gekielt, die Mündung stark vorspringend.

Ein Exemplar, durch die stark gekielten Kammern leiclit zu unterscheiden.

40. Triloculina angusta n. sp.

Länglich, stumpf, mit schmalen, auf dem Rücken gerundeten Kammern und stark vorspringender

Mlündung.

Zwei Exemplar, die schmalste unter den angeführten Arten.

41. Quinqueloculina trisulcata Röm.

„Länglich-oval, im Durchschnitt ungleich fünfseitig; Kammern jede mit drei breiten, tiefen Fur"chen und schmalen Zwischenrüumen."6

S. liömer p. 393. f. 75.

Von Ilerrn Leunis gefunden, so wie die folgende.

42. Quinqueloculina sulcifera Röm.

„Länglich-oval, im Durchschnitt dreiseilig, mit gerundeten Kammern, welche drei bis sechs scharfe, "meist anastomosirende Längsfurchen tragen."“

43. Orbiculina nummismalis Lamk.

Scheilenförmig, sehr flach gellrückt, beiderseits gleich; die Kammern durch schr stark spiralförmig gewvindene Wände getheilt und durch senkrechte und quere Scheidewände in Unterabtheilungen getheilt; zahlreiche Oeflnungen in Längslinien.

S. Lamarck hist. VII. p. 609. - Enc. múth. t. 468. f. 1. - Blainv. Manuel p. 373. t. 7. f. 4. D’Orbigny p. 139 etc.

Ein Exemplar. Lebend soll diese Art bei den Antillen und Mariannen vorkommen.

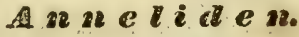

1. Serpula corrugata Golif.

Fast stielrund, runzelg, schwach gekielt, verlïngert kriechend oder in ein Gerwinde verschlungen; der Kiel undeutlich knotig; die Seitenrúnzeln gedrängt.

S. corrugata Goldf: 1. p. 241. t. 71. 1. 12. a. d.

Ein schötres Exemplar von Hern Leunis bei Diekholz gefunden.

2. Serpula contorta n. sp.

Stielrund, dünn, schwach in die Qucre gcrunzelt, unregelmüssig zusammengesclłungen. 
Ein Exemplar auf einem Dentalium strangulatam aufsitzend; es hat keine hervorstechende Kennzeichen. Die Dicke der liöhre heträgt nur $1 / 2$ "', und nimmt nur schr allıählig zu. Wollte man die Verschlingung der Röhre lediglich als Folge des Standortes betrachten, so könnte diese Art identisch mit einer im Mittelmeer lebenden sein, die ich wegen der merkwürdigen Bildung ihres Deckels S. pappigera nenne.

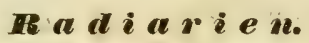

1. Cidarites.

Nur ein Bruchstïck von einem Stachel, $2^{\prime \prime \prime}$ lang, fast $2 / 3 "$ im Durchmesser, stielrund, zchnkantig, die Kanten mit zahlreichen ( 7 auf $2^{\prime \prime \prime}$ ) nach vorn gerichteten Sägezahn-artigen Höckern besetzt, sonst ist der Stachel ziemlich glatt.

2. Echinus pusillus v. Mürist.

Nur $t^{\prime \prime \prime}$ gross, haltkugelfürmig dicht mit kleinen Körnchen bedeckt; die Felder mit zwei Reihen Höcker, die Fühlergànge etwas geschlängelt.

S. Goldf. I. p. 125 . t. XL. f. 18.

Sehr selten; auch die Stacheln kommen vor.

3. Echinus osnaburgensis v. Münst. (in Litt?).

Herr Aintsassessor Römer hat mir einen bei Dickholz gefundenen Steinkern zur Ansicht unter diesem Namen mitgetheilt. Derselbe ist flach gedrückt und hat einen Durchmesser von $8^{\prime \prime \prime}$; der Durchmesser der Afteröfnung beträgt $4^{2}{ }^{\prime \prime \prime}$; die Ambulalira stehen dicht bei einander in schwach wellenförmigen, fast geraden Linien, wie bei Arhacia, für welches Genus auch die Weite der Afteröffnung spricht. Von dẹ Mundöffnung ist nichts zu sehen.

4. Spat angus IIoffmani?

Bruchstück, zu klein um eine Bestimmung zu crlauben.

5. Echinoneus ovatus v. Mïnst. S. p. 6 .

Häufig.

6. Nucleolites subcarinatus Goldf.

„Gewölbt, vorn niedergedrückt, hinten schwach gekielt, im Umfange fist sechsseitig, an der Basis „,ausgehöhlt; die Fühlergänge auf dem Rücken geradlinig, im Umfange der Mundöfnung keulenför,mig convergirend; dic Ilöcker gleich; der After vorgezogen in einer Furche auslaufend. “

S. Goldf. I. p. 142. t. XLIII. f. 10.

Von Ilerm Assessor Römer habe ich vor mehreren Jahren ein Exemplar, als aus der Gegend von Hildesheim stammend, ohne nähere Bezeichnung des Fundortes, erhalten.

7. Asterias propinqua v. Münst. (brieflich?)

Es sind nur die kalkigen Stücke, welche den Rand der Strahlen bei der neuerlich aus Asterias geschiedenen Gattung Stellaria Nardo, Asterias Ag. (sensu strict.) bilden, und welche in ziemlicher Menge vorkommen.

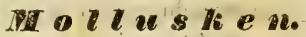

\section{Acephalen oder Muschelthiere.}

1. Solen Ensis L. var. minor. S. p. 6. nr. 1.

Nicht selten. 
2. Panopaea intermedia Sow. S. p. 7. nr. 3.

Ein Kern, unter dem Namen P. anatina v. Münster ist mir vom Herrn Prof. Leunis mitgetheilt.

3. Panapoea elongata v. Münster (brieflich?).

Stark verlängert, dritthalbmal so lang wie hoch, gewölbt, beiderseits stark klaffend; die Wirbel im dritten Theil der Länge.

Ein wohlerhaltener Kern von IIrn. Leunis zur Ansicht mitgetheilt, ist $56^{\prime \prime \prime}$ lang, $22^{1 / 2}{ }^{\prime \prime \prime}$ hoch, $18^{\prime \prime \prime}$ dick.

4. Crassatella minuta: $n$. sp.

Klein, kreisfürmig-dreiseitig;, quer gefurcht; die Wirbel glatter; der vordere Rückenrand concav, der Buturhanil ungekerbt; das Schloss der linken Schale hinten mit einem Suitenzahn.

Eine liske Schale von Freden $2^{\prime} / 3^{\prime \prime}$ lang, fast $2^{\prime \prime \prime}$ hoch, flach, beinah gleichseitig, beiderseits wohl abgerundet. Die Oberfläche ist mit ziemlich regelmässigen Querfurchen durchzogen, die gegen den kleinen, spitzen Wirlel verschwinden. Keine Area und I.unula. Das Schloss zeigt vorn zwei kleine Zähnchen, dann eine breite, dreieckige Grube, endlich hinten einen lamellenartigen Scitenzahn, der beinah so lang ist, wie die hintere lä̈ckenseite, also fast genau, wie bei Cr. trigonata Lamk., von der sich gregenwïrtige Art leicht durch den concaven vordern Rückenrand unterscheidet. Bemerkenswerth ist die grosse Achnlichkeit mit Astarte.

5. Lutraria.

Ein Exemplar, zu stark besclädigt, um genau bestimmt werden zu können. Umriss und Grösse scheint fast genau wie bei solen tellinella besh. Par. t. IV. f. 12 gewesen zu sein; das wohlerhaltene Schloss ist fast genau wie bei L. piperata.

6. Mactra, triangula Ren. S. p. 7.

Nicht selien.

7. Corbula nucléus Lamk. S. p. 7.

Häufıg, scheint nicht so gross gewesen zu sein, wie die Art jetzt im Mittelmeer wird.

8. Corbula revoluta Broc.

Länglich dreickig, ziemlich bauchig, mit grossen wenig zahlreichen Querrunzeln, übrigens glatt; die hintere Seite eckig, ziemlich, spitz.

(Tullina) revoluta Brocchi. p. 516. tab. XII. f. 6. - C. rugosa Lamk. Ann. d. Mus. vol. 8. p. 467. etc. Eine linke Schaale ist vom Ilerrn Prof. Leunis gefunden.

9. Corbula? granulata n. sp.

Quer cỉörmig, hinten wenig länger und breiter; die Oberfläche mit zablreichen, dicht gedrängten, ep̧habenen Punkten besetz, die Innenseite perlmutterartig.

Die untere odter rechte Schale, vom Ilerrn Leunis aufgefunden, vollkommen unversehrt, ist $3^{1 / s^{\prime \prime \prime}}$ lang, $3^{\prime \prime \prime}$ hoch; die $\mathbf{W}$ öllung betrïgt $1 \frac{1}{4}$. Die Gestalt ist quer eiförmig, hinten etwas breiter, beinah gerad aligestutzt; die Wirbel sind zicmlich stark eingebogen. Die Aussenfläche zeigt auf der hintern Seite schwache Andeutungen von Falten, wie sie z. B. bei C. nucleus vorkommen, und ist mit zahlreichen, eylindrischen Papillen besctat, die strahlenförmig und fast so dicht wie Pflastersteine gestellt sind. Das Schloss zeigt rorn einun schwachen Zahn und dahinter eine grosse, schiefe, dreieckige Grube. Auf der hintern Seite ist der Sehlossrand durch eine scharfe Kante von dem übrigen Theil der Muschel geschieden. Die Innenseite ist ganz perlmutterartig, daher die Muskeleindrücke nicht zu sehen, was, eben so wenig wie eine ähnliche Skulptur der Aussenseite, bei keiner mir bekannte Corluula vorkommt, Jaher das Gienus etwas zweifelhaft bleibt.

10. Tellina pusilla Ph. S. p. 8. nr. 13. Häufig. 
11. Tellina distorta Poli? S. p. 8. nr. 10.

Eine rechte Schale mit beschälligtem Wirbel weicht von den lebenden noch mehr ab, als die Exemplare von Kassel, indem sie fast vollkommen glatt ist.

12. Lucina albella Lamk? S. p. 8. nr. 14 .

Nicht häufig.

13. Lucina.

Ein Kern $13^{\prime \prime \prime}$ lang, $12^{\prime \prime \prime}$ hoch, $3 \frac{1}{2}{ }^{\prime \prime \prime}$ dick, ist nicht näher zu bestimmen.

14. Diplodonta lunularis n. sp.

Klein, rundlich-dreieckig, schwach gewölbt, glatt; die Lunula stark verticft; der Bauchrand gekerbt.

Sieben Exemplare, $1 \frac{1 / 2}{2 \prime \prime}$ lang, beinah ehenso hoch, beinah gleichseitig, vollkommen glatt. Der hintere Rückenrand ist convex, der vordere nahe hei den Wirbeln etwas concav; die vordere Extremität etwas spitzer als die hintere, übrigens wohl alogerundet. Inwendig ist die Schale im Schloss sehr breit, die Lunula ungemein vertieft, wenigstens so tief wic breit, herzlanzettförmig; auf der rechten Schale sieht man einen, auf' der linken zwei schmale Mittelzähne im Schloss, keine Seitenzähne. Beide Muskeleindriucke sind oval, der Manteleindruck einfach. Der gelierbte Bauchrand zeichnet diese Art sehr aus, die tiefe Lunula erinnert an Lucina uncinata Désh.

15. Astarte incrassata (Venus) Broc. S. p. 9. nr. 20.

Nicht häufig.

16. Astarte propinqua v. Münst.

„Cowrx, ciförmig-kreisrund, mit stumpfen in der Mitte liegenden Wirbeln, einer kleinen flach „concaven, schmal lanzettlichen Lunula, und sehr zahlreichen convexen Rippen, deren Zwischen„räune ( henso breit sind als sie.6

S. Goldf: II. p. 194. t. CXXXY. f. 3.

Zivei Exemplare.

17. Astarte gracilis v. Münst.

Von der vor:gen Art einzig und allein durch eine hrcitere Lunula und was damit zusammenhängt, spitzen Wirbel verschieden. S. Goldf. p. 19ł. t. CXXXV. f. 4.

Ein Excmplar.

18. Astarte lacvigata v. Münst. S. p. 9. nr. 17.

Sehr gemein, auch die Varietät mit ungekerbtem Rande.

19. Astartc suborbicularis v. Münst. S. p. 9. nr. 18.

Gemein.

20. Astarte pygmaea v. Münst. S. p. 9. nr. 19.

Iläufig.

21. Cyprina islandica (Venus) L. S. p. 10. nr. 22.

Nur kicrne von Dickholz.

22. Cytherea inflata Goldf. S. p. 10. nr. 23.

Selten.

23. Cytherea suberycinoides Desh. S. p. 10. nr. 24 Nicht selten. 
24. Cytherea deltoidea Lamk:

„Eiförmig-dreicckig, fast gleichseitig, sehr fein in die Qucre gestreift; die Lunula gross, eiförmig; „die vordere Seite ahgerundet; das Schloss der einen Schale zweizähnig." Desh.

S. Desh. Par. I. p. 131. t. XX. f. 6. 7. tab. XXII. f. 12.13.

Zwvei Schalen. Länge $5 \frac{3}{4}{ }^{\prime \prime \prime}$, Höhe ${ }^{4} /{ }^{\prime \prime}$.

25. Cytherea distans Lamk.

„Quereiförmig, beinah dreieckig, zusammengedrückt; die Vorderseite mit abgekürzten, entfernt „stehenden Streifen; Schloss der einen Schale mit 2 der andern mit drei Zähnen; die Lunula sehr „klein, lanzettförmig." Desh.

S. Desh. Par. I. p. 138. t. XXI. f. 10. 11.

Sieben Schalen; wird $3{ }^{1} 2^{\prime \prime \prime}$ lang und $2^{2} / 3^{\prime \prime \prime}$ hoch.

26. Cardium multicostatum Broc. S. p. 12 . nr. 32.

Nur Bruchstücke.

27. Cardium hillanum Sow.

Herzlörınig, aufgehlasen, mit undeutlichen Längsfurchen, die nur auf der vordern Seite deutlich erscheinen und mit kleinen Spizchen besetzt sind; der Rand mit spitzen Zähnchen.

Venus cypria Brocchi p. 545. t. XIII. f. 24. - Cardium hillanum Sow. Min. Conch. nach Defrance und Procchi.

Selten, nur Bruchstücke. Diese Art, ist bei Goldfuss nicht angegeben.

28. Cardium striatulum Broc. S. p. 11. nr. 29.

Nicht selten.

29. Cardium lurgilum Brand? S. p. 11. nr. 30 .

Beschädigte Excmplare.

30. Cardium pulchellum n. 4 .

Klein, heinalı kreisłörınig, schief, mit etwa 27 flachen Rippen, die mit halbmondförmigen Falten besetzt sind; die Zwischenriume schmal, dicht und zierlich quergefurcht; der hintere Rand tief gesägt. Ein selir wohl erhaltenes, und sechs beschäligte Exemplare, wird $3 \frac{1}{3^{\prime \prime \prime}}$ lang und $3^{1} /^{\prime \prime \prime}$ hoch.

31. Cardita scalaris (Venericardia) Sow. S. p. 12. nr. 33 und 34.

Sehr häufig.

+ 32. Isocardia Cor Lamk? S. p. 12. nr. 35.

Kommt nach Ilerru Prof. Leunis bei Diekholz vor.

33. Arca didy ila Broc. S. p. 12 . nr. 37.

Schr häufig.

34. Pectunculus crassus Pl. S. p. 13. nr. 40.

Nicht selten, fast immer zerbrochen.

35. Pectunculus pulvinatus Desh? S. p. 13. nr. 41.

Scheint writ suttencr zu scin. - Sonderbar ist es, dass Dujardin in seinem Memoire sur la Tou. raine Mcm. I. I. Enc. 1. Góol. de France vol. II. 2. p. 267 - 08 die von Deshayes Par. 1. p. 220. als in der Toumine vorkommend, crwiblinte Art, nicht auffüht, ungeachtet er nach p. 253 die Sammlung und den Rath von Deshaves benutzt hat.

36. Pectuncu! us alritus (irca) Broc.

Eiförmig̈, schief, nach oben verschmälert, in die Quere runzelig gefurcht; die Runzeln gedrāngt, 
erhaben; das Schloss [oft] geöhrt, mit einer dreieckigen-Grube für das Ligament; der Rand ungekerbt.

S. Brocchi pag. 485 . t XI. X. 9.

Ich habe sechs Exemplare-gesehen.

37. Pectunculus granulatus Laink.

„Kreisförmig, linsenförmig, mässig zusammengedrückt, beinah glcichseitig, kreuzweise gestreift; „die Längssireifen schmaler, körnig, das Schloss durch eine dreieckige Grube für das Ligament ,unterbrochen.6 Desh."6

S. Desh. Paris. I. p. 227. t. XXV. f. 4. 5. 6.

Selten, ich habe nur drei Exemplare gesehen.

38. Pectunculus minutus $\mathbf{P h}$. S. p. 14. nr. 42.

Sehr häufig.

39. Nucula placentina Lam. S. p. 14. nr. 43. Selten.

40. Nucula sulcata Bronn S. p. 14. nr. 44. Selien.

41. Nucula margaritacea Lamk. S. p. 14. nr. 45. Selten.

42. Nucula minuta (Area) Broc. S. p. 14. nr. 46. Häufiger als die vorigen.

43. Nucula nitida (Arca) Broc. S. p. 18. nr. 47. Desgleichen.

44. Modiola sericea Bronn S. p. 15. nr. 48.

Ziemlich selten.

45. Pecten bifidu'v Münst. S. p. 15 nr. 51. Selten:

46. Pecten striatus v. Münst.

Ziemlich flach, hallıkreisförmig, mit schmalen gerundeten, gekörnten zwei- oder dreitheiligen Rippen bedeckt; die Zwischenfurchen liniirt; die Ohren ungleich, das vordere mit fünf körnigen Rippen.

S. Goldf. p. 6t. t. XCVI. f. 3.

Ich rechne zu dieser Art, von welcher nur eine obere Schale bekannt, eine $3^{1 / 3}{ }^{\prime \prime \prime}$ lang, $2^{3} / 4$ breite Oberschale, auf welcher siehen Rippen stälker hervortreten, und eine etwas flachere untere Schale, der das Ohr fehlt. Diese Art unterscheidet sich von dem sehr ähnlichen P. bifidus fast allein durch geringere Breite im Verhälıiss zur Ilöhe.

47. Pecten asperulus v. Münst. S. p. 16. nr. 53.

Selten.

48. Pecten macrotus Goldf?

„Gleichklappig, gleichseitig, eiförmig kreisrund, convex, mit $28-30$ gleichförmigen, convexen, "glatten Rippen; die Zwischenfurchen haben die Breite der Rippen und etwas entfernte, regelmässig ,sichtliche concentrische Linien; die Ohren sind gross [in der Figur um nichts grösser, als bei ,qun meisten andern Arten], das vordere der untern Schale ist weit über den-Rand hinausverlän- 
"gert [auf der Figur nicht] und etwas abgerundet. Ueber ihre Rippenbüschel laufen die concen"trischen Linien hinweg. $-63_{2}^{\prime \prime \prime}$ hoch, $6^{\prime \prime \prime}$ breit."

S. Goldf. p. 70. to XCVIII. f. 2.

Die wenigen Exemplare, welche ich nicht ohne Zweifel hierher rechne, sind nur $2^{1 / 2}{ }^{\prime \prime \prime}$ hoch.

49. Pecten ambignus v. Münst.

Kreisförmig, flach convex, ungleichklappig, mit 12-14 beinah gleichen, gewölbten, sehr fein liniirten Rippen; dic Zwischenräume halb so breit, und auf der linken Schale mit $1-3$ gezähnten Rippchen; Ohren ungleich, gerippt, schuppig. 17'"' hoch, ebenso breit.

S. Goldf. p. 64. t. XCVI. f. 2.

Nur ein stark beschädigtes, jedoch mit Sicherheit zu bestimmendes Exemplar.

50. Pecten II offmanni Goldf.

Kreisförmign, ungleichklappig, die rechte Klappe gewölbt, die linke eben, mit gedrängten, schuppig rauhen Linien, von denen die äussern gezweit, die kleinern dazwischen stehen, die Ohren gleich; mit durchkreuzten Linien bedeckt. Bis $32^{\prime \prime \prime}$ breit und $28^{\prime \prime \prime}$ hoch.

S. Goldf. II. p. 64, to. XCVI. f. 4.

Diekholz; von IIerrn Prof. Leunis zur Ansicht erhalten.

51. Pecten.Münsteri Goldf.

„Gleichklappig, gleichseitig, oval kreisförmig, flach convex; mit zahlreichen, linienförmigen Rippen. „Die Zwischenräume haben dieselle Breite und zeigen deutliche, regelmässige Querlinien. Die "Ohren sind ungleich, schief abgeschnitten. Das vordere der rechten Schale ist abgerundet, und ,hat drei Rippen, über welche deutliche Linien hinweglaufen. Das hintere so wie die Ohren der , linken Schale haben keine Rippen, sondern lassen nur zarte concentrische Streifen bemerken. ,10"lang, eben so hoch.6

S. Goldf. II. p. 70. t. XCVIII. f. 3.

Sehr'selten.

52. Pecten crinitus v. Münst.

${ }_{3}$ Gleichseitig, flach convex, an untern Rande halbkreisfürmig, mit sehr zugespitztem Wirbel. Die „Oberfläche zeigt 7-8 ausstrahlende [sehr] flache Erhöhungen und Furchen, und ist mit sehr ,Zarten gedrängten Linien bedeckt, welche durch concentrische Wachsthumsstreifen unterbrochen "werden. Dio ungleichen, grossen, fast rechtwinkligen Ohren haben zahlreiche kleine Rippen. ,20"' hoch, 11"' breit."

S. Goldf. p. 71. tab. XCVIII. f. 6.

Ich glaube diese Art von Herrn Prof. Leunis zur Ansicht erhalten zu laben, bin jedoch meiver Sache nicht ganz gewiss.

53. a. Pecten decussatus v. Münst. S. p. 15. nr. 52.

Oval-kreisförmig, ungleichklappig, beinah flach, sehr fein concentrisch gestreilt, und mit zahlreichen feinen Längsrippen, die schmaler sind als die Zwichenräume; Ohren ungleich, gefaltet-linïrt.

53. b. Pecten pectoralis v. Münst.

„Gleichklappig, fast gleichseitig, eiförmig-kreisrund, flach convex, mit sehr zarten concentrischen „Streifen, und schr zahlreichen, linienförmigen, öfters gespaltenen, glatten Rippen, deren Zwischen"furchen dieselbe Breite haben. Die Ohren sind ungleich und fast rechtwinklig; das vordere der "rechten Schale ist verlängert, und hat einige schwache Falten." $5^{\prime \prime}$ hoch, ebenso brcit.

S. Goldf. p. 71. tab, XCVIII. f. 4. 
33. c. Pecten textus n. sp.

Eiförmig kreisrund, schwach gewölbt, mit äusserst zahlreichen dichotomischen, divergirenden, auf dem kreisförmigen Rande überall senkrecht stehenden Linien; bisweilen mit erhabenen zarten Rippen und äusserst ungleichen Ohren.

Auf den ersten Anschein wird Jedermann die drei, so eben mit ihren Diagnosen angeführten Formen für äusserst verschiedene und gut charakterisirte Arten halten, namentlich die letzlere, welche, oft ohne alle Spur von Rippen, die Skulptur von P. pictus Goldf. und P. Lens Sow. etc. zeigt, und doch sind sie alle eins, wie mich zah!lose Uebergänge unter mehr als hundert Exemplaren gelehrt hahen. P. pectoralis unterscheidet sich von decussatus durch etwa doppelt so viel Längsrippen und weniger deutliche Anwachsstreilen; beide Formen sieht man durch Spalten der liippen etc. in cinander übergehen; ehenso bemerkt man bisweilen an P. decussatus an den Seiten, weit häufiger aber noch bei P. pectoralis den Anfang der dichotomischen, auf dem Rande überall senkrecht gestelten Linien, welche bei P. textus so sehr auffallen. Anfings bleiben noch die Rippen des P. pectoralis, werden aber bald flacher, undeutlicher, endlich versehwinden sie ganz spurlos. Das andere Extrem ist das p. 15. nr. 52, angegebene.

Wenn man an lebenden und fossilen Arten die Erfahrung von der grossen Veränderlichkeit der Skulptur bei Pecten gemacht hat, so wird man sehr geneigt zu glauben, dass bei Goldf. die Zahl der Arten $\mathrm{zu}$ sehr vervielfältigt ist.

54. Pecten pygmaeus vं. Münst: S. p. 16. nr. 54.

Selten.

55. Pecten antiquatus n. sp.

Klein, beinah kreisformig, schwach gewölbt, ohne alle Spur von Rippen, mil regelmässigen vertieften Querlinien, innen bisweilen mit 12-14 erhabenen Längslinien; die Ohren klein, ungleich. Eine Schale. Diese wegen der eigenthümlichen Skulptur sehr merkwürdige Art wird nur $3 \frac{1}{2}{ }^{\prime \prime \prime}$ hoch und chenso breit und ist von mir auch in Calabrien im Lamatothale aufgefunden.

56. Ostrea deltoidea Goldf. S. p. 16. n. 56.

Bruchstücke.

57. Anomia Lens Lam.? S. p. 17. nr. 59.

Eine gute, durch ihre constante Grösse unter andern Merkmalen ausgezeichnete Art; ich halıe davon nicht weniger als 159 Exemplare gesehen.

58. Anomia asperella $n$. sp.

Klein, schief oval, mit zahlreichen, erhabenen, strahlenförmigen Linien, die mit gewölbten Schuppen ziegelartig beseizt sind.

Selten, nur $2^{\prime \prime \prime}$ lang, $1^{1} / 3-1 \frac{1}{2} 2^{\prime \prime \prime}$ hoch, oval-elljptisch, schief, die Wirbel klein, spitz, im dritten Theil der Länge. Etwa dreissign strahlenförmig auslaufende Linien, halb so brcit als die Zwischenräume. Wo Anwachstreifen dieselben durchschneiden, erheben sie sich in hohlziegelartigen Schuppen; die Zwischenräume sind glatt.

\section{Gaster o p o d e n.}

59. Calyptraea vulgaris Ph. S. p. 17. nr. 60 .

\section{Schr häufig.}

60. Pileopsis hungarica Lamk.

Spilz-konisch, der Länge nach gestreift, der Wirbel hakenförmig, spiralförmig eingerollt.

S. Lamarck VI. 2. p. 17 etc.

Selten, fast nur die Spitzen. 
61. Emarginula punctulata n. sp.

Mässig gewölbt, im Umfange elliptisch, mit zahlreichen Länsgreihen schiefer eingestochener Punkte, die undeutliche Rippen bilden; der. Wirbel ziemlich stark nach hinten gestellt.

Ich halıe drei Exemplare und cinzelne Bruchstïcke gesehen; das grösste war $3^{3} /{ }^{\prime \prime \prime}$ lang, $2^{1} / 2^{\prime \prime \prime}$ breit, $2^{\prime \prime \prime}$ hoch. Sehr zahlreiche, schmale, äusserst schwach erhahene Rippen sind jederseits durch eine Reihe schiefer, eingestochener Punkte oder Gruben begränzt, eine sehr eigenthümliche Skulptur. Die Spalte ist mässig lang und breit.

62. Bulla Utriculus Broc. S. p. 18. nr. 61.

Mehrere, wohl erhaltene Exemplare.

63. Bulla lignaria L.?

Oblong, locker cingerollt, nach dem Gewinde zu verschmälert, dort abgestutzt, genabelt, quergestreili; die Oeflnung weit.

S. Lamarck VI. 2. p. 33 etc.

Ein junges $3^{\prime \prime \prime}$, grosses Exemplar dürfte vielleicht hierher gehören.

64. Bulla ovulata Broce. S. p. 18. nr. 64.

Nicht häufig.

65. Bulla intermedia Ph. S. p. 18. nr. 65.

Selten.

66. Bulla a cuminata Brg.

Klein, vollkommen glatt, auf heiden Seiten zugespitzt; das Gewinde nicht sichtbar.

S. Brocchi p. 276. Ph. Enum: Noll. Sicil. p. 122. t. VII. f. 18.

Selten.

67. Bulla Lajonkeireana Bast. S. p. 18 nr. 66.6 .

Selten.

68. Auricula conoidea (Turbo) Brocc.

Verlängert kegelförmig, beinah thurmförmig, vollkommen glatt; die. Windungen vollkommen eben; die Columella mit einer seharfen Falte.

S. Brocchi p. 660. t. 16. f. 2.

Mehrere wohl erhaltene Exemplare, kleiner als die Italienischen. - Gehört wohl bestimmt nicht in dies Genus.

69. Kissoa Ovulum Ph.

Eilörmig, stumpf, ganz glatt; die Windungen schwach gewölbt; die Oeffnung so lang wie das Gewinde, oben spitzwinklich; die Aussenlippe einfach; die Innenlippe deutlich, fast ahgelöst.

Ein Lxemplar $11_{2}^{\prime \prime \prime}$ hoch, $1 \frac{1}{\prime \prime \prime}$ breit, von sechs Windungen. Die Gestalt ist fast genau die eines Eies; die Oeflnung liegt fast in einer Ebene mit der Axe; die Innenlippe ist nicht ausgebreitet, deutlich verdickt, durch eine Spalte geschieden von der vorletzten Windung. - Am nächsten verwandt ist R. lactea Mich. bei welcher jedoch die Innenlippe nicht so geschieden ist.

70. Rissóa varicosa Bast. S. p. 19. nr. 70.

Sehr häufig, ich habe alle Uebergänge bis zur Form von Melania reticulata Dubois Conch. foss. du plat. Wolh. p. 47. t. III. f. 26. 27 und M. spiralissima desselben p. 46. t. III. f. 30.31 gefunden.

71. Rissoa crenulata Michaud.

Eiförmig, bauchig, durch Längsrippen und wenig zahlreiche erhabene Querlinien grob g'egittert; 
die Aussenlippe aussen gerandet, gekerbt, innen schwach gefurcht; die Columella aussen mit einem Körnchen besetzt.

S. Michaud's Monographie von Rissoa p. 13. nr. 10. f. 1. 2. und Lamk. ed. 2. VIII. p. 465.

Ein Exemplar, vollkommen übereinstimmend mit den lebenden des Mittelmeers.

72. Rissoa nana Ph.

Länglich kegelförmig, bauchig; die Windungen stark gewölbt, gerippt; die Mündung eiförmig, weit kürzer als das Gewinde; die Aussenlippe einfach.

S. Ph. Enum. Holl. Sicil. 1. 15t. t. X. f. 13 unter dem Namen R. pusilla, der geândert werden musste, weil er schon früher vergeben war.

Ein Exemplar von Herrn Prof. Leunis gefunden, $13 / 2^{\prime \prime \prime}$ gross.

73. Rissoa interrupta (Turbo) Adams.

Verlängert kegelförmig, stumpf, vollkommen glatt; dic Windungen gewölht, durch eine tiefe Nath geschieden, die Mündung läıglich elliptisch, zwei Fünftcl der ganzen Länge einnehmend, einfach.

S. Montagu Testacea britannica p. 329.

Drei Exemplare, 1"' lang', kaum 1/2"' breit, mit fünf Windungen; sie stimmen vollkommen mit lehenden Exemplaren von IIelgoland überein.

74. Rissoa unidentata (Turbo) Montagu.

Länglich thurmförmig, stumpf', ziemlich glatt; die Windungen beinah eben, durch eine tiefe Nath getrennt; die Mündung länglich-ciförmig mit einer Falte an der Columella.

Turbo unidentatus Montagu Test. brit. p. 324. t. XXI. f. 2. Odostomia Flem. hist. of brit. animals p. 310 .

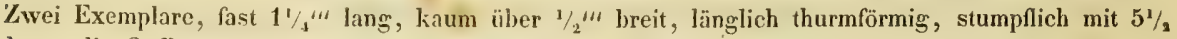
Windung; die Oeffnung kaum etwas länger als der dritte Theil des Gehäuses.

75. Rissoa rimata n. sp.

Verlängert kegelförmig, vollkommen glatt, mit einer Nabelspalte; die Windungen schwach gewölbt, durch eine tiefe Nath getrennt; die einfiche ovale Mundöfnung von der Länge des Gewindes.

Ein Exemplar $1^{\prime \prime \prime}$ hoch, $3 / 3^{\prime \prime \prime}$ breit, fast genau kegelförmig, aus sechs Windungen bestehend, die rollkommen glatt, mässig gewölbt, und durch tiefe Näthe geschieden sind. Ein schmaler Nabelritz zeichnet diese Art vor den ähnlichen aus. Sie ist breiter und kleiner als Paludina thermalis = baltica = muriatica ctc., von welcher sie vielleicht nur eine Abart ist.

76. Hissoa Terebellum n. sp.

Schlank, thurmförmig; die Windungen stark gewölbt, mit drei glatten Querleisten; die Mündung oval, einfach, so lang wie der dritte Theil des Gewindes.

Nicht selten, $1^{\prime \prime \prime}$ lang, ctwa $1 / 3^{\prime \prime \prime}$ lireit, aus $6-7$ stark gewölbten Windungen bestehend, die durch ihre Querleisten schr ausgezeichnet sind. Die jungen Turritellen, mit denen diese Art auf den ersten Blick verwechselt werden kann, sind weniger schlank, die Windungen im Verhältniss zu ihrer Breite höher, die letzte kantig, die Basis glatt, nicht mit Leisten bedeckt.

77. Eulima subulata Donov. S. p. 20. nr. 73.

Nicht häufig.

78. Eulima nitida (Melania) Lamk.

Thurmförmig, fast pfriemenförmig, vollkommen glatt und glänzend; die Windungen eben, die Mündung länglich eiförmig.

Lamk. VII. p. 546. - Enum. Moll. Sicil. p. 157. t. IX. f. 17.

In Basitz des Herrn A. A. Römer. Weniger schlank als die vorhergehende Art. 


\section{$-53-$}

79. Eulima Scillae (Melania) Scacchi.

Thurmförmig, fast pfriemenförmig, die Windungen vollkommen glatt und eben, durch eine tiefe $\mathbf{N}$ ath geschieden, die Mündung viereckig; die Columella senkrecht.

Zwei Exemplare stimmen genau mit den fossilen Exemplaren von Palermo und Appulien. Diese Art wird $4^{\prime \prime \prime}$ lang, $11 / 4^{\prime \prime \prime}$ breit und hat dann 11 Windungen; sie ist verhälnissmässig dickschalig.

80. Eulima quadristriata Ph. S. p. 19. nr. 71.

Schr unvollkommene Exemplare, deren Bestimmung zweifelhaft ist.

81. Eulima Leunisiin. sp.

Thurmförmig, fist pfriemenförmig; die Windungen kaum gewölbt, undeutlich gefaltet, mit undeutlichen Querstreifen, die Mündung oval viereckig, mit senkrechter Columella.

Niclit selten, $4^{1} / 4^{\prime \prime}$ lang, $1^{\prime \prime \prime}$ dick, mit mehr als zehn Windungen. Diese sind sehr srhwach gewölbt, deutlich durch Näthe geschieden, und haben etwa 12 gerade Längsfalten, die bisweilen vollkommen vershwinden, und ungefähr sechs Duerstreifen, die sehr wenim ausgesprochen sind, und dem Glanz und der Glätte der Schale keinen Eintrag thun. Die Oeffnung ist oval vicreckig, die Columella macht mit der letzten Windung einen stumpfen, jedoch noch deutichen Winkel. - E. quadristriata ist breiter, nic deutlich gefaltet, und durch vier regelmässige, tiefe Querstreifen ausgezeichnet, die Mündung ist eckiger. - Melania tenuiplieata Desh. Par. H. p. 111. t. 13. f. 20. 21. ist nur $\mathbf{1}^{3} /^{\prime \prime \prime}$ lang und hat eine eiförmige, oben spitze Mündung, wo die Columella mit der vorletzten Windung keinen Winkel macht.

82. Niso*) minor $n$. sp.

Verlängert kegुelförmig, beinah thurmförmig, die Windungen eben, $2-2 \frac{1}{2}$ mal so breit wie hoch.

Ich hahe seclis Excmplare von Freden vor Augen, nur $3^{\prime \prime \prime}$ hoch, nach einem Bruchstück zu urtheilen, wirl diese Art 5-6"' gross. Sie ist schlanker als N. Terebellum (Turbo) Chemn., indem die Windungen im Verhältniss zur Breite höher sind; bei $\mathbf{N}$. Terebellum ist dic Breite beinah dreimal so gross wie die llöhe.

83. Pyrgiscus elongatus n. sp.

Nadelförmign, die Windungen mässigi gewölht, fünfviertel mal so breit wie hoch, mit 15-17 fadenförmigen gebogenen Rippen, ohne Querstreifen.

Zwei Excmplare, 21/3" lang, nicht voll $1 / 2$ "' breit. Die Oefnung ist länglich, 11/2 mal so hoch wie breit. Die letzte Windung zeigt eine stumpfe Kante, eine Fortsetzung der Nath.

84. Pyrgiscus Kochii n. sp.

Schmal thurmförmig, die Windungen ziemlich eben, doppelt so breit wie hoch, mit 12 Rippen, die so breit sind wie die Zwischenrume, ohne Querstreifen, die Basis glatt.

Ein Exemplar, an der Spitze beschädigt, $2^{\prime \prime \prime}$ lang, $1 / 2 "$ breit. Zu der Diagnose ist nichts hinzuzufügen, als dass die Oeffnung länglich rhombisch und $1 \frac{1}{2}$ mal so hoch wie breit ist.

A nmerk: Gleichzcitig mit meincm Genus Pyrgiscus ist von Lowe dasselbe unter dem Namen Parthenia und von d'Obigny unter dem Namen Chemnitzia aufgestellt; es ist mir aber, seitdem wir durch Lowe die Kenntniss des Thieres erhalten haben, zweifelhaft, ob man es von Eulima, trennen dürfe; die E. Scillae, quadristriata, Lcunisii machen auch in Bezug auf die Schale den Uebergang. Ebenso ist wahrscheinlich auch Niso nicht davon zu trennen.

- Niso Risso ist einerlei mit Bounellia Deshayes in cd. 2 Lamk. VIII. p. 286. Diescr letzte Name muss gestrichen werden, weil 1) Rolando schon frŭher einc Gattung von Würmern so genannt hatte; und 2) der Name von Risso alter ist: 
85. Natica castanea Lamk. S. p. 20. nr. 74 .

Häufig.

86. Cryptostoma (Sigaretus) elegans Ph. S. p. 20. nr. 76.

Sehr selten.

87. Pyramidella terebellata (Auricula) Lamk.

Verlängert thurmförmig, glänzend, glatt; Windungुen zahlrcich, schmal, flach, durch eine wenig vertiefte Nath getrennt; Mündung schmal eiförmig; Spindel mit 3 ungleichen Falten.

S. Auricula tereb. Lamk. VII. p. 540. - Bronn Lethaea p. 1026.

Selten und nicht vollständig genug crltalten, um zu crkennen, ob sie zur ersten oder zur zweiten der bei Bronn unterschiedenen Formen gehört.

88. Tornatella punctalo-sulcata Ph. S. p. 20. nr. 77.

Nicht häufig.

89. Scalaria decussata Lamk. S. p. 21. nr. 78.

Nicht häufig.

90. Scalaria amoena n. sp.

Thurmförmig, undurchbohrt; Windungen ziemlich stark gewölbt, mit etwa 26 sehr dünnen rippenartigen Lamellen und fünf erhabenen (Quergürteln; ein Kiel am Grunde; die Basis durch Verlängerung der lippen gestreift.

Ein Exemplar mit alıgelorochener Spize im Besitz ron Herrn Prof. Leunis $4^{3} / 4^{\prime \prime \prime}$ lang, fast $2^{2} / \mathbf{s}^{\prime \prime \prime}$ breit, unversehrt wohl $b-8 \frac{1}{2} "$ "' lang. Die Querleisten sind viel stïrker als die Längsrippen, beinah breiter als ihre Zwischenräume. Unten ist eine Scheibe, mit haarfeinen erhabenen Linien, welche Fortsetzungen der lijpen sirrl. - Sc. cancellata (Turbo) Brocehi p. 377. t. VII. f. 8. ist sehr ähnlich, hat aber wenigere und stäkere Lingsripuen (nach der Figur etwa 16) Vielleicht zeigt aber eine Vergleichung von Exemplaren, dass beide Arten identisch sind.

91. Scalaria insignis Leunis.

Thumförnig, undurchbohrt; die Windungen stark gewöllt, mit etwa 20 lamellenartigen, oben in einc Spitze auslaufenden Rippen und sechs erhabenen Oucrlinien; ein Kiel am Grunde.

Zwei Excmplare, eins im Besitz von Ilerrn A. Römcr als Sc. insignis Römer zur Ansicht erhalten: Diese Art war lrei $13-14^{\prime \prime \prime}$ Länge $5^{\prime \prime \prime}$ dick. Die erhabenen Querlinien, weit schmaler als die Zwischenräume, laufen auch über die Rippen hinweg; eine siebente aul der letzten Windung, eine Fortsetzung der Nath, tritt weit stärker hervor und bildet einen Kiel. Die Basis ist ohne Lamellen und ohne Querstreifen. - Die an nüchsten verwandte Art ist Sc. decussata lien. p. 21. t. 7. f. 23. (von der Kiener sehr mit Unrecht lichauptet, sic sei cinerlei mit Sc. decussata Lamk., welche unten eine Scheibe, vertiefte nicht erhabene Querlinien besizt, und viel kleiner ist), von dieser unterscheidet sie sich aber durch breitere, weniger hohe, stärker gewölbte Windungen, sechs, nicht vier erhabene Querlinien und der Mangel der Querstreifen auf der Basis.

92. Scalaria pusilla n. sp.

Schmal lhurmförmig, mit gewölhten Windungen, etwa 10 stumpfen faltenförmigen Rippen und einer schwieligen Lamelle an der Basis.

Ich hahe zehn Exemplare gesehen, die meisten beschäligt. - Die vollståndige Grösse mag 6"' erreichen, $3^{1} / 2^{\prime \prime \prime}$ lange Exemplare zeigen schon 9-10 Windungen. Die Rippen sind ziemlich breit, flach, und gehen allmählig in die etwa drei mal so breiten Zwvischenräume über. Die Mündung ist von einer stärkeren Wulst umgeben. Die Scheibe der Basis ist glatt und tritt mit ihrem wulstigen 
Rande stark hervor. Gewöhnlich sind die Windungen ganz glatt, bei einer Varietät sehr fein in dic Quere gestreift. - Sc, minuta Sow, kann ich nicht nachsehen.

93. Scalaria reticulata n. sp.

Schr klein, pfriemenförmig, durch erhahene, gleichmässig abstehende Längs- und Querlinien netzförmig gegittert; die Windungen schwach gewölbt, die Basis quergestreift.

Nicht häufig. Das grösste Excmplar hat eine Breite von $1^{\prime \prime \prime}$ und mag cine Länge von $43_{2}^{3 / \prime}$ gehabt haben. Die beiden ersten Windungen sind glatt; die folgenden haben sechs crhabene Querstreifen, welehe von erhabenen, rippenartigen Längsstreifen durehkreuzt werden, so dass dadurch regelmässige, qualratische vertiefte Felıler entstehen; sonst ist die Schale ausgezeichnet glatt. Die Mündung scheint keine verdickite Aussculippe gehabt zu haben. Ein Kicl ist am Grunde nicht vorhanden, und es fehlen hier die erhabenen Längslinien.

94. Delphinula dubia Ph. S. p. 21. nr. 80.

Fünf Excmplare.

95. Delphinula carinata Ph. S. p. 21. nr. 81 .

Ein jugendliches Exemplar.

96. Delphinula minima Ph.

Selı klein, ziemlich flach gedrückt, vollkommen glatt; die Windungen stark gerundet; der Nabel mässig gross, meist mit zwei erhahenen Leisten umgeben.

Ich hahe neun Exemplare verglichen, sie sind $3 / 4^{\prime \prime \prime}$ hoch, $1^{\prime \prime \prime}$ breit, mässig flachgedrückt, und bestehen aus vier Windungen, die oben stark gewölbt, und durch tiefe Näthe getrennt sind. Die zwei Leisten, welche den Nabel einfassen, sind durch eine clonso breite Furche getrennt. Zwei andern Exemplaren fehlen diese Nabelleisten.

97. Delphinula suturalis n. sp.

Schr klein, kegelförmig; die Windungen stark gewölbt, quergestreift, an der Nath gekerbt, un den Nabel liufen zwei gekerlite Leisten.

Vier Exemplare $5 / 6$ "' hoch, $1 \frac{1}{10}{ }^{\prime \prime \prime}$ breit, mit vier $W$ indungen, von denen die obersten $11 / 2$ ganz glatt sind. Dic letzle ist in der Nitte deutlich kantig und zeigt 9 vertiefte Querlinien, von denen vier auch auf den oberen Windungen sichtbar sind. Der ziemlich grosse Nabel ist auch hier von zwei Leisten umgeben, von denen besonders die innere deutlich gekerbt, fast perlschnurförmig ist.

98. Delphinula scabricula n. sp.

Klein, ziemlich kegelförmig, die Windungen stark gerunlet, mil einer dreifachen Reihe spitzer Knötchen verziert; der Nahel eng.

Nur ein beschäliggtes Exemplar wenigstens $1^{\prime \prime \prime}$ hoch, $1^{\prime \prime \prime}$ breit. Die spitzen Knötchen entstehen dadurch, dass lamellenartige regelmässig entfernte Anwachsstreifen sich über drei erhabene Querleisten hinwegzichen, und wo sie dieselben schneiden, dornenlörmig vorgezogen und in die Höhe gerichtet sind.

99. Trochus? nur die ohere Seite:

Dem Tr. patulus zum Verwechseln ähnlich an Grösse, Skulptur etc.; der Rand der oberen Windung läuft hie und da in unregelmässsige Dornen aus und die Anwachsstreifen laufen nicht rückwärts, sondern in der Richtung. der Zacken.

100. Trochus elegantulus. S. p. 22, nr. 84 .

Ein schönes Exemplar Leunis.

101. Trochus'scrutarius Ph. s. p. 22 . nr. 83.

Nur selır kleine beschädigte Exemplare. 
102. : Turbo simplex n. sp.

Conoidisch, undurchbohrt, dicht in die Quere gestreift; die Windungen mässig gewölbt, die letzte wohl gerundet; die Columella an der Basis mit einer Grube bezeichnet.

Selten, wird $6^{\prime \prime \prime}$ hoch und ebenso hreit. Die Windungen sind mässig gewöllht oben nach der Nath zu flacher; die letzte zeigt oben 13-14 schmale Querfurchen, dic Anwachsstreifen sind ziemlich stark. Die Oeffnung ist vollkommen kreisförmig, die Aussenlippe cinfach, die Innenlippe in der Nabelgegend erweitert. Die Columelle hat unten eine schräge perlmutterartige Grube, wie sie bei Trochus tuber, carneolus und andern, nur weit schwächer, vorkommt, und tritt daher winkelartig hervor.

103. Turbo exigus n. sp.

Klein, etwas flachgedrückt, durchbohrt, die Windungen oben flach, übrigens gerundet, mit drei bis vier Querstreifen, die Basis dicht quergestreift.

Zwei Exemplare in Besitz von Ilerrn Prof. Leunis, $1^{\prime \prime \prime}$ hoch, 11/2"' breit, aus vier Windungen bestehend. Der Zwischenraum zwischen der ersten und zweiten Querlinie ist doppelt so weit, wie zwischen den übrigen und wie der Raum von der Nath bis zur ersten; zwischen der zweiten und dritten, so wie zwischen der dritten und vierten sind die Zwischenräume gleich gross.

104. Turritella imbricataria-Lamk.

Sehale verlängert thurmfürmig, pfriemenförmig, mit flachen Windungen; welche mit ihrem untern mehr oder weniger gelichen Rande üher einander vorstehen, durch eine tiefe Nath getrennt und ungleich spiralgestreift sinl; die kleineren Streifen sehr fein gekörnelt.

T. imbricataria Lamk. hist. VII. 561. - Bronn Lethaea p. 1045. tab. XI.I. f. 1. 2. XLII. f. 36 etc. Ziemlich häufig.

105. Turritella commun is Risso S. p. $22 . \mathrm{nr} .86$.

Ziemlich häufig. Ich habe sie in Sammlungen unter dem falschen Namen T. subangulata Stud, gesehen.

106. Cerithium perversum Brg. S. p. 23. nr. 89.

Ziemlich selten.

107. Cerithium trilineatum Ph. S. p. 22 . nr. 88.

Ziemlich selten. Kommt in Sammlungen unter dem falschen Namen Turritella trica.inata vor. Turho tricarinatus Brocchi ist eine Varietät der Turritella communis, mit 3 stärker hervortretenden erhabenen Querlinien.

108. Pleurotoma belgica v. Münst. S. p. 23. nr. 93.

Nicht häufig, einige sehr schöne bis $24^{\prime \prime \prime}$ hohe Exemplare sind in Besitz des Herrn Prof. Leunis.

109. Pleurotoma Leunisii n. sp.

Schale spindelförmig, die Windungen dicht mit erhabewen Querlinien besetzt etwas unterhalb der Mitte kantig; oberhalb ausgehöhlt; die Näthe etwas wulstig und nebst der Kante mit zahlreichen knotenförmigen Längsfalten besetzt; die Mündung so lang wie das Gewinde.

Eine schöne Art, $12^{\prime \prime \prime}$ lang, $4^{2} / 3^{\prime \prime \prime}$ dick mit $10 \mathrm{~W}$ indungen. Die obersten vier Windungen sind vollkommen glatt und irleichmässig gewölbt, die fünfte ebenfalls gleichmässig gewölbt, mit dichten Längsrippen, erst die folgenden Wiudungen haben die oben angegebene.Beschaffenheit. Die Anwachsstreifen sind sehr deutlich und machen die ganze Schale ziemlich rauh. Die Einbucht der rechten Lippe ist sehr weit offen und liegt in der Kante der Windungen.

110. Pleurotoma Roemeri n. sp.

Die Schale rerlängert spindelförmig, regelmässig quergestreift; die Windungen mässig gewölb! 
oben etwas ausgehöhlt, mit 12-14 Rippen die nach oben und unten abgekürzt sind; die Oeffnung etwas länger als das Gewinde.

Ein Exemplar ist $4^{\prime} \overline{2}^{\prime \prime \prime}$ lang, beinah $2^{\prime \prime \prime}$ dick, und besteht aus 7 Windungen; die drei obersten sind gewölbt, vollkommen glatt, die vierte ebenfalls regelmässig gewölbt, mit sieben gleichen, erhabenen Querlinien. Die Oeffnung mit dem Kanal ist etwas länger als das Gewinde, länglich; der Kanal selbst weit, offen, schräg, deutlich abgesetzt, kaum den dritten Theil so lang, wie die eigentliche Oeffnung. Die Anwachsstreifen zeigen keinen Einschnitt, sondern nur eine schwache Ausbuchtung, deren tiefster Punkt da liegt, wo der gewölbte Theil der Windungen in den concaven übergeht.

\section{Pleurotoma simplex n. sp.}

Die Schale schmal spindelförmig; die Windungen fast ganz eben mit 10-12 gleichen Querstreifen; die Oeffnung kürzer als das Gewinde.

Ich habe sechs Exemplare gesehen, ein kleines war fast vollkommen unversehrt, das grösste mochte bei einer Breite von $2^{3} / 4^{\prime \prime \prime}$ etwa $10^{1} /_{2}^{\prime \prime \prime}$ lang gewesen sein. Die Windungen sind bald fast ganz eben, bald nach der Nath zu beiderseits gewölbt; die letzte geht bald allmähliger, bald plötzlicher in den Kanal über. Die Anwachsstreifen sind sehr deutlich und zeigen einen breiten Einschnitt der rechten Lippe in der Gegend des vierten oder fünften Querstreifens. Ein Exemplar hat auf der vierten, fünften und sechsten Windung kleine Knötchen und ist oberhalb derselben schwach ausgehöhlt: diese Form macht den Uebergang zu der von Goldfuss Petref. CLXXI. f. 12 vom Rücken abgebildeten Art (zu der gegenwärtig noch Namen und Beschreibung fellen). Sie scheint sich hauptsächlich durch deutliche, wenn gleich schwache Rippen und Knötchen zu unterscheiden. Durch deutliche Rippen und bedeutendere Grösse unterscheidet sich auch Pl. multicostata Desh. Paris. II. p. 466. tab. 64. f. 8-13.

112. Pleurotoma

*) S. Goldf. Pet. t. CLXXI. f. 8.

Die Schale thurmförmig-spindelförmig mit einzelnen entfernten erhabenen Querstreifen; die Windungen in der Mlitte kantig, mit einem stumpfen, zahlreiche Knoten tragenden Kiel; die Nath erhaben, mit feinen Knötchen besetzt.

Ein Bruchstück $5^{1} /_{2}^{\prime \prime \prime}$ lang, $2^{1 /} 3^{\prime \prime \prime}$ dick; die Spitze fehlt, die Lippe ist ausgebrochen. Es weicht von der Figur bei Goldfuss dadurch ein wenig al,, dass die erhabene Leiste an der Nath nicht gekerbt oder knotig ist. Zwischen derselben und den Knoten des Kieles liegen auf den oberen Windungen drei erhabene Linien, auf der unteren mehr. Der Schnabel ist schlank.

113. Pleurotoma Hausmanni n. sp.

Die Schale thurmförmig, quergestreift; die Windungen oben flach, mit dem untern Dritheil hervortretend aber ebenfalls flach; der Schnabel kurz, plötzlich abgesetzt; der Einschnitt der Aussenlippe schmal, sehr tief eindringend, in $2 / 3$ Höhe der Windungen.

Ein Exemplar, von Herrn Ass. Römer zur Ansicht erhalten, $7^{3} / 4^{\prime \prime \prime}$ lang, 31/4 dick, ohne Spitze und Schnabel; unversehrt mag es $9-9^{1} / 2^{\prime \prime \prime}$ lang gewesen sein. - Durch den Eirschnitt der Lippe weicht diese Art sehr ab von Pl. subcanaliculata v. MIünst. Goldf. III. p. 20. tab. CLXXI. f. 3., die ihr sonst äusserst ähnlich ist, wo aber der Einschnitt höher steht und sehr weit und flach ist. - uch Pl. Borsoni Basterot p. 6.t. t. 3. f. 2. steht unserer Art äusserst nah, ist aber etwas breiter, ( $30^{\prime \prime \prime}$ hoch, $10^{\prime \prime \prime}$ breit). Leider ist keine Beschreibung gegeben, denn die Worte: „testa sublaevigata, suturis marginatis striatis“ sind doch gar zu dürftig.

114. Pleurotoma curvicosta Lamk. S. p. 23. nr. 94.

Selten. Vielleicht auch Goldf. t. CXLXXI. f. 7. (Namen und Text fehlen noch).

*) Namen und Beschreibung sind noch nicht erschicnen. 
115. Pleurotoma undatella n. sp. S. p. 24. nr. 95 . Nicht häufig.

116. Pleurotoma acutangularsi Desh.? S. p. 24. nr.96. Selten.

117. Pleurotoma plicatilis Desh.

Die Schale verlängert spindelförmig, sehr fein in die Quere gestreift; die Windungen schwach gewölht mit gerandeter gefïltelter Nath, und feinen Falten in der Mitte; die Oeffung etwas kürzer als das Gewinde; der Einschnitt der Lippe breit, buchtig.

Pl. plicatilis Desh. Paris. Il. p. 463. t. 63. f. 20. 21. 22.

Ueber 19 Exemplare möchte ich zu dieser Art rechnen. Sie sind alle jung und beschädigt, das grösste mit 7 Windungen ist nur 31/2" lang; die Art von Deshayes ist nach der Figur $9^{1} \mathbf{2}^{\prime \prime}$ lang (nach der Beschreibung $8,8^{\prime \prime \prime}$ ) im Ubrigen wohl übereinstimmend. Yon Pl. curvicosta unterscheidet sich die Art durch feinere Querstreifen, feinere und zablreichere Rippen und die gerandete Nath.

118. Pleurotoma discors Ph.

Die Schale verlängert spindelförmig; die oberen Windungen fein gefaltet, übrigens ganz glatt; die unteren mit gedrängten erhabenen Querlinien, von denen einige sich bisweilen zu lielen erhelsen, ohne Falten; die Oeflunng etwas kürzer als das Gewinde; der Einschnitt der rechten Lippe breit buchtig.

Nicht selten, sehr veränderlich. Das grösste, sehr wohl erhaltene Exemplar $8{ }^{\prime \prime \prime}{ }^{\prime \prime}$ hoch, fast $3^{\prime \prime \prime}$ breit, hatte $10 \mathrm{~W}$ Windungen, ist daher wohl als ausgewachsen anzusehen. Die Mündung mit dem Kanal nimmt etwa $3 / 2$ der ganzen Länge ein. Die Verschiedenheit in der Bildung der cinzelnen Windungen, zwar auch bei andern Arten sehr bemerklich, (S. z. B. Pl. Leunisii und Pl. Roemeri) ist bei dieser höchst auffallend. Die drei crsten Windung'n sind ganz glat und stark gewölbt; die beiden folgenden ebenfalls stark gewölht, ebenfalls glatt, aber mit etwa 17 schicfen Längsfalten versehen; auf der folgenden sechsten Windung treten zu den Falten drei Kiele, wovon einer oben an der Nath und unter dem letzten mehrere erhabene Querlinien. Auf der siebenten, achten, neunten und zehnten Windung ist keine Spur von Rippen, zu den Kiclen gesellen sich zahlreiche gedrängte erhabene Oucrstreifen. Die gestreiften Windungen sind sehr mässig gewölbt. Während nach der einen Seite hin Formen auftreten, wo sich ein Kiel stïrker entwickelt, bis er zuletzt bedeutend hervortritt und mit Knötchen besetıt erscheint, ähnlich wie Pl. undatella, verschwinden auf der andern Seite die Kiele, und die Windungen erscheinen bei den entgegengesetzten Exiremen fast ganz eben und kaum bemerkbar gestreift; so möchte man, wenn man die zahlreichen Uebergangsformen nicht sicht, beide Exireme für zwei neue ganz verschiedene Arten halten.

119. Pleurotoma rugulosum Ph.

Die Schale länglich spindlelförmig; die Windungen oberhalb kantig, sonst zicmlich eben, mit etwa zehn Längsfalten, sehr fïnen vertiefien und etlichen erhabenen Ouerlinien; die Oeffnung länglich, so lang wie das Gewinde; die Aussenlippe verdickt mit einer Einbucht an der Nath.

Nicht häufig. Diese Art wird nur $3 \frac{1}{2} " \prime$ lang, und kommt lebend im Mittelländischen Meer vor, und fossil bei Palermo und Reggio in Calabrien. Pl. cinctella Pfeif. aus Cuba ist kleiner, etwas anders gefärbt und hat schmalere Rıppen. Vielleicht verdient indessen Pl. rugulosum nicht als Art davon getrennt $\mathrm{zu}$ werden.

120. Cancellaria buccinula Lamk.

„Die Schale oval kegelförmig, der Länge nach fein gerippt, quergestreift, gegittert; die Windun"gen gewölbt; die Näthe eingezogen; die Columella mit 3 Falten." 


\section{$-59$}

Cancellaria buccinula Lamk. hist. VII. p. 117. nr. 5. - Bastèrot p. 46. t. II. f. 12.

Ein sehr schönes Exemplar von Ilerrn Prof. Römer zur Ansicht geschickt, 71/3"' hoch, 4\%/4"' breit. Die letzte Windung ist etwas länger als das Gewinde. Ich zähle 14 liippen, die schmaler sind als die Zwischenräume. Die Zahl der erhabenen Querlinien nimmt mit den Windungen zu, und dieselben stehen daher auf' der letzten Windung doppelt so gedrängt, als auf der vorhergehenden. Die verdickte Aussenlippe hat innen 5 schwache Zähnchen. - Kommt im Valois, bei Bordeaux und bei Wien vor.

121. Fasciolaria fusus Ph. S. p. 25. nr. 98.

Selten, nur in Bruchstücken.

122. Fasciolaria pusilla'n. sp.?

Die Schale klein, spindelförmig; die Windungen gewölbt mit rippenartigen Längsfalten und schmalen erhabenen Querlinien, die Mündung länglich eiförmig, etwas kürzer als das Gewinde, in einen sehr kurzen Kanal auslaufend; die Columella mit drei Falten.

Mehrere Exemplare, wenig über $3^{\prime \prime \prime}$ lang, $1^{1} /_{2}^{\prime \prime \prime}$ breit, mit sieben Windungen; ausgewachsen mag die Art 5-6"' lang sein. Die Windungen sind oben beinah kantig; die Längsfalten $11-13$, die Querlinien auf der fünften Windung vier, auf der sechsten sechs, auf der sicbenten über 20. Die Falten der Säulchen stehen tief im Innern und sind leicht zu übersehen. - Sollte diese Form nur der Jugendzustand von Cancellaria buccinula scin?

123. Fusus cheruscus n. sp.

Die Schale verlängert spindelförmig mit (c. 22) erhaben, gedrängten, abwechselnd stärkern und schwächern Querstreifen, und mit feinen erhabenen Anwachsstreifen; die WVindungen mässig gewöllıt mit etwa 10 wellenförmigen Rippen: die Columella ausgehöhlt, der Schwanz gekrümmt.

Zwei Exemplare, eins von llerrn Prof. Leunis, das andere von Herrn Ass. Römer gefunden, das grösste $13^{\prime \prime \prime}$ lang (unbeschädigt etwa $15^{\prime \prime \prime}$ lang) $5 \frac{1}{2} 2^{\prime \prime \prime}$ breit, mit zehn Windungen. Die drei ersten Windungen sind vollkommen glalt, die vierte und fünfte zeigen ein ungemein zierliches Netz von haarfeinen crhabenen Quer- und Länģslinien mit quadratischen Maschen. Auf der vorletzten Windung zähle ich 22 Querlinien, 11 stärkere, 11 schwächere.

124. Fusus Schwarzenbergii n. sp.

Die Schale verlängert spindelförmig mit etwa 6-7 erhabenen Querstreifen, übrigens glatt, die Windungen stark gewölbt mit etwa 11 Längsrippen, die Oeffnung so lang wie das Gewinde, der Kanal halb-so laing wic dic Oeffnung.

Iläufig, so dass ich mehr als zwanzig Exemplare vergleichen konnte; das grösste Exemplar war 4"' lang $13{ }^{3}{ }^{\prime \prime \prime}$ lreit und hatte 8 Windungen. Sollte diese Art nur der Jugendzustand der vorhergehenden sein? Ausser der geringeren Grösse unterscheidet sie sich fast nur durch die geringere Zahl der erhabenen Querlinien, welehe so breit so wie die Zwischenräume und weit glatter sind.

Beide Arten erinnern an F. syracusanus und dessen Verwandte. Dieser hat aber zahlreichere Rippen und Querstreifen, F. rustratus einen längeren Kanal etc.

125. Fusus elegantulus n. sp.

Die Schale verlängert spindelförmig; die Windungen in der Mitte kantig, oben abschüssig, unten walzenförmig mil zwei erhabenen Leisten und erhabenen Längslinien, welche ein zierliches Gitter bilden, die letzte WVindung mit vier Querleisten; der Schwanz plötzlich abgesetzt so lang wie die Oeffnung. Ein fast vollständiges Exemplar 51/2"' lang, $21^{\prime \prime \prime}$ ' breit mit 7 Windungen. Von den beiden Querleisten der oberen Windungen steht die obere auf der Kante; die erhabenen Längslinien sind fast ebenso breit und ebenso erhaben. Die letzte Windung ist sehr bauchig, der Schwanz ohne erhabene Langs* linien aber mit mehreren erhabenen schiefen Querlinien. Mündung und Kanal zusammengenommen sind anderthalbmal so lang wie das Gewinde. 
126. Fusustexilis Ph. S. p. 25. nr. 102.

Nicht häufig. - Ich bemerke noch, dass F. exiguus Desh. Paris II. t. 76. 14-17 nicht kantig ist und eine längere Spira hat; vielleicht sind indessen beide Arten besser als Varietäten zu vereinigen.

127. Fusus striatus Sow. S. p. 25. nr. 100.

Nicht hâufigg, nur die Spitzen und Bruchstücke.

128. Pyrula clathrata Lamk.? S. p. 26. nr. 104.

Fast nur Fragmente.

129. Murex Capito n. sp.

Die Schale breit spindelförmig, fast keulenförmig; die Windungen glatt, unten kantig, oben eben, die Varices ganz einfach, 8-9 in jeder Windung, nur eine Kante bildend; der Schwanz. mässig, gerade; die Oeffnung mit dem Kanal zweimal so lang wie das Gewinde.

Herr Prof. Lcunis hat 2 Exemplare gefunden, ein junges, vollständiges, $8^{1} / 2^{\prime \prime \prime}$ langes, $4^{1 /} 4_{4}^{\prime \prime \prime}$ dickes und die Spira eines grösseren, fast $13^{\prime \prime \prime}$ hreit, was auf eine Länge von $26^{\prime \prime \prime}$ schliesen lässt. Das Gewinde ist keğelförmig, die Spitze jedoch stärker in die Höhe gezogen; die einzelnen Windungen eben, dachförmig, unten nahe der Nath etwas kantig, glatt, nur mit (schwachen) Anwachsstreifen; die Varices stehen schwach hervor, bilden mehr Kanten als Lamellen, und sind auf der Kante der Windungen in einen kurzen Dorn vorgezogen. Am nächsten verwandt mit dem weit schlankeren Murex vaginatus.

130. Typhis simplex S. p. 26. nr. 107.

Nicht häufìg, ein vollkommen wohl erhaltenes Exemplar 11"' lang, 51/2"' breit.

131. Typhis horridus Brocchi.

Die Schale thurmformig, die Windungen in der Mitte kantig, glatt; die Varices mit 2 Dornen, von denen der obere hohle auf der Kante der Windungen emporsteht, der untere von der Nath halb verdeckt wird; die mit den Varicibus abwechsclnden Röhren auf der Kante der Windungen.

Murex horridus Broc.

tab: VII. f. 17.

Nicht häufig; ich halse vier Exemplare gesehen, deren grösstes, fast vollständig erhaltenes $9^{1 / 2}{ }^{\prime \prime \prime}$ lang, und ohne die Dornen $6{ }^{1} 3^{\prime \prime \prime}$ breit ist. - Die Gestalt ist breit thurmförmigg, die Spitze schr in die Höhe gezogen, die Oeffnung sellbst olne den geschlossenen Kanal, nimmt kaum den vierten Theil der Länge ein; der Schwanz ist breit, schief und so lang wie die Ocffunng. Die Windungen erscheinen im Ganzen mässig gewölbt, sinı in der Mitte kantigg und unten und oben ziemlich flach. Es sind auf jeder Windung vier Varices, welche dicht anliegen; fast eine Linie vor ihnen stehen 2 rundliche, auf dem Bruch hohle, nicht rinneniörmige Dornen, der obere aul' der Kante, der untere abwärts gekehrte auf der Nath, halb in dieser versteckt. Die letzte Windung ist sehr bauchig, plötzlich in den Schwanz algesetzt, dreikantig und hat je drei Dornen bei jedem. Varix.

\section{Tritonium tortuosum n. sp.}

Die Schale verlängert thurmlürmig; die Windungen mässig gewölbt, verdreht, schwach netzförmig gegittert durch wenig erhabene Querlinien und Längsrippen; Mündung . . . .

Herr Prof: Leunis hat 2 Exemplare gefunden, heide ohne Basis; das grössere ist $15^{1 / 2}{ }^{\prime \prime}$ lang (mit dem Kanal möchte die Länge 19 - $20^{\prime \prime \prime}$ betragen) und $81 / 2^{\prime \prime \prime}$ breit. Es zeigt sechs Windungen und die abgebrochene Spitze muss deren wenigstens noch drei gehabt haben. Die Windungen sind mässig gewöllbt und verdreit, so dass lie Näthe nicht parallel laufen, indem, wie bei manchen Arten Tritonium, bald die eine bald die andere Seite bauchiger ist. Sie haben etwa 18 Längsrippen, die auf der letzten Windung undeutlicher sind, und auf der obcren von zahlreichen erhabenen Querlinien durchschnitten werden, von denen 8-12 stärker hervorragen. Auf der letzten Windung treten zwei derselben stärker hervor, so dass zwei Reihen undeutlicher im Quadrat stehender Knoten entstehen. Die 
Wülste stehen ziemlich regelmässig um $3 / 4$ Windungen auseinander. - Tr. corrugatum Bronn Lethaea โ. XLI. f. 28. weicht ab durch die geringere Zahl und das stärkere Hervortreten der Längsrippen; Tr. cancellinum ibid p. 1084. t. XLI. f. 27 durch deutliche Kinötchen etc. - Tr. turriculatum Desh. Paris II. p. 608. t. LXXX. f. 7. 8. 9 und noch melir die Fig. 10 u. 11 abgebildete Varietät ist zwar auch sehr ähulich aber höchstens $14^{\prime \prime \prime}$ lang und nicht verdreht.

133. Chenopus paradoxus Ph. S. p. 24. nr. 97.

Nicht so häufig wie bei Kassel.

134. Cassis Rondeleti Basterot S. p. 27. nr. 110.

Ein sehr schönes, fast ganz unversehrtes Exemplar im Besitz von Herrn Prof. Leunis, ausserdem mehrere Bruchstücke.

135. Buccinum Macula Mont? S. p. 27. nr. 111.

Sehr häufig, allein fast kein Exemplar vollstāndigg mit der Aussenlippe. Viclleicht ist es eher B. variabile, die Windungen sind schwächer gewölbt, die Form ist bald schlanker, bald dicker, die letzte Windung bald ohne Rippen, bald mit 24 Rippen etc. - Vielleicht gehören die bei Kassel gefundenen Bruchstücke auch eher zu B. variabile als zu B. macula.

136. Purpura trochlea?

Zwei Bruchstücke im Besitz von IIerrn Prof. Leunis sind der lebenden P. trochlea (Lamark hist. VII. p. 248 - Kiener tab. 28 f. 75 jedenfalls nah verwandt. Es sind blosse Spitzen von $5-6$ Windungen, die ersten $2^{1 / 2}$ Windungen sinil ganz glatt, die folgenden haben 2 starke wulstige Querleisten, deren Durchschnitt beinah quadratisch ist, und deren freie Kanten überstehen. Dieselben sind dureh Anwachsstreifen rauh, während die Zwischenräume ziemlich glatt sind. Von der lebenden P. trochlea unterscheidet sich diese Art durch Folgendes: 1) der Zwischenraum von der Nath bis zum ersten Quergürtel ist weit schmaler, nur so breit wie der Quergürtel selbst; 2) man erkennt noch cinen dritten unteren Quergürtel, der nur zur Hälfte von der folgenden Windung verdeckt wirl. - Von IIerrn Ilofiath Menke hahe ich eine schöne Versteinerung von Weddinghausen zur Ansicht bekommen, welche der Purpura Grayi kien. 1. 28. f. 77 selır nahe kommt, welcher aber auch leider die Basis fclalte. Vielleicht gehören beide fossilen Arten zusammen.

137. Terebra plicatula Lumk. S. p. 27. nr. 113.

Nicht hãufig:

138. Mitra cupressin a Brocchi p. 319. tab. IV. f. 6.

Die Schale selir schlank thurmförmig, die Windungen mässig gewölbt mit (c. 14) schmalen schiefen Längstippen und (c. 7) vertieften Querlinien; die Oeffnung mit dem Kanal nicht viel länger als das halle Gewinde; dic Columella mit 3 Falten; ein deutlicher Kanal.

Zwei Exemplare im Besitz von Ilerrn Prof. Leunis stimmen genau mit Ex. von Castell'arquato und von Cutro in Calabrien.

139. Mitra Ebenus Lamk. var. lacvis, ecostata.

Die Schale lanzettlich-thurmförnig, glatt, an der Basis quergestreift; die Windungen schwach gewölbt, die Oeflnung so lang wie das Gewinde; die Columella mit vier Falten.

Ein Exemplar. Ueber diese' schr veränderliche Art, welche ohne Frage Linnés Voluta cornicula ed. XII. p. 1191. nr. 415 (exclus. syn. Gualt. welche zu Linnés Beschreibung nicht passt) ist, siehe Enum. Moll. Sicil. p. 229.

140. Ringicula striata Ph. S. p. 28. nr. 116. Häufig. 
141. Ancillaria glandiformis Lamk. S. p. 28. nr. 118.

Nicht eben häufig.

142: Ancillaria subulata Lamk. hist. VII. p. 415.

„Die Schale beinah thurmförmig, glatt, glänzend; das Gewinde verlängert, pfriemenförmig; Quer,binden an der Nath; die Wulst der Columella gestreift. - Die Oefnung nimmt kaum die halbe „Länge der Schale ein. - 161/4"! lang:"“

Vier Exemplare, dass grösste nur $5^{\prime \prime \prime}$ lang, $1^{3 / 4} 4^{\prime \prime \prime}$ breit, stimmen sehr gut mit der Figur Encycl. tab. 393. f. 5.' a. b.

143. Conus Brocehii Bronn S. p. 29. nr. 119.

Ein $11^{\prime \prime \prime}$ langes, schönes Exemplar im Besitz von Herrn Prof. Leunis.

144. Dentalium strangulatum Desh. S. p. 29. nr. 120.

Nicht selten, kommt in Sammlungen als D. bulbosum. Bronn. vor. Wenn diese letztere Art, welche mir unbekannt ist, sich allein durch die Alsschnürungen unterscheidet, so muss sie eingehen, denn diese Abschnürungen sind zufällige Erscheinungen und kommen fast bei jeder Art, namentlich auch bei D. Dentalis vor.

145. Dentalium fossile L. S. p. 29. nr. 121.

Hâufig:

B a lanus stellaris auct.

Die Schale kegelförmig, die einzelnen Klappen stumpf-gefaltet, die vertieften Zwischenräume zwischen den Klappen breit, quergestreift.

Sehr häufig, aber meist nur in einzelnen Klappen, doch fand Prof. Leunis auch ein schönes vollständiges Exemplar von 31/3" Höhe, $2^{\prime \prime \prime}$ Durchmesser an der Basis und 11/2"' Durchmesser der Mundöffnung. Die Kalkplatte der Basis ist vorhanden. Die Farbe erscheint noch, violett mit einem weissen Gürtel an der Basis und an der oberen Oeffnung; cine Gruppe ron 10 wohlerhaltenen Exemplaren, welche wahrscheinlich der jugendliche Zustand sind, ist dadurch merkwürdig, dass noch die Deckel in ihnen enthalten sind. Dieselben sind stumplich; das hintere Stück hat unten nur einen schwachen Fortsatz, das vordere am Rande nur wenige, entfernte Zühnchen. - Diese Art ist vermuthlich Balanus stellaris Bronn Lethaea p. 1156 nicht Lepas stellaris Poli; welches ein Chthamalus Ranzani ist. Dieses Genus unterscheidet sich sehr wesentlich durch zwei wichtige Merkmale von Balanus 1) ist das Gchäuse unten nicht durch eine Kalkplatte, sondern nur durch eine Membran verschlossen, 2) ist die vordere klappe des Deckels nicht durch eine gerade Linie mit der hintern verbunden, sondern durch eine stark geschwungene. Ueberhaupt liefert die Beschaffenheit des Deckels die besten Merkmale zur Unterscheidung der Balaniden. - Balanus hemisphaericus Brug. Ph. Enum. p. 249. tab. XII. f. 27., welchen Bronn 1. c. zu scinen B. stellaris zählt, ist weder diese Art, noch auch die Lepas stellaris Poli, sondern eine von beiden verschiedene, kleine eigenthümliche Art. Auch muss ich bemerken, dass Bronn's Balanus sulcatus Lethaea p. 1155. tab. XXXVI. f. 14. wohl schwerlich mit dem Balanus suleatus Chemn. 8. p. 301. t. 97. f. 820 einerlei ist, der eine ganz eckige Basis in Folge stark hervorspringender Kanten und Falten besitzt.

\section{$\mathbb{C}^{*} \boldsymbol{x} \boldsymbol{s} \boldsymbol{e} \boldsymbol{e} \boldsymbol{e}$}

1. Cytherina scrobiculata v. Münst.

„Länglich eirund, vorn zu einem Schnabel plötzlich verengt, hinten concentrisch gerunzelt, überall „mit runden Gruben, welche in undeutlichen Reihen stehen, dicht bedeckt; vorn am Schnabel „bemerkt man bei vollständigen Exemplaren einige kurze Zähne.“ 
C. scrobiculata v. M. bei Römer. Leonh. und Bronn. N. Jahrb. 1838. p. 515. nr. 1. f. 1. Häufig.

2. Cytherina a rcuata v. Münst.

"Fast mondförmig, etwas dreiseitig, beiderseits abgestumpft, gleichmässig gewölbt, glatt."

S. Römer l. c. p. 517. nr. 17. fig. 17.

Weit seltener.

3. Cytherina angustata von Münst.

„Länglich nierenförmig, durchscheinend, gewölbt, fast walzenförmig, vorn verschmälert, überall mit kleinen Pusteln bedeckt."

S. Römer l. c. p. 516. nr. 10. fig. 10.?

Etwa \& Exemplare, der Bauchrand ist gerade, die Schale mit Pusteln, nicht glatt, wie Römer von der, in hiesiger Gegend" vorkommenden Form angibt.

4. Cytherina ventrosa n. sp.

Länglich dreieckig, sehr stark gewölbt, ganz glatt, vorn in cine Art Schnabel verlängert mit einigen Zähnen.

Nur eine Schale, aber durch die angegebenen Kennzeichen leicht von den übrigen Arten zu unterscheiden.

\section{E i s t ite.}

Auch bei Freden finden sich nicht selten Fischversteinerungen, jedoch nicht so häufig wie auf der Wilhelmshöhe. Die gemeinsten darunter sind Gehörknöchelchen, nächstdem Zähne von Sphaerodus parvus Ag. und von einem kIeinen Galeus. Sehr merkwürdig ist aber das Vorkommen von einem Rückenstachel aus dem Rochengeschlecht, welchen Uerr Prof. Leunis dort gefunden. Derselbe ist $81 / 2$ lang, 61/2" breit, $3^{\prime \prime \prime}$ hoch, der eigentliche Stachel jedoch ausgebrochen. Die Ränder sind mit zahlreichen strahlenförmigen Furchen und mehrere Anwachsstreifen durchzogen.

\section{Coprotithen?}

Herr Prof. Leunis hat bei Freden eine Menge kleiner problematischer Körper gefunden, die ich fraglicherweise hier als Coprolithen auführen will, um die Aufmerksamkeit auf sie zu lenken. Sie sind im allgemeinen wal\%enförmig, bisweilen nach dem einen Ende etwas verschmälert, durch schräge Einschnürungen mehr oder weniger tief' in breitere oder schmalere Abtheilungen getheilt, zwischen $1 / \mathbf{2}^{\prime \prime \prime}$ und $1^{\prime \prime \prime}$ im Durchmesser. Jhre Iänge schwankt von $1^{1}{ }_{2}^{\prime \prime \prime}-3^{\prime \prime \prime}$; sie sind gerade oder schwach gebogen, nicht selten an dem einen Ende in eine Schlinge gezogen, immer an beiden Enden abgerundet, lehmfarbig. Sie sind schr fest, auf dem Querbruch erkennt man eine Menge eckiger Kalkspathstïcke, unter dem Mikroskop liessen sich keine organische Formen mit Deutlichkeit wahrnehmen. - Aus dem Gesagten folgt keinesweges, dass diese Körper Coprolithen seien, allein es geht wenigstens so viel daraus hervor, dass man sie nicht wohl für zufällige Bildungen und anorganische Concretionen halten kann. Vielleicht gelingt ès einem andern Beobachter, ihre Natur zu enträthseln.

Vergleichen wir jetzt die Molluskenarten mit den noch lebenden und in einigen andern Tertiärformationen vorkommenden, auf ähnliche Weise, wie wir es p. 30 mit den Versteinerungen von Kassel gethan haben, so ist das Resultat folgendes: 


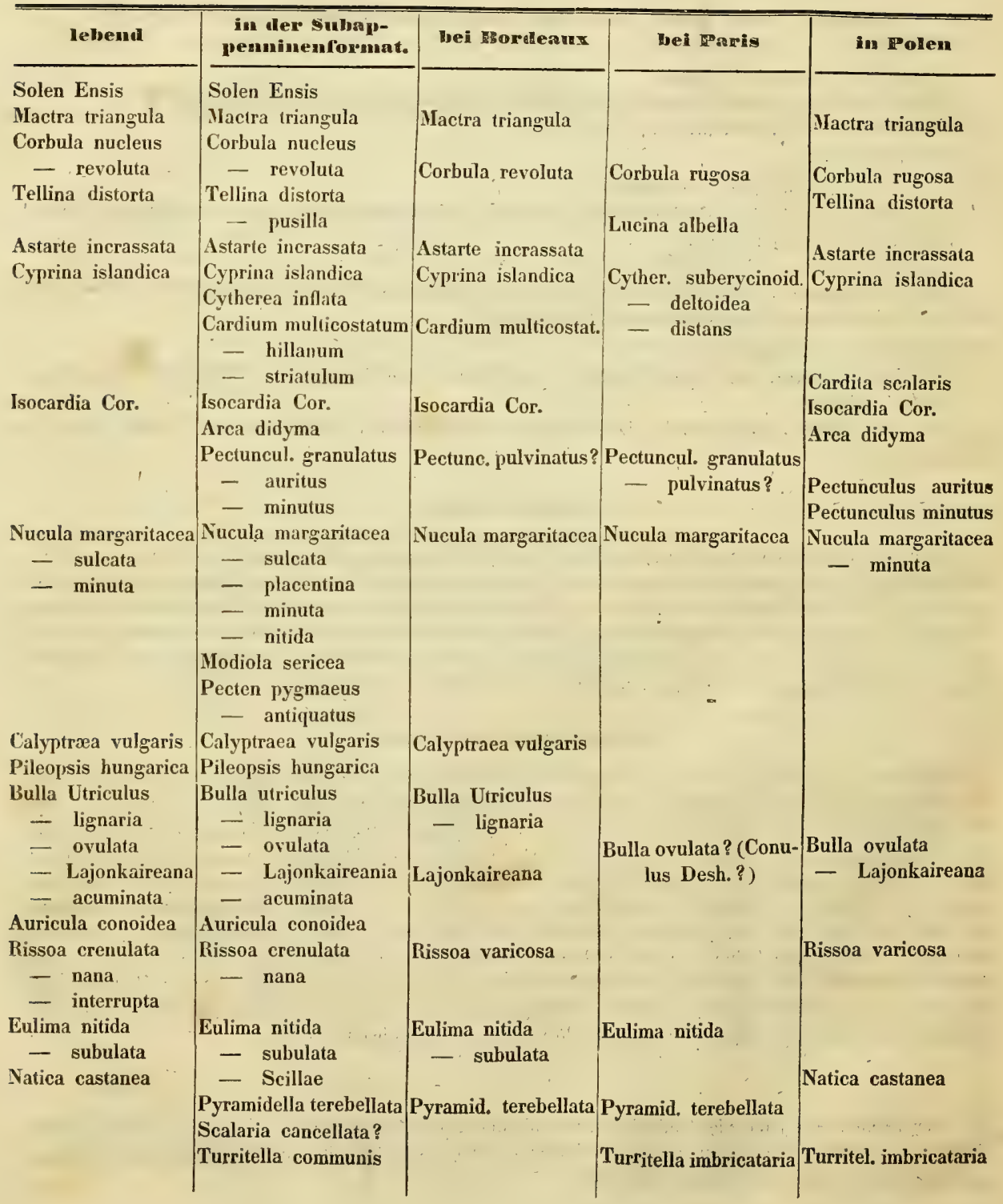




\begin{tabular}{|c|c|c|c|c|}
\hline lebend & $\begin{array}{l}\text { in der Subap- } \\
\text { penuinenform. }\end{array}$ & bei Mondenux & bel Pris & in Polen \\
\hline Turritella communis & Turritella communis & Turritella communis & & \\
\hline $\begin{array}{c}\text { Cerithium perversum } \\
\text { - trilineatum }\end{array}$ & $\begin{array}{l}\text { Cerithium perversum } \\
\text { - trilineatum } \\
\text { Pleurotoma rugulosum }\end{array}$ & Cerithium perversum & $\begin{array}{l}\text { Cerithium perversum } \\
\text { Pleurot. curvicosta } \\
\text { - acutangulare }\end{array}$ & Cancell. buccinula \\
\hline Pleurot. rugulosum & $\begin{array}{l}\text { Pyrula clathrata } \\
\text { Murex horridus } \\
\text { Cassis Rondeleti }\end{array}$ & Cancellar. buccinula & $\begin{array}{l}\text { - plicatile } \\
\text { Pyrula clathrata }\end{array}$ & $\begin{array}{l}\text { Pyrula clathrata } \\
\text { Cassis - Rondeleti }\end{array}$ \\
\hline Buccinum Macula & $\begin{array}{l}\text { Buccinum Macula } \\
\text { Terebra plicatula }\end{array}$ & $\begin{array}{l}\text { Buccinum Macula } \\
\text { Terebra plicatula }\end{array}$ & Terebra plicatula & Buccinum Macula \\
\hline $\begin{array}{l}\text { Mitra Ebenus } \\
\text { Dentaīium strangul. }\end{array}$ & $\begin{array}{l}\text { Mitra Ebenus } \\
\text { - cupressina } \\
\text { Conus Brocchii } \\
\text { Dentalium strangul. }\end{array}$ & Ancillaria glandifor. & & $\begin{array}{l}\text { Mitra Ebenus } \\
\text { - cupressina } \\
\text { Ancillaria glandif. }\end{array}$ \\
\hline - fossile? & - fossile & 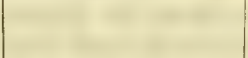 & & Dentalium fossile \\
\hline
\end{tabular}

Es sind also: lebend 33 Arten oder 0,22 bei Kassel war das Verhältniss: 0,25

in der Subappenninenformation $55, \quad$ " 0,38 ",$\quad$ " " 0,38

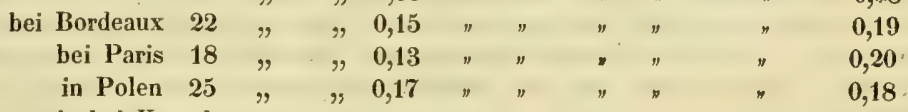

Also fast genau so wie bei Kassel.

Betrachten wir auch hier die Bivalven und Univalven gesondert, so finden sich:

\begin{tabular}{|c|c|c|c|c|c|c|c|c|}
\hline \multirow{3}{*}{$\begin{array}{l}\text { Lebend } \\
\text { appenninenformation }\end{array}$} & \multicolumn{4}{|c|}{ Bivalven } & \multicolumn{4}{|c|}{ Univalven } \\
\hline & 11 & Arten & oder & 0,19 & 22 & Arten & oder & 0,24 \\
\hline & 25 & $"$ & $"$ & 0,43 & 30 & $"$ & , & 0,34 \\
\hline bei Bordeaux & 7 & $"$ & " & 0,12 & 15 & $n$ & 》 & 0,17 \\
\hline in Polen & 12 & $"$ & $n$ & 0,20 & 13 & y & ” & 0,14 \\
\hline bei Paris & 8 & , & $"$ & 0,14 & 10 & $”$ & , & 0,11 \\
\hline
\end{tabular}

so dass unter den Versteinerungen des Hildesheimischen verhältnissmässig mehr Univalven mit del' jetzigen Schöpfung und mit der Formation von Bordeaux; mehr Bivalven dagegen mil der Subappenninenformation, und mit den Tertiärbildungen von Polen und Paris gemein sind; ein Verhältniss, welches von dem bci Kassel beobachteten etwas abweicht.

Von den 55 Arten, die auch in der Subappenninenformation vorkommen, sind 30 lebend, d. i. 0,54

" " 22 " " " dem Becken von Bordeaux " " 14 lebend, d. i. 0,63

" " 28 " " " " " " 15 lelenend, d. i. 0,60

" " 18 ." " " dem Becken von Paris " " 5 lebend, d. i. 0,27,

Also auch hier, fast genau so wie wir p. 32 gesehen haben, ist bei weitem die Mehrzahl der den Tertiärformationen Deutschlands, Italiens, Polens und Bordeaux's gemeinschaftichen Arten, von noch lebenden Species gebildet, nur mit Paris ist dies nicht der Fall.

Von den 33 lebenden Arten, welche im Hildesheimischen versteinert vorkommen, sind 27 im Mittelmeer, nur 13 in der Nordsce anzutreffen, während keine einzige Art in wärmeren Meeren vorkommt. 


\section{Verze i c h n is s

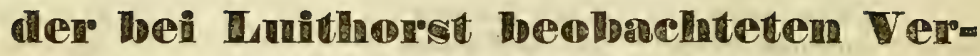

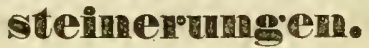

Ich verdanke die Versteinerungen von Luithorst Herrn Bergrath Koch in Grünenplas und Herrn Forstsekretar Fiorillo in Nordheim so wie Herrn Dr. Dunker.

Ueber das Vorkommen derselben bin ich ebenfalls nicht im Stande Aufschluss zu geben, da ich diese Gegend nie besucht habe. Nach einer sehr kurzen Notiz von Hern Hofrath Hausmann an dem o. a. Ort p. 260 kommen diese Tertiärversteinerungen, theils in der Feldmark des Dorfes Luithorst vor, theils auf dem bewaldeten Elfass, einem gleich dem Sollinge aus buntem Sandstein bestehenden Flötzrücken. Auf letzterem Berge finden sie sich nach einer mündlichen Mittheilung meines Freundes und Collegen Dr. W. Dunker in einer muldenartigen Vertiefung, welche nur wenige Schritte im Durchmesser inisst. Auśgezeichnet sind die tertiären Ablagerungen von Luithorst durch ihren Reichthum an Korallen.

1. Cyathina? granulata (Turbinolia) v. Münst. S. p. 4.

Häufig.

2. Cyathina firma n. sp.

Verkehrt kegelförmig, nach unten wenig verschmälert, mit eincr stark verbreiteten Basis festgewachsen, auf der Oberläche gefurcht, rauh, mit etwa $40-48$ Randlamellen welche șchnal und mit starken Auswüchsen versehen sind.

Ziemlich häufig; es liegen 16 Exemplare vor, bis $5^{\prime \prime \prime}$ hoch, der Durchmesser des Sterns $33^{1 / 2}$. Diese Art zeichnet sich durch die starke Erweiterung der Basis aus, welche ihr einen sehr festen Ansatz gewährt haben muss. Die Lamellen des Sternessind sämmtlich dünn und mit sehr starken Auswüchsen versehen, die nicht bloss Höcker und Körnchen, sondern selbst kleine Blättchen bilden. Der Centrallamellen scheinen nur wenige aber gebogen gewesen zu sein; die Kranzlamellen liessen sich nicht erkennen.

3. Cyathina pusilla.n. sp.

Sehr schlank, walzenfürmig, an der Basis kaum verschmälert; die Oberfläche glatt? gegen 24 ziemlich dicke, stark gekörnte Randlamellen.

Ieh habe 6 Exemplare gesehen. Die Höhe beträgt etwa $3^{\prime \prime \prime}$, der Durchmesser des Sterns $1^{1 / 3} 3^{\prime \prime \prime}$. Diese Dimensionen erinnern an C. Peziza Ehrenb. (Die Korallenthiere des rothen Meeres p. 76), von der sich die fossile Art durch dickere Randlamellen und eine glattere Oberfläche unterscheidet, wenn letztere nicht bloss Folge der Abreibung ist. 


\section{$-67-$}

4. Desmophyllum Stellaria Ehrenb.

Kurz, beinah walzenförmig, zusammengedrückt; der Stern elliptisch mit zwölf Bündeln Randlamellen und einem kleinien Centrum.

S. Ehrenberg Korallenthiere etc. p. 76.

Ein Exemplar, welches vollkommen mit den lebenden Exemplaren aus dem Mittelmeere übereinstimmt.

5. Lunulites radiata Lamk. S. p. 3 .

Häufig.

6. Millepora truncata L. S. p. 35. nr. 7.

Häufig.

7. Millepora punctata n. sp.

Aestig, dichotomisch? die Aeste stielrund; die Mündungen der Zellen gross, kreisrund, regelmässig in Längsreihen gestell!; die Zwischenräume dicht punktirt; porös.

Zwei Bruchstücke; das eine verkehrt kegelförmig, eine Gestalt die bei M. truncata wohl nie vorkommt, $1{ }^{1}{ }^{\prime \prime \prime}$ lang, oben fast $11^{1 / \prime \prime}$ breit, der andere $3^{1 / 2}{ }^{\prime \prime \prime}$ lang, oben verschmälert, unregelmässig, nicht abgestuzt wie allemal die Enden der M. truncata. Die Oeffnungen der Zellen sind noch ein weniges grösser, genau von derselben Gestalt, die Zwischenräume sind durch verhältnissmässig grosse eingestochene Punkte porös.

8. Retepora cellulosa Lamk. S. p. 35. nr. 8.

Häufig.

9. Hornera gracilis Ph. S. p. 35. nr. 9.

Häufig.

10. Hornerabiseriata Ph. S. p. 36. nr. 10.

Häufig.

11. Idmonea? biseriatan. sp.

Die Aeste zusammengedrückt, die Zellenmündungen stark hervorragend in schrägen Querreihen zweizeilig gestellt; die hintere Fläche (durch Abnützen?) netzförmig porös.

Vier Bruchstücken, der IIornera seriata sehr ähnlich, allein sogleich dadurch zu unterscheiden, dass die Oberfläche der vordern Seitc ohne alle Poren, glatt, und durch Längslinien bezeichnet ist, welche die einzelne röhrenförmigen Zellen unterscheiden. Die schrägen Querreihen, in welchen zu beiden Seiten die Zellenmündungen stchen, greifen in der Mittellinie nicht über einander; und bestehen bald aus einer einfachen, bald aus einer gedoppelten, am Ende der Zweige auch aus mehrfachen Reihen; die hintere Fläche zeigt ein grossmaschiges Porennetz, welches wahrscheinlich durch mechanische Zerstörung der äussern Kalkmembran entsanden ist, während auf der vordern Seite die hervorstehenden Zellenmündungen eine ähnliche Zerstörung verhindert haben.

12. Ceriopora variabilis v. Münster S. p. 36. nr. 12.

Gemein.

13. Ceriopora stellata Goldf. S. p. 36. nr. 13.

Gemein.

14. Ceriopora verrucosa.n. sp.

Beinah kreisförmig ausgebreitet, in Centrum angewachsen, unten runzelig, übrigens glatt; oben mit unregelmässigen, erhabenen Strahlen und durch eine Furche getheilt; sehr kleine Zellenmündungen sowohl auf den Strahlen als auf den Zwischenrãumen.

Ein Exemplar, beinah $7^{\prime \prime \prime}$ lang, $5 \frac{1}{2}{ }^{\prime \prime \prime}$ breit, unregelmässig oval. Die untere Fläche ist ziemlich 
eben, unregelmässig runzelig, aber glatt, ohne alle Poren; nur in der Mitte erscheinen solche, indem hier der Korallenstock festgewachsen war, und die Verbindungsstelle abgebrochen ist. Die Oberfläche wird durch eine beinah der Länge nach verlaufende Furche in zwei Theile getheilt, jeder Theil zeigt erhabene Strahlen, welche an ihrem der Furche zugekehrten Ende am höchsten sind, und nach der Peripherie abfallen. Sie sind durchaus unregelmässign, bisweilen verästelt, bisweilen zusammengewachsen. Sowohl die Strahlen wie die Zwischenräume zeigen feine Poren, die auf den Zwischenräumen regelmässiger stehen als auf den Strahlen. - Am nächsten verwandt ist C. Diadema Goldf. p. 39. t. XI f. 12. aus der Kreide des Petersberges bei Mastricht. Diese Art ist aber nur $2{ }^{2} 3^{\prime \prime \prime}$ gross und scheint grössere Poren bei geringerer Unregelmässigkeit in der Vertheilung der Strahlen zu zeigen.

15. Eschara punctata Ph. S. p. 38. nr. 22.

Ziemlich häufig.

16. Eschara.glabra Ph. S. p. 38. nr. 21.

Iläufig. Es lionmt auch eine breitere Form vor, wo die Aeste über $2^{\prime \prime \prime}$ breit sind, die daher auf den ersten Blick sehr abweichend erscheint und sich an E. clathrata p. 4. anschliesst. Sie unterscheidet sich jedoch durch regelmässig sechseckige nicht verlängerte Zellen und durch wenig erhabene Abgränzungen der Zellen.

17. Eschara porosa Ph. S. p. 38. nr. 23.

18. Eschara diplostoma n. sp.

In schmale stark zusammengedrückie Aeste getheilt; die Zellen länglich, durch eine einfache Reihe eingestochener Punkte gुeschieden; mit einer kleinen kreisrunden Oeffnung: unterhalb derselben.

IIäufig. Die Aeste sind nicht breiter als $1^{\prime \prime \prime}$ und oft nur $1 / 3^{\prime \prime \prime}$ dick mit etwa 7 Reihen Zellen, welche in sehr schrägen Reihen gestellt, einen unregelmässigen Quincunx bilden. Diese Zellen sind flach, nnr durch die eingestochenen Punkte geschieden, schr verlängert; die eingestochenen Punkte selbst sehr klein.

19. Eschara imbricata n. sp.

In schmale zusammengedrückte Aeste getheilt; die Zellen kreisförmig, gewölbt, durch Furchen geschieden, regelmässig im Quincunx gestellt, jede mit zwei kreisförmigen Oeffnungen von denen die grössere, die eigentliche Mundöffnung, oberhalb des Centrums der Zclle.

Nicht eben selten; die Bruchstücke sind $1^{\prime \prime \prime}$ breit, $1 / s^{\prime \prime \prime}$ dick und bestehen aus etwa 7 Längsreihen Zellen, welche stark gewölbt, durch tiefe Furchen geschieden und beinahe kreisförmig sind, wegen der äusserst regelmässigen Anordnung im Quincunx aber rautenförmig erscheinen. Sie sind ganz glatt, dic zweite Oeffnung kreisrund, ziemlich klein, liegt im Centrum der Zelle, die eigentliche Mundöffnung, welche nur wenig grösser ist, zwischen dieser und dem obern Rande. Auf einigen Zellen bemerke ich eine dritte untere Oeffnung, an anderen eine vertiefte, fein punktirte, wic poröse Stelle anstatt derselben.

20. Cellepora S. p. 39.

Nicht selten, aber immer abgerollt, keine nähere Bestimmung erlaubend.

21. Discopora mammillata n. sp.

Die Zellen zitzenförmig erhaben, die Oeffnung klein, central, auf den Spitzen der Zellen, kreisförmig.

Ein Exemplar auf dem Stamm von Millepora truncata eine Masse von $3^{\prime \prime \prime}$ im Durchmesser bildend, durch die ungemein stark hervortretenden Zellen sehr ausgezeichnet. Die Oberfläche derselben scheint vollkommen glatt gewesen zu : sein.

22. Cumulipora angulata v. Münster S. Bronn Lethaea p. 879. tab. XXXVI. f. $7^{1} / 2$. Ein knolliger Polypenstock mit grossen prismatischen Zellen. 
Ein Exemplar über einen Zoll im Durchmesser haltend. Ich betrachte diesen Polypenstock nicht sowohl als zusammengesetzt aus langen durch Querscheidewände in Fächer getheilte Zellen, als vielmehr gebildet durch concentrische Schichten von Zellen, welche sich nach und nach über einander entwickeln, wie bei Cellepora.

Auf der Oberfläche erscheinen die Zellen allemal durch die hervorragenden Seitenwände getheilt und mit einer flach-convexen kalkigen Platte geschlossen, welche nur am Rande eingestochene Punkte zeigt, aber keine Zellenöffnung. Diese Bildung erinnert offenbar an die kleinen Oeffnungen bei mancher Foraminiferen. In einzelnen wenigen Fällen sieht man zwar eine runde ziemlich grosse Oeffnung am Rande; allein diese muss man für eine neue sprossende Zelle halten. Ilierfür sprichı, dass sie nur hie und da, nicht ${ }^{-}$an allen Zellen vorkommen, und ihre verschiedene Grösse und Entwickelung.

23. Cellaria hexagóna v. Münst. S. p. 37. nr. 16.

Sechs Bruchstücke.

24. Cellaria marginata v. Münst. S. p. 37. nr.-18.

Sieben Bruchstüke.

25. Manón? cylindraceum n. sp.

Beinahe cylindrisch, die Fasern dicht verwebt, die grösseren Oeffnungen kreisförmig;, ohne Ordnung ziemlich gedrängt.

Zehn Bruchstücke, das grösste $5^{1}{ }_{2}^{\prime \prime}$ lang, $1 \frac{1}{2}{ }^{\prime \prime \prime}$ im Durchmesser. Die Stellung der grösseren Löcher erinnert an Scyphia z. B. an Sc. calopora Goldf. p. 5. tab. II. f. 7; auch sind die grossen Oeffnungen nicht mit einer Rinde ausgekleidet, wie es von Manon verlangt wird; allein ebenso wenig kann ich eine Spur der röhrenförmigen Bildung finden, welche Scyphia wenigstens an den Spitzen zeigt.

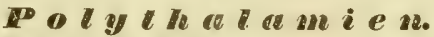

1. Nodosaria intermittens Röm. S. p. 4 .

Nicht selten.

2. Nodosaria radicularis v. Münst. S. p. 39. nr. 3.

Nicht selten.

3. Lingulina oblonga v. M. (Frondiculina) S. p. 4. nr. 3.

Ein Exemplar.

4. Lingulina ovata v. M. S. p. 4. nr. 4 .

Ein Exemplar.

5. Lingulina striata S. p. 40. nr. 12.

Mehrere Exemplare.

6. Marginulina compressiuscula. Ph. S. p. 5. nr. 11.

Vier Exemplare.

7. Polymorphina lingua Röm. S. p. 41. nr. 21.

Drei Exemplare.

8. Polymorphina compressa n. sp.

Verkehrt eirund, oben zugespitzt, zusammengedrückt, unten beinah zweischneidig, die (5-6) Kammern nur äusserst schwer zu unterscheiden.

Drei Exemplare, nur $2 / 3^{\prime \prime \prime}$ gross, fast von der Gestalt der 1'. gibba d'Orb. Röm. 1. c. p. 386. f. 32, aber unten nicht stark gewölbt, sondern zusammengedrückt, an den Rändern fast schneidend, und an der Basis abgerundet. 
9. Polymorphina anceps Ph. S. p. 41. nr. 19. Hăufig.

10. Polymorphina regularis v. M. S. p. 41. nr. 18. Ein Exemplar.

11. Polymorphina obscura Röm. S. p. 41. nr. 20. Ein Exemplar.

12. Polymorphina communis d'Orb. S. p. 5. nr. 8. Hâufig.

13. Polymorphina crassa tina v. Niünst. $S$. p. 41. nr. 25. Häufig.

14. Polymorphina minuta Rôm. S. p. 42. nr. 28. Ein Exemplar.

15. Robulina subnodosa v. Münster S. p. 42. nr. 32. Häufig.

16. Rotalia discus Röm. l. c. p. 38. nr. 8. f. 52 . ,Scheibenförmig, die eine Seite gewöllbt, mit 8 bis 10 ausstrahlenden Furchen und in der Mitte „mit glānzender, gewōlbter Nabelscheibe; die andere Seite flach gewölbt, glänzend mit drei sicht„baren flachen Umgängen; der Rücken scharf.“

Ein Exemplar.

17. Cristellaria subcostala v. Münst، S. p. Sechs Exemplare.

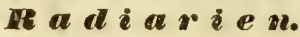

1. Spatangus.

Fragmente, welche keine Bestimmung erlauben.

2. Echinus

Stacheln, zu gross für E. pusillus, könnten vielleicht zu E. osnabrugensis gehören.

3. Asterias propinqua v. Münst. S. p. 44. nr. 7.

\section{त्ञ}

\section{A cephalen oder Muschelthière.}

1. Corbula Nucleus Lam.

Ein Exemplar.

2. Corbula Kochii n. sp.

Die Schale ist länglich eiförmig; hinten in einen schmalen Schnabel verschmälert, mit drei scharfen, von Wirbeln strahlenden Kielen; vorn stark in die Quere gefurcht, beinahe runzelig.

Eine rechte Schale sehr beschädigt, (restaurirt) etwa $4^{1 / 2}{ }^{\prime \prime \prime}$ lang, $21 / 2^{\prime \prime \prime}$ hoch, beinah gleichseitig, durch ihre Skulptur schr ausgezeichnet. Sie hat hinter der Mitte drei scharfe von den Wirbeln ausstrahlende Kiele, der Theil hinter denselben ist ganz glatt; die vordere Hälfte mit regelmässigen concentrischen, erhabenen Runzeln. Im Schloss ein starker, hervortretender, hinterer Zahn. - Aehnlich ist Corbula radiata Desh. Paris p. 58. t. IX. f. 11. 12 hat aber zahlreiche, erhabene strablende 


\section{$-71-$}

Linien und keine Querrunzeln, und C. costellata Desh. aus Calabrien und Griechenland, welche ebenfalls mehrere erhabene strahlende Längslinien besitzt.

3. Lucina albella Lamk.? S. p. 8. nr. 14.

Drei Exemplare.

4. Astarte incrassata (Venus) Broc. S. p. 9. nr. 20.

Sechs Exemplare.

5. Astarte suborbicularis v. Münst. S. 9. nr. 18.

Zwei Exemplare.

6. Astarte pygma ea v. Münst. S. p. 9. nr. 19.

Ein Exemplar,

7. Astarte la evigata v: Münst. S. p. 9. nr. 17.

Zwei Exemplare.

8. Cytherea suberycinoides Desh. S. p. 10. nr. 24.

Iläufig.

9. Cytherea incrassata (Venus) Sowerby.

„Dic Schale aus dem dreieckigen ins kreisförmige übergehend, schief, aufgeblasen, glatt; die Wir„Lel vor der Nitte; die Lunula gross, herzförmig, oberflächlich; am Rande unregelmässige Run,zeln; der cinzelne Zahn des Schlosses klein."6

S. Goldf. II. p. 240. t. CXLIX. f. 12. (einziger Fundort Tongern in Belgien; 15"' lang, 14"' hoch.) Diese Art ist mir in einem verdrückten, aher übrigens wohl erhaltenen Exemplar welches $12^{\prime \prime \prime}$ hoch ist, vorgekommen.

10. Cardium hillanum Sow.? S. p. 47. nr. 27.

Häufig.

11. Cardita scalaris (Venericardia) Sow. S. p. 12. nr. 33.

Nicht selten.

12. A rea Noac L.

Die Schale verlängert, sehr ungleichseitig, strahlenförmig gefurcht, die Furchen durch die Anwachsstreifen gekerbt; hinten ausgerandet; dic Wirbel eingekrümmt entfernt, dureh ein breites ebenes Schlossfeld geschieden.

A. Noac L. ed XII. p.1140. - Lamk. V1. 1. p. 37. etc.

Ein Exemplar etwas beschädigt, noch 17"' lang (ergänzt $24^{\prime \prime \prime}$ lang) von der lebenden Art in nichts verschieden.

13. Area quadrilatera Lamk.? S. p. 12. nr. 38.

Zwei Exemplare $2^{1} /^{\prime \prime \prime}$ lang, ungleichseitiger noch als die Figur bei Goldfuss, ob daher vielleicht junge $A$. barbatula? dafür scheint auch die feinere Skulptur zu sprechen.

14. Pectunculus pulvinatus Lamk, var.? S. p. 13. nr. 41.

Häufig, nur $8^{\prime \prime \prime}$ gross.

15. Pectunculus crassus Ph. p. -13 nr. 40.

Nicht selten, es liegen 2 vollständige Exemplar: vor.

16. Pectunculus polyodontus (Arca) Broc.? S. p. 13. nr. 40.

Hierher rechne ich drei Exemplare, welche 25"' hoch, 26" lang, $8^{\prime \prime \prime}$ dick sind, die Area misst $1 \frac{1}{2}-2 \frac{1}{2}{ }^{\prime \prime \prime}$; die Zahl der Schlosszähne jederseits $13-15$. 
17. Pectunculus a uritus S. p. 47 . nr.: 36 .

Ein Exemplar.

18. Pectunculus granulatus Lamk. S. p. 48. nr. 37.

Ein Exemplar.

19. Pectunculus minutus $\mathrm{Ph}$. S. p. 14. nr. 42.

Zwei Exemplare.

20. Nucula minuta Bronn S. p. 14. nr. 46.

Ein beschädigtes Exemplar.

21. Chama gryphoides L.

Die Schale beinahe kreisförmig, aus schindelförmig über einanderliegenden, gefalteten kurzen LamelIen gebildet; die untere stärker gewölbte Klappe mit ihrem Wirbel rechts gewunden.

Ch. gryphoides L. ed. XII. p. 1139 - Lamk. VI. 1. p. 94 etc.

Drei Exemplar, welche mit den lebenden vollkommen übereinstimmen.

22. Mytilus.

Das Bruchstück einer Art von mittlerer Grösse, welches ich gesehn, erlaubt keine nähere Bestimmug.

23. Pecten pygmaeus v. Münster S. p. 16. nr. 54 .

Die untere Schale.

24. Pecten textus. S. p. 50. nr. 53. c.

Eine Schale. Es kommen dort noch andere Arten Pecten vor, ich habe jedoch nur unkenntliche Bruchstücke derselben erhalten.

25. Spondylus bifrons v. Münster.

Die Schale schief eiförmig, gewölbt, concentrisch-gestreift; die Wirbel hervorragend; die rechte Schale an der Spitze angewachsen mit etwa $11-12$ breiten undeutlichen stacheligen Rippen, die linke mit zahlreichen kleinen, gerundeten, ungleichen, hie und da stacheligen Rippen.

Sp. bifrons v. Münst. Goldf. II. p. 99. t. CVI. f. 10. (Osnabrück und Castelgomberto.)

Sieben Exemplare, wird $32{ }^{1 / 2 \prime \prime}$ hoch $26^{\prime \prime \prime}$ breit.

26. Ostrea deltoidea Goldf. S. p. 16. nr. 56.

Ein Exemplar.

27. Anomia lens Lamk.? S. p. 17. nr. 59.

Nicht selten.

28. Anomia asperella Ph. S. p. 50. nr. 58.

Ein paar Schalen.

\section{G a s t e r o p o d e r.}

29. Emarginula pileolus Michaud.

Die Schale in Umfang rundlich eirund, hoch, kegelförmig; der Wirbel stark eingerollt, die Rippen gleich, von den Anwachssreifen durchkreuzt, beinah körnig.

E. pileolus Mich. Bull. Sec. Lin. de Bord. III. 1829. p. 271. f. 23-14.

E. capuliformis Ph. Moll. Sicil. p. 116. tab. VII. f. 12.

Drei Exemplare, von den lebenden nicht verschieden. 
30. Auricula conoidea (Turbo) Broc. S. p. 51. nr. 68.

Vier Exemplare.

31. Auricula gracilis n. sp.

Die Schale klein, pfriemenförmig, beinah walzenförmig, sehr glänzend; die Windungen elen, durch eine tiefe Nath getrennt, die Oeffnung länglich, die Columella verlängert, mit einer Falte. Ein Exemplar, welches bei ${ }^{2} /{ }^{\prime \prime}$ Dicke $2 \frac{1}{2} "{ }^{\prime \prime}$ lang gewesen sein mag, (die Spitze fehlte). Es hat den Habitus von Eulima, die Falte von Auricula conoidea, von der sie sich durch viel grössere Schmalheit und den sehr verlängerten Collumellarrand sogleich unterscheidet.

32. Auricula subcylindrica n. sp.

Die Schale sehr klein, beinah walzenförmig, sehr glänzend; die Windungen schwach gewöllst, unten etwas vorstehend; die Oeffnung beinah rautenförmig; die Columella mit einer Falte.

Ein Exemplar an der Spitze beschädigt nur ${ }^{1 / 2}{ }^{\prime \prime \prime}$ dick, (ergänzt) wohl $2^{1 / 2}{ }^{\prime \prime \prime}$ lang, durch die angegebenen Merkmale leicht zu erkennen.

Diese drei Arten gehören wohl schwerlich in das Genus Auricula.

33. Rissoa varicosa Bast.? S. p. 19. nr. 70.

Zwei Exemplare, stark abgerieben.

34. Rissoa interrupta Adams. S. p. 52. nr. 73.

Ein Exemplar.

35. Rissoa interstincta (Turbo) Mont.

Die Schale thurmförmig, die Windungen (5) schwach gewölbt, mit zahlreichen Längsrippen; die Mündung länglich eiförmig, oben spitz, einfach; die Columella mit einem Zahn.

Turbo interstinctus Montag. Testac. brit. t. XII. f. 10. - Odostomia Flem. p. 310.

Ein Exemplar 1 1/3" gross, stimmt vollkommen mit der citirten Beschreibung und Abbildung, doch zeigt letztere den Zahn der Columella nicht; lebend an der Küste von Devonshire.

36. Rissoa reticulata Ph.

Die Schale lanzettlich thurmförmig, spitz; die Windungen gerundet, mit Längsfalten und grohen Querfalten, beinah netzförmig verziert; die Oeffnung eiförmig, die Aussenlippe einfach.

R. reticulata Ph. Moll. Sicil. p. 156. tab. X. f. 14.

Zwei Exemplare, welche nur dadurch etwas abweichen, dass die letzte Windung nur 6-7 erhabene Querlinien zeigt, während die Exemplare von Palermo deren 8-9 erkennen lassen.

37. Eulima nitida (Melania) Lamk. S. p. 52. nr. 78.

Ein junges Exemplar.

38. Eulima Scilla e Scac. S. p. 53. nr. 79.

Ein kleines Exemplar.

39. Eulima? Leunisii Ph. S. p. 53. nr. 81.

Ein Exemplar.

40. Melania? plicatula Desh.?

"die Schale thurmförmig-kegelförmig; der Länge nach fein gefaltet; die Windungen schwach gee"wölbt; die Näthe einfach; die Oeffnung einfach, schief, gerandet."

M. plicatula Desh. Paris II. p. 115. t. VIV. f. 5. 6-12"' nach der Beschreibung 51/3"' lang, Albecourt bei Beauvais.

Eilf mehr oder weniger beschädigte Exemplare die Windungen sind sehr schwach gewölbt, mit 
wenigstens 20; dicht gedrängten, schwachen Falten, die sich nicht auf die Basis fortsetzen. Diese ist durch eine deutliche Kante abgesetzt und quergestreift. Die Mündung ist schief, unten und oben ausgeschweift, wie bei Rissoa Bruguieri. - Vielleicht ist die Art von Deshayes verschieden, was jedoch nur die Ansicht von Originalexemplaren entscheiden kann.

41. Niso minor Ph. S. p. 53. nr. 82 .

Drei Exemplare.

42. Natica castanea S. p. 20. nr. 74 .

Neun Exemplare.

43. Pyramidell a terebellata (Auricula) Lamk. S. p. 54. nr. 87.

Drei Exemplare.

44. Tornatella punctato-sulcata Ph. S. p. 20. nr. 77.

Ein Exemplar.

45. Scalaria decussata Lamk. S, p. 21. nr. 78.

Zwei Exemplare.

6. Scalaria pusilla Ph. S. p. 54. nr. 92.

Ein Exemplar mit vollkommen glatten, ein anderes mit fein quergestreiften Windungen.

47. Siliquaria anguina Lamk. (Serpula L.)

Die Schale drchrund, unbewehrt, die oberen Windungen spiralförmig einander genähret, querrissig, die letzten verlängert, längsgestreif $t$.

Siliquaria anguina Lamk. V. p. 337. ctc. - Phil. Moll. Sicil. t. IX. f. 24.

Ein charakteristisches Exemplar und mehrere Spitzen. Diese zeigen die das Genus bezeichnende

Spalie noch nicht. In diesem Zustand ist diese Art von Brocchi als Serpula ammonoides p. 629 beschrichen und tah. XV. f. 13 abgebildet.

48. Solarium Acies n. sp.

Die Schale klein, flachgedrückt, scharf gekielt; die Windungen oben eben, mit drei Reihen flacher Knötchen, unten gewölbt, mit einer Leiste nahe dem Rand; der Nabel mittelmässig, gefaltet.

Zwei Exemplare, beile nicht ausgewachsen, doch gewiss eigenthümlich, kaum $2^{\prime \prime}$ im Durchmesser, $2 / 3$ "' hoch, mit vier Windungen. Die Windungen scheinen vollkommen glatt zu sein; auf der untere Seite ist die glatte Leiste vom Kiel durch eine tiefe Furche getrennt. Der Nabel ist mässig, am Rande gekerbt, die Kerhen laufen in Falten aus. - S. marginatum Desh. Paris. II. p. 218. t. 25. f. 21. 22. 23., ist auf der oberen Fläche durch fünf Querstreifen und durch Längsstrcifen regelmässig .gegittert; der Nabel ist schr weit, und sein wulstiger Rand aussen durch eine ticfe Furche begränzt; kommt sonst dieser. Art sehr. nahe.

49. Trochus scrutarius Ph. S. p. 22. nr. 83.

Nur Bruchstücke.

50. Turbo simplex. Ph. S. 1. 56. nr. 102 :

Sieben Exemplare.

51. Turbo bicarinatus n. sp.

Die Schale kegelförmig, stumpf, alt ungenabelt; die Windungen eben, glatt, mit vier Reihen stumpfer Knötchen, die letzte am Rande zweikantig, die obere Kante mit stärkern Knoten besetzt, die Basis stark convex, glatt; die Mündung beinah kreisförmig. 
Sehr häufig, aber kein vollkommenes Exemplar, wird $8^{\prime \prime \prime}$ hoch und ebenso breit. Diese Art zeigt, wie T. rugosus, die aufallendsten Verschiedenheiten nach dem verschiedenen Alter. Jung, erst aus 3 Windungen zusammengesetzt, ist es eine vollkommene Delphinula, unten sehr weit genabelt, oben vollkommen eben, glatt, am Rande gekielt, mit 8 strahlenförmigen grossen Dornen, unten ist ein zweiter Kiel mit 8 kleinen Spitzchen. Späterhin erscheinen die Windungen abgesetzt, der Nabel wird immer enger, lange bleiben die Dornen des obersten Kieles in der Nath sichtbar und verwandeln sich erst auf der letzten Windung vollstấndig in zahlreiche gedrängte Knoten. Die letzte Windung zeigt zwischen beiden Kielen einen freien gekerbten Reifen. Die Columella zeigt am Ende zwei stumpfe schwache Auskerbungen.

52. Deckel von Turbo-S. p. 22. nr. 85.

sind sehr gemein, der Grösse nach zu urtheilen, haben sie wohl eher zu T. simplex, als zu T. bicarinatus gehört.

53. Turritella commun is Risso. S. p. 22. nr. 86 .

Sehr häufig.

54. Turritella imbrieataria Lamk. S. p. 57. nr. 104.

Mehrere Exemplare, stark abgerollt.

55. Turitella carinifera Lamk.?

„Die Schale thurmförmig, gekielt, glatt, durchsichtig, weiss; die Windungen in der Mitte mit

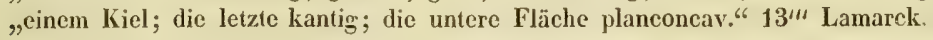

T. carinifera Lamarsk VII. p. 59.

Ich besitze durch die Güte des Herm Prof. Bronn 2 Exemplare aus Java, wovon das eine 15"' lang, $5 \frac{1}{2}{ }^{\prime \prime \prime}$ dick, welche vollkommen mit Lamarck's Diagnose übereinstimmen, und 9 fossile Bruchstücke von Luithorst, die mir hiermit vollkommen identisch erscheinen. Ich bemerke noch, das der Kiel etwas unterhalb der Mitte liegt, und dass die Windungen ohne den Kiel fast vollkommen eben sein würden. Feine Querstreifen sind mit der Lupe auf den lebenden, nicht auf den fossilen zu erkennen, offenbar nur wegen des schlechten Zustandes der Conservation. - Vollkommen identisch hiermit scheint mir ferner der: Turbo spiratus Brocchi aus den Mergeln von Siena zu sein. S. dessen vortreffliche Beschreibung p. 369 und die Abbildung t. VI. f. 19. Er hat nur 4"' lange Spizen gefunden.

56. Turritella.

Die Schale thurmförmig mit 2 runden Leisten, einer oben an der Nath, der anderen unten, wenig oberhalb der untern Nath, zwischen beiden stark concav.

Mehrere Exemplare, alle so stark an der Oberfläche beschädigt; dass die Skulptur nicht zu sehen und eine genauere Beschreibung nicht wohl zweckmässig ist; ich kenne keine Art mit weIcher sie verglichen werden könnte.

57. Cerithium Lima Brug. S. p. 22. nr. 88.

Ein Exemplar.

58. Cerithium perversum Lamk. S. p. 23. nr. 89.

Neun Exemplare.

59. Cerithium trilineatum Ph. S. p. 23. nr. 90.

Drei Exemplare.

60. Fasciolaria Fusus Ph. S. p. 25. nr. 98.

Ein paar Bruchstücke. 
61. Fusus elegantulus Ph. S. p. 59. nr. 125.

Ein schönes Exemplar, welches beim Versuch, es völlig aus dem Muschelsand herauszulösen, ganz und gar zerbrach.

62. Pyrula clathrata Lamk.? S. p. 26. nr. 104.

Nur Bruchstücke, an der eigenen Skulptur leicht zu erkennen.

63. Chenopus paradoxus. S. p. 24. nr. 97.

Drei Exemplare ohne Spur der Aussenlippe.

64. Buccinum Macula Montag? S. p. 27. nr. 111 und pag. 61 nr. 135.

Ein kleines abgeriehenes Exemplar.

65. Terebra plicatula Lam.? S. p. 27. nr. 113.

Ein kleines abgeriebenes Exemplar.

66. Cypraea inflata Lamk. S. p. 28. nr. 117

Ein Exemplar.

67. Erato.

Eine Art von $2^{\prime \prime}$ Grösse, leider ist die Spitze und die Aussenlippe beschädigt:

68. Ringicula striata Ph. S. p. 28. nr. 116.

Zwei Exemplare.

69. Conus Brocchii Bronn? S. 58. nr. 119.

Ein kleines Exemplar ohne Spira mag dieser Art angehören.

70. Dentalium strangulatum Desh. S. p. 29. nr. 120.

Häufig.

71. Dentalium fossile L. S. p. 29. nr. 121.

Sieben Exemplare.

72. Dentalium grande Desh.

„Die Schale gross, stielrund, schwach gekrümmt, gestreift; die Streifen sehr zahlreich, gedrängt, „dünn; das hinter. Ende mit einer schmalen, tiefen Spalte.“

S. grande Desh. Monogr. Mem. Soc. d'hist. nat. de Paris II. p. 356. tab. XVII. f. 1. 2. 3. Lamk. ed. 2. vol. V. p. 594.

Nicht ohne grossen Zweifel rechne ich hierher ein Bruchstïck, welches bei einer Länge von $15^{1} / 2^{\prime \prime \prime}$ unten $3 \frac{1}{4} \mathbf{4}^{\prime \prime}$ im Durchmesser lat und zahlreiche, breite, flache, gedrängte Rippen besitzt, da man nicht wissen kann, ob die Spitze eine Spalte gehabt hat. die Abbildung von D. Bonei t. 18. f. 8. stimmt auch so leidlich, allein mein Exemplar hat keine Querstreifen, wodurch D. Bouei hauptsächlich charakterisirt $\mathrm{zu}$, sein scheint.

73. Dentalium striatum Lamk.?

„Die Schale der Länge nach gestreift; die Streifen häufig, stumpf, gleich; das hintere Ende tief "gespalten. 66

D. striatum Lamk. ed. 2. V. p. 598. - Desh. I. c. p. 364. fig. 4. 5.

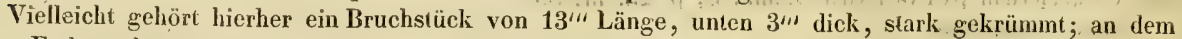
obern Ende stehen 14 abgerundete grössere, abwechselnd mit ebensoviel schwächeren Rippen, nach unten werden alle Rippen gleich. Ob die Spitze gespalten gewesen oder nicht, kann mian nicht sehen, daher die Bestimmung zweifelhaft bleibt. D. striatum Desh. t. 18. f. 4 ist etwas dicker und schwächer gekrümmt; D. sexangulare schlanker, und hat wenigep Streifen; D. eleghantinum ist weiv schwächer gekrümmt und dabei dicker. 


\section{$-197-$ \\ Cir ro pod e n.}

74. Bal a nus stellaris auct.? S. p. $62 . \mathrm{nr} .146$.

Einzelne Valven.

75. A n a tifa.

Von einer Anatifa oder Pollicipes habe ich das unpaare Schalenstück, und das oberste Deckelstück der einen Seite gefunden; wage aber hiernach nicht die Art zu bestimmen.

\section{$\mathbb{C}$ a}

Eine Krebsscheere, zu sehr beschädigt, um das Genus erkennen zu lassen.

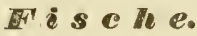

Sehr gemein ist: Sphaerodus parvus S. p. 29. nr. 3.

Nächstdem Gehörknöchelchen allerlei Art,

Endlich habe ich auch ein paar Zähne von Galeus gefunden.

Vergleichen wir auch die Versteinerungen von Luithorst mit den lebenden Mollusken und mit den in den Tertiärformationen Italiens, Polens, von Paris und Bordeaux vorkommenden, wie wir es mit den Versteinerungen von Kassel uud von Freden gethan haben, so ergiebt sich folgendes Resultat:

\begin{tabular}{|c|c|c|c|c|}
\hline Ieloenat & $\begin{array}{l}\text { in der Sub̆p- } \\
\text { penminenform. }\end{array}$ & bei Bordeanx & ber Truis & in Polen \\
\hline Corbula nucleus & $\begin{array}{l}\text { Corbula nucleus } \\
\text { Lucina albella }\end{array}$ & & Lucina albella & Corbula nucleus \\
\hline Astarte incrassata & Astarte incrassata & & Cyther. suberycinoid. & Astarte incrassata \\
\hline Arca Noae & $\begin{array}{l}\text { Arca Noae } \\
\text { Pectunc. polyodontus }\end{array}$ & $\begin{array}{l}\text { Arca Noae? } \\
\text { Pectunc. polyodont. }\end{array}$ & $\begin{array}{l}\text { Aroa quadrilaterae } \\
\text { Pectunc. granulatus }\end{array}$ & $\begin{array}{l}\text { Cardita scalaris } \\
\text { Arca quadrilatera }\end{array}$ \\
\hline & - auritus & & & $\begin{array}{c}\text { Pectuncul. auritus } \\
\text { - minutus }\end{array}$ \\
\hline $\begin{array}{l}\text { Nucula minuta } \\
\text { Chama gryphoides }\end{array}$ & $\begin{array}{l}\text { Nucula minuta } \\
\text { Chama gryphoides } \\
\text { Pecten pygmaeus } \\
\text { Spondylus bifrons }\end{array}$ & Chama gryphoides & $\therefore$ & $\begin{array}{l}\text { Nucula minuta } \\
\text { Chama gryphoides. }\end{array}$ \\
\hline Emarginula pileolus & Emarginula pileolus & & & \\
\hline Auricula conoidea & Auricula conoidea & & & \\
\hline $\begin{array}{l}\text { Rissoa interrupta } \\
\text { - interstincta } \\
\text { Natica castanea }\end{array}$ & $\begin{array}{l}\text { Rissoa varicosa } \\
\text { - reticulata }\end{array}$ & Rissoa varicosa & Melania plicatula & Rissoa varicosa \\
\hline Eulima nitida & $\begin{array}{l}\text { Eulima nitida } \\
\text { - Scillae } \\
\text { Pyramidella terebellata }\end{array}$ & $\begin{array}{l}\text { Eulima nitida } \\
\text { Pyram. terebellata }\end{array}$ & $\begin{array}{l}\text { Eulima nitida } \\
\text { Pyram. terebellata }\end{array}$ & \\
\hline $\begin{array}{l}\text { Siliquaria anguina } \\
\text { Turritella communis } \\
\text { - carinifera }\end{array}$ & $\begin{array}{l}\text { Siliquaria anguina } \\
\text { Turritella communis } \\
\text { - carinifera }\end{array}$ & Turrit. Turris * & $\begin{array}{l}\text { Scalaria decussata } \\
\text { Turrit. imbricataria }\end{array}$ & Turrit. imbricataxia \\
\hline
\end{tabular}

*) Ialte ich nur für cine Vartetät von communis, die auch im Mittelmeer lebt. 


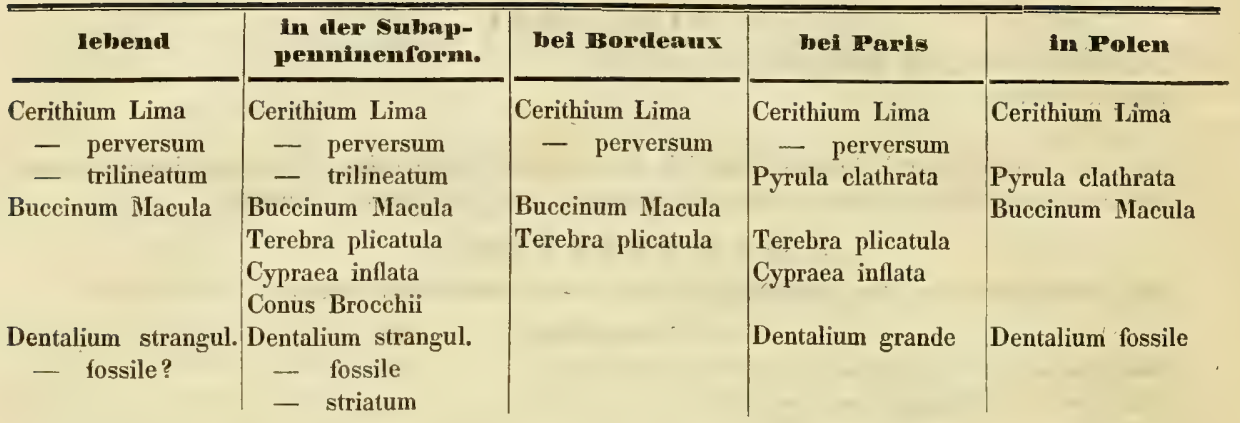

Es sind also:

lebend 20 Arten oder 0,26 bei Kassel w. d. Verhältn.: 0,25 bei Freden w. d. Verhältn.: 0,22

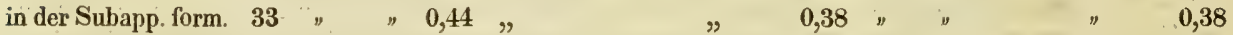

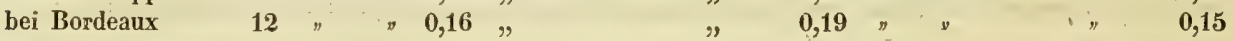

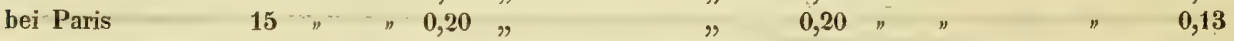

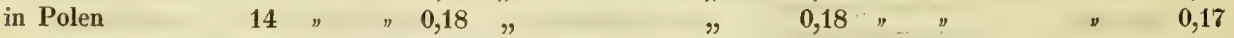

Die geringen Abweichungen, welche in diesen Verhältnissen bei den einzelnen betrachteten Lokalitäten vorkommen, dürften sich, aller WVahrscheinlichkeit nach, noch mehr verlieren, wcnn man eine grössere Zahl von Versteinerungen untersuchen würde; die Hauptresultate:

1) dass die Tertiärversteinerungen des nordwestlichen Deutschlands mit dem Grobkalk (Pariserformation) eine sehr geringe, mit der Subappenninenformation dagegen eine sehr grosse Uebereinstimmung zeigen;

2) dass der vierte Theil derselben von noch lebenden Arten gebildet wird;

3) dass von diesen lebenden Arten kaum eine in wärmeren Meeren, die Mehrzahl im Mittelmeer und nur die Minderzahl in der Nordsee vorkommt

werden auf eine übereinstimmende Weise durch die gesonderte Betrachtung der von den einzelnen Lokalitäten aufgefundenen Versteinerungen erwiesen. 


\title{
Nachtrag und Berichtigungen
}

\author{
Z IIII
}

\section{Verzeichmiss der bei Wassel beobachteten Versteinerungen.}

Seite 22 ist zwischen $\mathrm{nr} .86$ und $\mathrm{nr} .87$ einzuschalten:

86 b. Cerithium plicatum Lamk.

„Schale verlängert thurmförmig, schmal, spitz, der Länge nach gefaltet, mit vier Quer,furchen; Windungen beinah flach, durch eine knotige Nath geschieden; die letzte an der „Rasis gewöllıt, mit körnigen Querleisten; Mündung eiförmig, schief; Collumella kurz, „abgestutzt; Aussenlippe dünn, zerbrechlich, gefaltet, an der Seite buchtig." Desh.

S. Desh. Paris II. p. 389. t. LV. f. 5. 6. '7. 8. 9. $17^{\prime \prime \prime}$ lang, $5^{\prime \prime \prime}$ breit.

Ein auf der Wilhelmshöhe gefundenes Exemplar habe ich von Herm Dr. Dunker erhalten. Diese Art findet sich bei Paris, Bordeaux und Casiclgombertó.

Seite 5. nr. 11. 12. 13.

Diese drei als Marginulina angeführten Arten dürften vielleicht zu Planularia ggehören. Die Genera dieser kleinen Polythalamien sinl vou d'Orbigny nicht immer scharf charakterisirt. Marginulina unterscheidet sich nach d'Orbigny Tableau mèthod. de Ia classe des Céphalopodes p. 92, durch: „eine runde Mundöffnung, welche am Ende einer Verlängerung des ,Gipfels der letzten Kammer an deren vorderen Winkel liegt; Gchäuse in Gestalt einer ge„,krümmten Scheide, Spitze flachgedrückt, an ilırem Ursprung mit einer Spur von WVindung ,(ayant à son origine l'empreinte volutatoire); die Kammern aufeinander gestellt, etwas "schief. - Die Kammern drehen sich hinten ivie ein Krummstab."

Allein diese angegebenen Kennzeichen passen gleich auf die erste Art nicht. Dies ist M. Raphanus, Nautilus Raphanus L., welche Art, nach d'Orbigny, bei Soldani 2. tab. 94. f. N. P. Q. R. X. Y, dargestellt ist. Fig. N. und $\mathrm{X}$ sind vollkommen gerade und zeigen keine Spur von einer empreinte volutatoire, die nur bei Fig. Q. und $\mathrm{Y}$ zu sehen ist; an der Spitze zusammengedrückt, ist lediglich Fig. Q, die übrigen Figuren sind vollkommen stielrund. Es bleibt demnach nur die schiefe Stellung der Ocflnung übrig (dic bei N, R und $\mathbf{Y}$ auch fehlt, vielleicht wegen der Lage?) zun Unterschied von Nodosaria, denn die etwas schiefe Stellung der Kammern ist bei keiner diescr Fjguren zu sehen, ebenso wenig wie bei M. carinata Sold. 2. 97. fg. mm, hh., wo die Oeffnung central ist. Diese Art ist stark zusammengedrückt, ähnlich der Kasselschen Arten. M. sublituus d'Orb ist wieder stielrund mit ausgezeichnet schiefer Stellung der Mündung. - Planularia unterscheidet sich durch stärkere Zusammendrückung und bedeutendere Grösse des gewundenen Theiles des Gehäuses. Vielleicht thäte man besser, die stielrunden gerippten Marginulinen zu Nodosaria, die platten zu Planularia zu stellen und das Genus Marginulina ganz eingehen zu lassen. 



\section{Re g ister.}

Serpula anguina $L$. vide Sili-

\section{Aanceliaten.} quaria unter den Mollusken

\section{- contorta Ph. \\ - corrugata Goldf. \\ Crostaceen.}

Fr.

Fr.

Cytherina angustäta v. Münst. Fr.

- - arcuata v. Münst. Fr.

- - scrobiculata v. Münst. Fr.

- - ventrosa $\mathrm{Ph}$.

Platycarcinus sive

Xantho

sp. indet. W

\section{risctee.}

Carcharias megalodon Ag.

W.

Galeus denticulatus Ag. ob früher Lamna ejusd.?

- - minor Ag.

W.L.

Lamna denticulata $\mathrm{Ag}$. ob Galeus? WV.

Myliobatus sp.

W.

Notidanus primigenius Ag.

Otodus Ag. sp. indet.

W.

W.

Fr.

W. Fr. L. 29.63.77.
Raja sp. indet.

Sphaerodus parvus Ag.

\section{DFolhs:sen.}

Anatifa? sp. indet. Ancillaria glandiformis Lam. - - subulata Lam.

Anomia asperella $\mathrm{Ph}$. - _ Lens Lam?
L. 77 .

W. Fr. 28.62 .

Fr. 62 .

Fr. 50.

W. Fr. 17.50 .
Arca barbatula Lam.

Lokalitäf pag.

- didyma Broc.

W.

12.

- diluvii Lam.

W. Fr

12. 47 .

IV.

12.

- Noae $\mathbf{L}$.

L.

71.

- quadrilatera Lam.

W. L.

12.71.

- v. auch Pectunculus und Nucula

Astarte gracilis v. Münst.

Fr.

46.

- incrassata Broc.

W. Fr. L. 9. 46.71.

- laevigata $\mathbf{v}$, Münst.

V. Fr. L. 9. 46, 71.

- propinqua v. Miünst.

Fr.

46.

- nygmaea v. Münst.

W. Fr. L. 9.46. 71 .

- suborbicularis v. Münst. W. Fr.

Auricula conoidea Broc.

Fr. L.

31. 73.

- gracilis $\mathbf{P h}$.

L. 73 .

- ringens var.v. Münst. vide Ringicula

- subcylindrica Ph.

L.

73.

- terehellata Lam. vide Pyramidella

Balanus stellaris auct.

Fr. L.

62.77.

Bonnellia Desh. vide Niso

Buccinum asperulum Broc. vide B. Macula

- Macula Mont. W. Fr. I. 27.61. 76.

- semicostatum Broc. W. W. 27.

Bulla acuminata Brg. $\quad$ Fr. 51 .

- intermedia Pl. W. Fr. 18.51.

- Lajonkaireana Bast. W. Fr. 18.51.

- lignaria $L$ Fr. 51 .

- ovulata Broc. W. Fr. 18.51.

- retusa Ph. $\quad 18$.

- Utriculus Broc. W. Tr. 18.51.

- terebelloides Ph. W. 18.

Bullina Lajonkaireana Bast. vide Bulla!

Calyptraea vulgaris $\mathbf{P h} . \quad \ldots \quad$ W. Fr.

17. 50. 


Cancellaria buccinula Lam.
Cardita scalaris Sow.
_ tuberculata v. Münst.
Cardium hillanum Sow.
_ multicostatum Broc.
- papillosum Poli
- pulchellum Ph.
- $\quad$ striatulum Broc.
_ turgidum Brand.
Cassidaria carinata Lam.
Cassis Rondeleti Bast.
Cerithium bitorquatum Ph.
- Lima Brg.
- melanoides Lam.
- perversum Lam.
- plicatum Lam.
- trilineatum Ph.
- vulgatum Brg.

Chama gryphoides L.
Lokalitāt.

Fr.

W. Fr. L. 12.47.71.

W. etc.

Fr. L.

12. etc.

IV. Fr.

47. 71 .

$$
\text { W. }
$$

Fr.

12. 41 .

IV. $\mathrm{Fr}$.

W. Fr.

W.

W. Fr.

W.

W. L.

W.

11.

47.

11. 47 .

11. 47 .

27.

27. 61 .

23.

22. 75 .

23.

WV. Fr. L. 23.56. 75.

W.

79.

W. Fr. L. 23. 56. 75.

W.

22.

L.

Chemnitzia d'Orb, vide Pyrgiscus

Chenopus paradoxus $\mathbf{P h}$.

Conus Brocehii Bronn.

Corbula carinata $\mathrm{Ph}$.

- cuspidata Bronn

- ?granulata Ph.

- Kochii $\mathrm{Ph}$.

- nucleus Lam.

- revoluta Broc.

- rumosa $\mathrm{Lam}$

Crasatella ninuta $\mathrm{Ph}$.

W. Fr. L. 24: 61: 76.

W. Fr. L. 28.62.76.

$\mathbf{W}_{i}$

W.

Fr.

L.

W. Fr, L. 7. 45. 70.

Fr.

$-45$.

Cryptostoma elegans $\mathbf{P h}$.

Cyclas cornea?

Cypraea inflata Lam:

Cyprina aequalis $=$ vide islandica

- islandica $\mathbf{L}$. .

- islandicoides $=$ islandica

Cytherea deltoidea Lam.

- distans Lam.

- incrassata Sow.

- inflata Goldf.

- suberycinoides Desh. W

Delphinula carinata Ph.

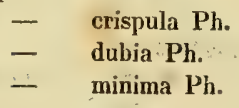

W. Fr.

Fr.

W. Iir.

WV:

W. L. 28.76.

20.5

45.

0.54 .

10.

10. 46 .$$
\text { F }
$$

Fr. -47.

Fr. 47.

L. 71 .

W. Fr. 10. 46 .

W. Fr.L. 10.46. 71.

W. Fr. 21.55.

W. 21.

W. Fr. 21. 55 .

Fr.

55.
Delphinula scabricula $\mathrm{Ph}$.

Lokalităt; , pag.

Fr. $\quad 55$.

Dentalium fossile L.

Fr.

55.

W. Fr. L. 29.62.76.

- grande Desh?

L.

76.

- strangulatum Desh. W. Fr. L. 29. 68, 76.

- striatum Lam?

L.

76.

Diplodonta lunularis Ph.

Fr.

46.

Emarginula capuliformis $\mathrm{Ph}_{\mathbf{0}}=$ pileolus

- pileolus Mich.

Erato sp. indet.

Eulima Leunisii Ph.

L.

72.

- nitida Lam..

- quadristriata $\mathrm{Ph}$.

Fr.

51.

- Scillae Scac.

L.

Fr. L.

76.

- subulata Donov.

7.

W. Fr. 19.53.

Fr. L. - 153.73.

Fasciolaria Fusus Ph.

W. Fr. 20. 62.

— pusilla? Ph.

Fusus cheruscus $\mathrm{Ph}$.

- costulatus Lam.

- elegantulus Ph.

- exilis Ph.

- Schwarzenbergii Ph.

- rugosus Parkins.

- striatus Sow.

- tenuis Desh.

Isocardia Cor Lam.

Limnaeus sp. indet

Lucina albella Lam.

- dentata Bast.

- parvula v. Müunst.

- sp. indet.

Lutraria sp. indet.

W. Fr. L. 25. 59. 75.
Fr. 59.

Fr. $\quad 59$.

W.

26.

Mactra triangula Ren.

Melania nitida Lam. etc. vide Eulima

- plicatula Desh.

Fr. L.

59. 76.

W.Fr.

25.60 .

Fr.

W.

W. Fr.

W.

59.

52.

25. 60.

W. Fr.

W.

12. 47.

25.

19.

W. Fr. L. 8.46.71.

W 8

W: 9 .

Fr. 46 .

Fr. 45.

- quadristriata Ph. vide Eulima

- reticulata Dúbois $=$ Rissoa varicosa

- secalina Ph.

W.

7. 45.

- spiralissima Dubois = Rissoa varicosa

Mitra cupressina Broc.

- Ebenus Lam. var.

Fr.

Fr.

W.

W.

Modiola carinata Broc.

W.1.

\section{3.}

19.

61.

61.

28.

14.

15. 
Modiola sericea Bronn

Murẹ Capito Ph.

- horridus Broc $=$ Typhis Fr.

- simplex $\mathbf{P h}=$ Typhis $\mathbf{W} \cdot \mathbf{F}$.

'- vaginatus De Cr. et Jan. W.

Mya intermedia Sow. vide Panopaea

Mytilus sp, indet.

L.

Natica castanea Lam.

- dilatata Ph.

W. Fr. L. 20.54. 74.

W.

20.

Niso minor $\mathrm{Ph}$.

Fr. L.

53. 74.

Nucula compta Goldf. $=$ sulcata

- margaritacea Lam. .'W:Fr.

- minuta Broc.

W. Fr. L.

14.48.

- nitida Broc.

W. Fr.

W. Fr.

W. Fr.

14. 48.71 .

14. 48 .

- placentina Lam.

- sulcata Bronn

Odostomia Flem. vide Rissoa

Ostrea bullata $\mathrm{Ph}$.

- caudata v. Münst.

W.

W.

- deltoidea Goldf non Lam. W.Fr.

Paludina sp. indet.

W.

14.48 .

14. 48 .

Panopaea elongata v: Münst.

Fr.

W. Fr.

intermedia Sow.

Parthenia Lowe vide Pyrgiscus

\section{Pecten ambiguus v: Münst.}

Fr.

- antiqualus Ph.

Fr.

- asperulus v: Münst.

W. Fr.

- bifidus v. Münst.

W. Fr.

- crinitus v. Münst.

Fr.

- decussatus v. Münst.

W. Fr.

- IIausmanni Goldf. v. bifidus

- Hoffmanni Goldf. Fr.

- limatıs v. Münst. W.

- lucidus Goldf.'v. bifidus

- macrotus Goldf?

- Münsteri Goldf.

Fr.

_ pecioralis v. Münst.

- pygmaeus.v. Münst.

Fr.

16.

16.

16. 50 .

7.45 .

- striatus v. Münst.

- textus Ph.

Pectunculus auritus Broc.

- crassus Ph.

- granulatus Lam.

$$
\text { Fr. }
$$

50 .

15. 48 .

15. 48 .

49.

15. 49 .

49.

48.

W.Fr. L. 15. 50. 73.

Fr.

48.

Fr. L.

Fr. L.

50. 72 .

47. 72.

W. Fr. L. 13.44.71.

Fr. L.

48. 72.

- minutus Ph. W. Fr. L.

14. 48.72 .
Lokalität.

pag.

Pect. pulvinatus Lam, var.? W. Fr. L. 13, 47.71.

Pileopsis ungarica Lam.

Fr.

50.

Pleurotoma acutangulare Desh. IW.Fr. … 24. 52.

- belgicum v. Münst. W. Fr. : 23.56 .

- curvicosta Lam. W. Fr. 23. 57.

- discors $\mathrm{Ph}$. $\mathrm{Fr}$. 58 .

- Hausmanni Ph. Fr. 57.

- plicatile Desh. $\quad$ Fr. 58.

- Roemeri Ph. 56.

- rugulosum Ph. Fr. 58.

- simplex Ph. $\mathrm{Fr}_{\mathrm{r}} \quad 57$.

- undatellum Ph. W. Fr. 24. 58.

- sp. innom. $\quad$ Fr. 57.

Pollicipes? sp.

Psammobia angusta $\mathbf{P h} . \mathbf{W} \quad \boldsymbol{7}$.

Purpura trochlea Lam? ? 61 .

Pyramidella terebellata Lam. $\quad F_{r .}$ L. 54. 74.

Pyrgiscus elongatus $\mathrm{Ph} . \quad \mathrm{Fr} .{ }^{\circ} \quad 53$.

- Kochii $\mathbf{P h}, \quad 53$.

Pyrula clathrata Lam, W. Fr. L. 26.60.76.

- megacephala $\mathrm{Ph} . \quad W_{\text {V }} 26$.

Ringicula striata Ph.

Rissoa crenulata Mich.

W. Fr. L. 28.61. 76.

- interrupta Adams Fr. L. 52.73.

- interstincta Mont. $\quad 73$.

- nana Ph. Fr. $\quad$ F2.

- ovulum Ph. 51.

- pusilla $\mathbf{P h}=$ nana

- reticulata Pho $\mathbf{L}$.

- rimata $\mathrm{Ph} . \quad \mathrm{Fr}$

- Terebellum Ph.

- unidentata Mont.

- varicosa Bast.

Scalaria amoena $\mathrm{Ph}$.

W. Fr L 21.54.

- decussata Lam. W.Fr. L. 21.54.74.

- insignis Leunis $\mathbf{F r}$. 54.

- pusilla Ph. $\quad$ Fr. L. 54.74.

- reticulata $\mathbf{P h} \quad$ Fr. 55.

- rudis $\mathrm{Ph}$. 21.

Sigaretus vide Cryptostoma.

Siliquaria anguina L. $\quad L$. $\quad 74$.

Solarium acies $\mathbf{P h} \quad$ L. $\quad 74$.

Solen Ensis L. W. Fr. 6. 45.

- Hausmanni Schloth $=$ S. Ensis.

71. - parisiensis Desh. W.

6. 


\section{Tellina distorta Poli \\ - pusilla $\mathbf{P h}$. \\ - rostralina Desh. \\ - tumida Broc.}

Terebra plicatula Lam.

Terebratula pusilla $\mathrm{Ph}$.

Tornatella punctato-sulcata Ph. WV.Fr.L. 27.61.76.

Tritonium rugosum $\mathrm{Ph}$. - tortuosum $\mathrm{Ph}$.

Trochus elegantulus $\mathrm{Ph}$.

- scrutarius $\mathrm{Ph}$.

$\div$ sp. indet.

Türbo bicarinatus $\mathrm{Ph}$.

- conoideus Broc. $=$ Auricula c.

- exiguus. Ph.

Fr.

IV.

27.

- interruptus Adams = Rissoa

- interstinctus Mont = Rissoa

- simplex $\mathrm{Ph}$.

Fr. L.

- spiratus Broc. = Turritella carinifera

- unidentatus Mont $=$ Rissoa

Turritella carinifera Iam.

L.

75.

- communis Riss. W. Fr. L. 22.56.75.

- imbricataria Lam.

Fr.L.

sp. indet.

L.

56.75.

Venericardia vide Cardita

Venus decipiens $\mathrm{Ph}$.

W:

- incrassata Sow. vide Cytherea

- incrassata Broc. vide Astarte

- islandica $\mathbf{L}$. vide Cyprina

- Lens Ph.

- plicata.L.

Voluta harpula Lam.

- plicatula Broc. vide Mitra.

\section{Polythalcmien.}

Cristellaria osnabrugensis v. M. . Fr. subcostata v. M. $\quad$ Wi Fr. L. 5.42.70.

Frondicularia elongata v. Münst. W.

$$
\begin{aligned}
& \text { - lancea Ph. } \quad \mathbf{F r} \\
& \text { - oblonga v. Münst. W. }
\end{aligned}
$$

Frondiculina y. Münst. vide Lingula p. 39 Note.
42.

75.

11.

11.

11.

28.

5.

39.

5.

5.

5. 


\section{Triloculina ovalis Röm. \\ Truncatulina communis d'Orb. \\ Vaginulina laevigata Röm. \\ Fandiarien.}

Apiocrinites obscurus v. Münst. W.

Asterias propinqua v. Münst.

Cidarites sp. indet.

Fr. L. $\quad$ 44. 70.

Fr.

W. Fr.

Echinoneus ovatus v. Münst.

Fr.

Fr.

— pusillus v. Münst.

Nucleolites subcarinatus v. Münst. Hildesh.

Spatangıs acuminatus v. Münst.

Cassel.

- Hoffmanni?

Fr. L ? pag.

6. 43.

42.

อ.
6.

4.

\section{zoophyten.}

Cellaria gracilis $\mathrm{Ph}$.

- hexagona v. Münst.

- marginata v. Münst.

- rhombifera v. Münst.

- tetragona v. Münst.

Cellepora sp. indet.

Ceriopora minuta $\mathbf{P h}$.

- spiralis Goldf.

- stellata Goldf.

- variabilis v. Münst.

- verrucosa Ph.

Cumulipora angulata v. Münst.

Cyathina firma $\mathrm{Ph}$.

- granulata v. Münst.

- Münsteri Röm.
Fr.

Fr. L.

Fr. L.

Fr.

Fr.

Fr. L.

Fr.

Fr.

Fr. L.

Fr. L.

L.

L.

L.

W. Fr. L

Fr.

Cyathina pusilla $\mathrm{Ph}$.

Lokalitāt.

L.

pas:

Desmophyllum Stellaria Ehrenb. L.

Discopora circumcincta $\mathbf{P h}$.

W. Fr.

L.

Fr.

W Fr.

Fr. 1 .

Fr. $\mathbf{L}$.

L.

Fr. L.

Fr. L.

Fr.

44. Flabellum irömeri $\mathrm{Ph}$.

Glauconome v. MIünst. vide Cellaria.

Hornera biseriata Ph.

- gracilis Ph.

Fr. L.

Fr. L.

36.67 .

- subannulata $\mathrm{Ph}$.

Fr.

36. 67.

Idmonea biseriata $\mathrm{Ph}$.

L.

36.

Lunulites perforatus v. Münst. $=$ radiatus.

37.69 .

37.69 .

37.

37.

39. 68 .

37.

37.

36. 67 .

36.67 .

67.

68.

66.

3. 35.66 .

38.
- radiatus Lamk.

W. Fr. L rhomboidalis v. Münst:

W.

L.

Manon? cylindraccum $\mathbf{P h}$.

Nillepora madreporacea vide truncata - punctata $\mathrm{Ph}$.

L.

Fr. L. truncata $\mathbf{L}$.

Fr. L.

Retepora cellulosa Lam. vibicata Goldf: $=$ cellulosa

Turbinolia granulata v. M. besser Cyathina. - intermedia v. Münst. IV. l'r. - sulcata Lamk?

Fr.

Vincularia Dfr. vide Cellaria.

Myriapora Blainv = Nillepora
66.

67.

4. 39 .

68.

39.

4. 38.

38,68 .

38.68 .

68.

38. 68 .

38. 68 .

34.

35. 67.

3. 34 



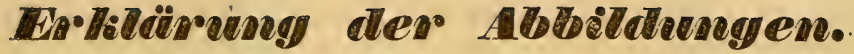

Bemerkung. Auf allen Tafeln bezeichnet $a$ die natürliche Grösse.

\section{Tab. I.}

Fig. 1. Cyathina? Münsteri Röm.

Pag.

2. Flabellum Römeri Ph.

3. Turbinolia sulcata Lam.? v. Freden

4. Turbinolia sulcata Lam? v. Paris

5. Cyathina pusilla $\mathrm{Ph}$.

6. Cyathina firma $\mathrm{Ph}$.

7. Hornera gracilis $\mathrm{Ph}$.

8. - biseriata $\mathrm{Ph}$.

9. - subannulata $\mathrm{Pl}$.

10. Ceriopora variabilis v. Münst.

* 11. - minuta $\mathrm{Ph}$.

v 12. - verrucosa Ph.

y 13. Millepora punctata $\mathrm{Ph}$.

* 14. Cellaria gracilis $\mathrm{Ph}$.

" 15. Idmonea biseriata $\mathrm{Ph}$.

" 16. Eschara imbricata $\mathrm{Ph}$.

* 17. Manon? cylindraceum $\mathrm{Ph}$.

* 18. Eschara porosa Ph.

* 19. - punetata Ph.

* 20 . - diplostoma $\mathrm{Ph}$.

" 21 . - glabra Ph.

v 22. Ceriopora spongiosa $\mathrm{Ph}$.

- 23. Discopora mammillata Ph.

* 24. Eschara clathrata Ph.

v 25. Discopora circumeincta $\mathrm{Ph}$.

* 26. Rotalia discifera $\mathrm{Ph}$.

y 27. Marginulina? (s. potius Planularia?) spirata $\mathrm{Ph}$.

- 28. Marginulina? (s. potius Planularia?) arcuata $\mathrm{Ph}$.
Fig. 29. Marginulina? (s. potius Planularia?) compressiuscula $\mathrm{Ph}$.

30. Cidarites sp.

31. Frondicularia lancea $\mathrm{Ph}$.

linearis $\mathrm{Ph}$.

" 32

33. Nodosaria acicula $\mathrm{Ph}$.

35. - compressa $\mathbf{P h}$.

36. Triloculina carinata $\mathrm{Ph}$.

37. Marginulina? Gladius $\mathbf{P h}$.

38. Planularia intermedia $\mathbf{P h}$.

39. - semicircularis $\mathbf{P h}$.

40. Triloculina angusta $\mathrm{Ph}$.

\section{Tab. II.}

Pag.

1. Panopaea elongata v. Münst. 45

2. Corbula? granulata $\mathrm{Ph}$. $\quad \mathbf{4 5}$

3. Corbula Kochii Ph. 70

4. Crassatella minuta $\mathbf{P h}$. $\quad \mathbf{4 5}$

5. Corbula carinata $\mathbf{P h}$, $\quad \mathbf{4 6}$

6. Psammobia angusta $\mathrm{Ph}$. 7

7. Diplodonta lunularis $\mathrm{Ph}$. $\quad \mathbf{4 6}$

8. Cardium pulchellum $\mathbf{P h}$. $\quad 47$

9. Venus? decipiens 11

10. Venus lens $\mathrm{Ph}$. 11

11. Astarte laevigata Münst. 9

12. Anomia asperella $\mathrm{Ph}$. 50

"13. Pectunculus pulvinatus Lam. varietas? 13

" 14. Modiola pygmaea $\mathrm{Ph}$. 15

15. Terebratula pusilla $\mathrm{Ph}$. 15 
Fig. 16. Pecten texius $\mathrm{Ph}$.

- 17. Ostrea bullata Ph.

\section{Tab. III.}

* 1. Emarginula punctulata $\mathrm{Ph}$.

51

- 2. Bulla lineata Ph.

* 3. - retusa Ph.

๖. 4. - intermedia $\mathrm{Ph}$.

5. - terebelloides $\mathrm{Ph}$.

- 6. Auricula gracilis $\mathrm{Ph}$.

* 7. Chemnitzia (Pyrgiscus) Kochii Ph.

* 8. Eulima (Melania) Leunisii $\mathrm{Ph}$.

\% 9. - - quadristriata Ph.

, 10. Chemnitzia (Pyrgiseus) elongata $\mathrm{Ph}$.

- 11. Auricula subcylindrica Ph.

, 12. Rissoa ovulum Ph.

* 13. - interrupta Adams

, 14. - unidentata Mont.

"15. Melania? secalina $\mathrm{Ph}$.

, 16. Niso minor $\mathrm{Ph}$.

y 17. Rissoa rimata $\mathrm{Ph}$.

* 18. - interstincta Mont.

, 19. - terebellum Ph.

" 20. Natica dilatata $\mathrm{Ph}$.

, 21. Scalaria insignis Leunis

* 22. Tornatella punctato-sulcata Ph.

* 23. Scalaria amoena Ph.

- 24. Sigaretus (Cryptostoma) elegans Pb.

, 25. Scalaria reticulata Ph.

๑ 26. Delphinula ? .carinata $\mathrm{Ph}$.

^ 27. Scalaria rudis Ph.

" 28. Delphinula? dubia $\mathbf{P h}$.

, 29. Scalaria pusilla Ph.

" 30. Delphinula? minima $\mathrm{Ph}$.

* 31. - crispula $\mathrm{Ph}$.

" 32. Solarium acies $\mathbf{P h}$.

" 33. Delphinula? scabricula Ph.

* 34. - suturalis $\mathrm{Ph}$.

35. Trochus elegantulus $\mathbf{P h}$.
Fig. 36. - sp.

\% 37. - scrutarius $\mathbf{P h}$.

\section{Tab. IV.}

1. Turritella sp.

2. Turbo exiguus $\mathrm{Ph}$.

3. - bicarinatus $\mathbf{P h}$.

4. - simplex Ph.

5. Cerithium bitorquatum $\mathbf{P h}$.

ø 6. Pleurotoma undatellum $\mathrm{Ph}$. 24

ע 7. - Leunisii Ph. 56

„8. - simplex Ph. 57

» 9. - 1 lausmanni Ph. 57

ข. 10 . - discors Ph. 58

" 11. Fasciolaria? pusilla Ph. , 59

„12. Fusus exilis $\mathrm{Ph}$. , 25

"13. Chenopus paradoxus Ph. ... . 24

„ 14. Fasciolaria Fusus Ph. _ : 25

๖. 15. Fusus Schwarzenbergii Ph. $\quad 59$

` 16. - elegantulus $\mathrm{Ph}$. 59

» 17. Purpura sp, alfinis P. trochleae 61

y 18. Pyrula megacephala $\mathrm{Ph}$. . 26

, 19. Murex capito Ph. 60

„20. Derselbe, jung $\quad 60$

y 21. Fusus cheruscus $\mathrm{Ph}$. $\quad 59$

ø 22. Murex (Typhis) simplex $\mathrm{Ph}$. 26

„23. Ringicula striata $\mathrm{Ph}$. _. 28

- 24. Tritonium tortuosum $\mathrm{Ph}$. 60

๖ 25. Tritonium rugosum $\mathrm{Ph}$. $\quad 27$

» 26. Cytherina *)

„27. Coprolithen?

28. Coprolith *).

*) Diese Cytherina und diesen Coprolithen habe ich erst nach Beendigung des Druckes erhalten, er ist aus Freden. Sollte eine Fortsetzung dieser Beiträge erscheincn, wozu mir von mehrern Seiten, namentlich von IIerrn S a ck Material versprochen ist, so werde ich $\mathrm{zu}$ den hier beschriebenen Versteinerungen noch den einen und den anderu Nachtrag liefern. 

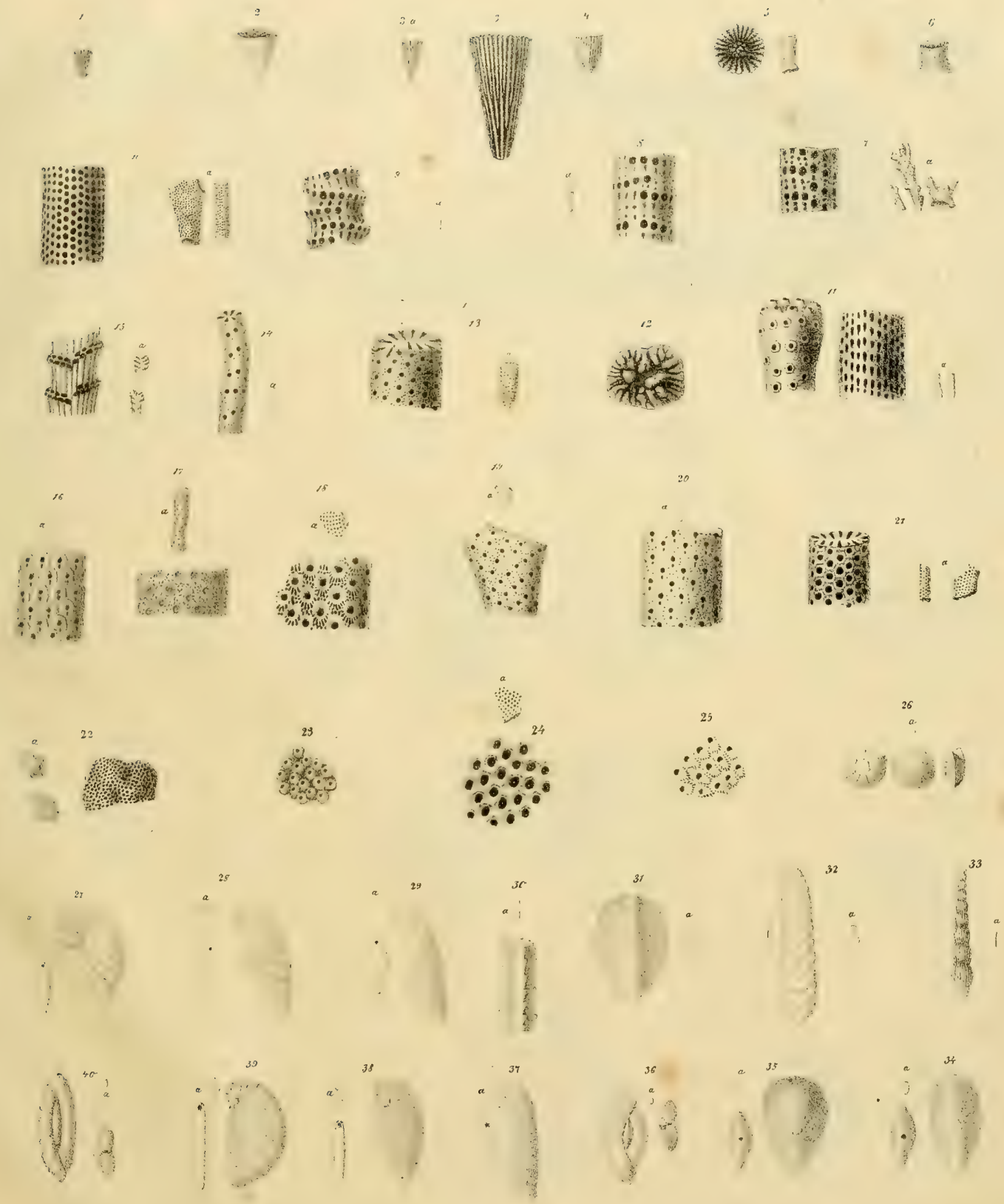

Tab.II.
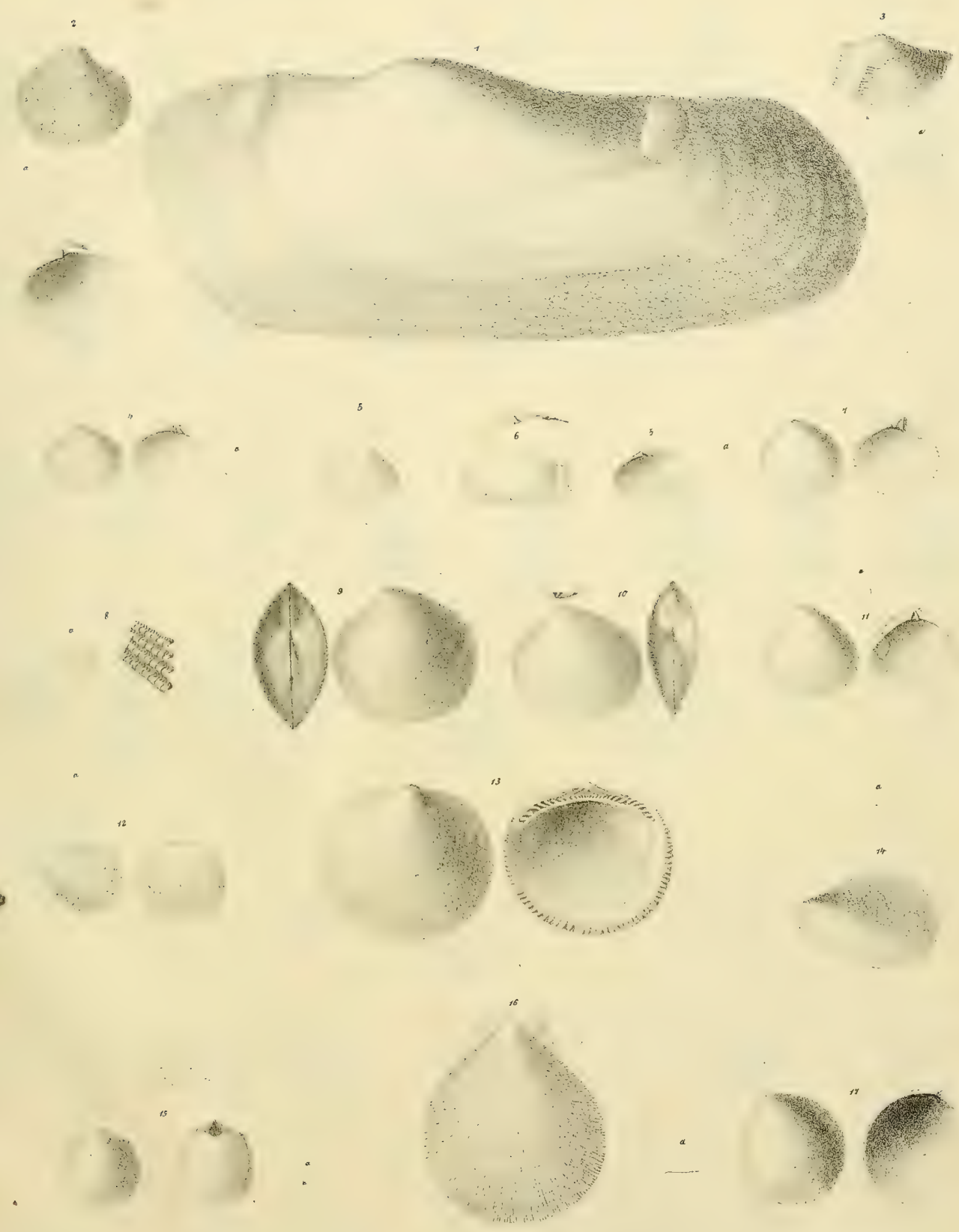

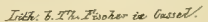



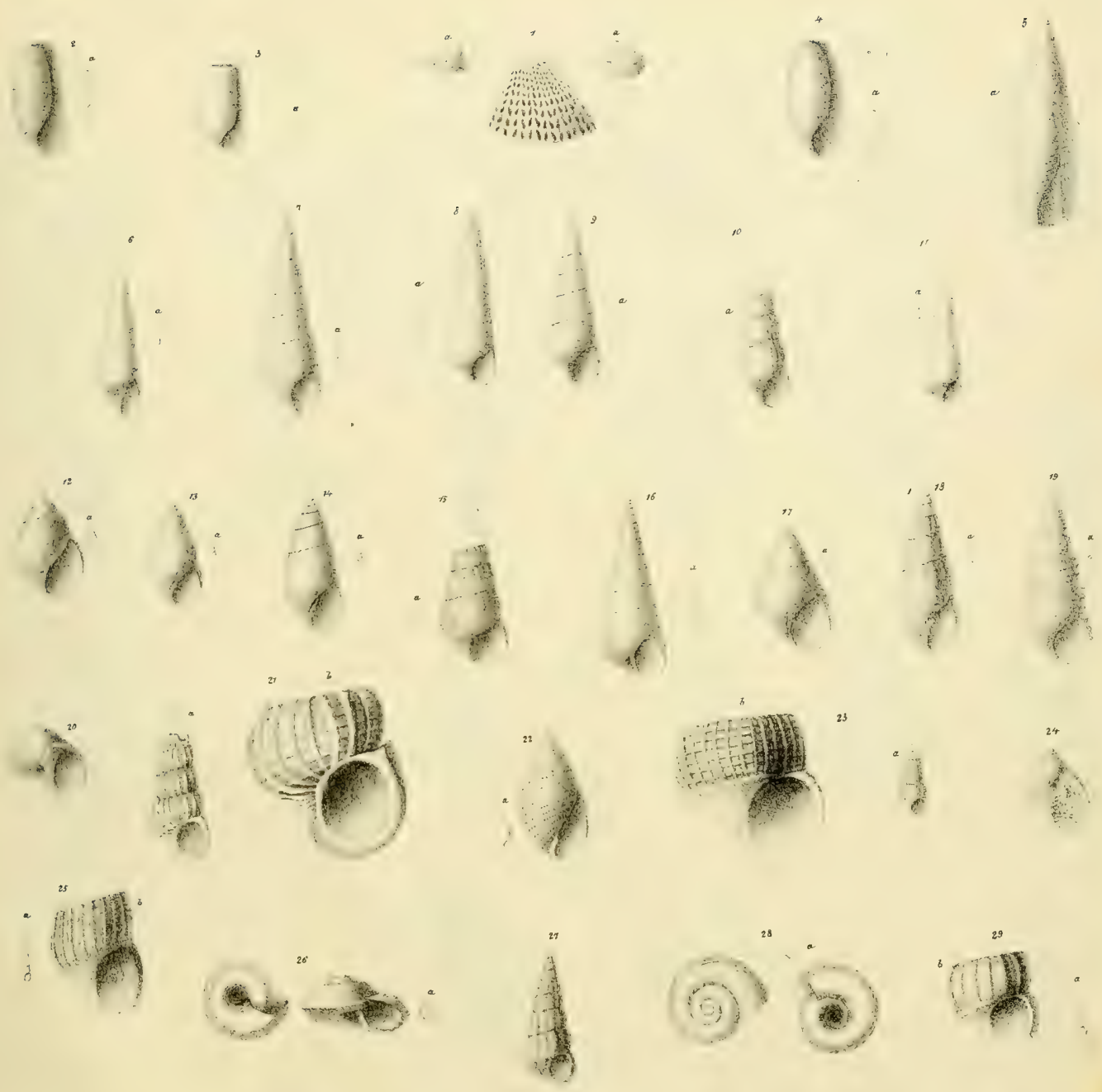

(6)
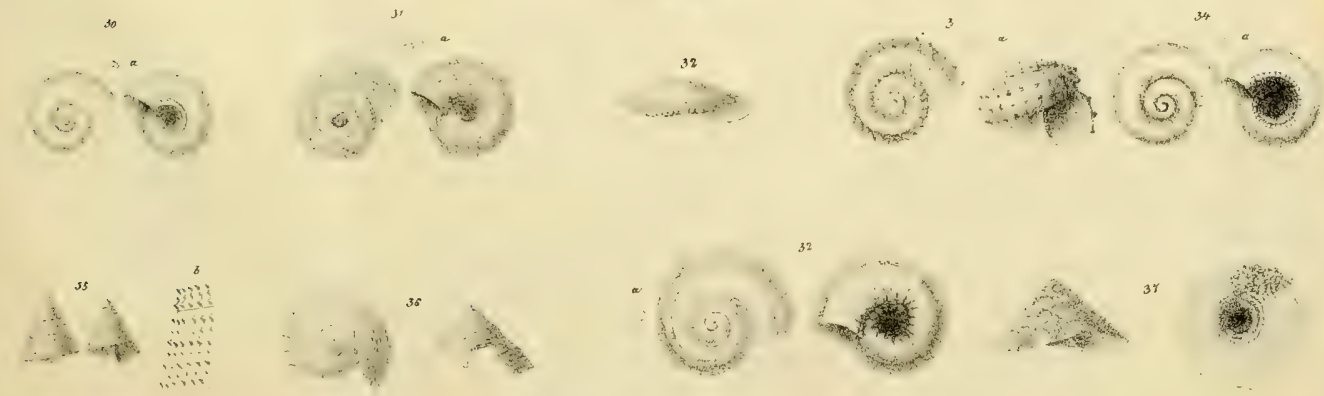

t
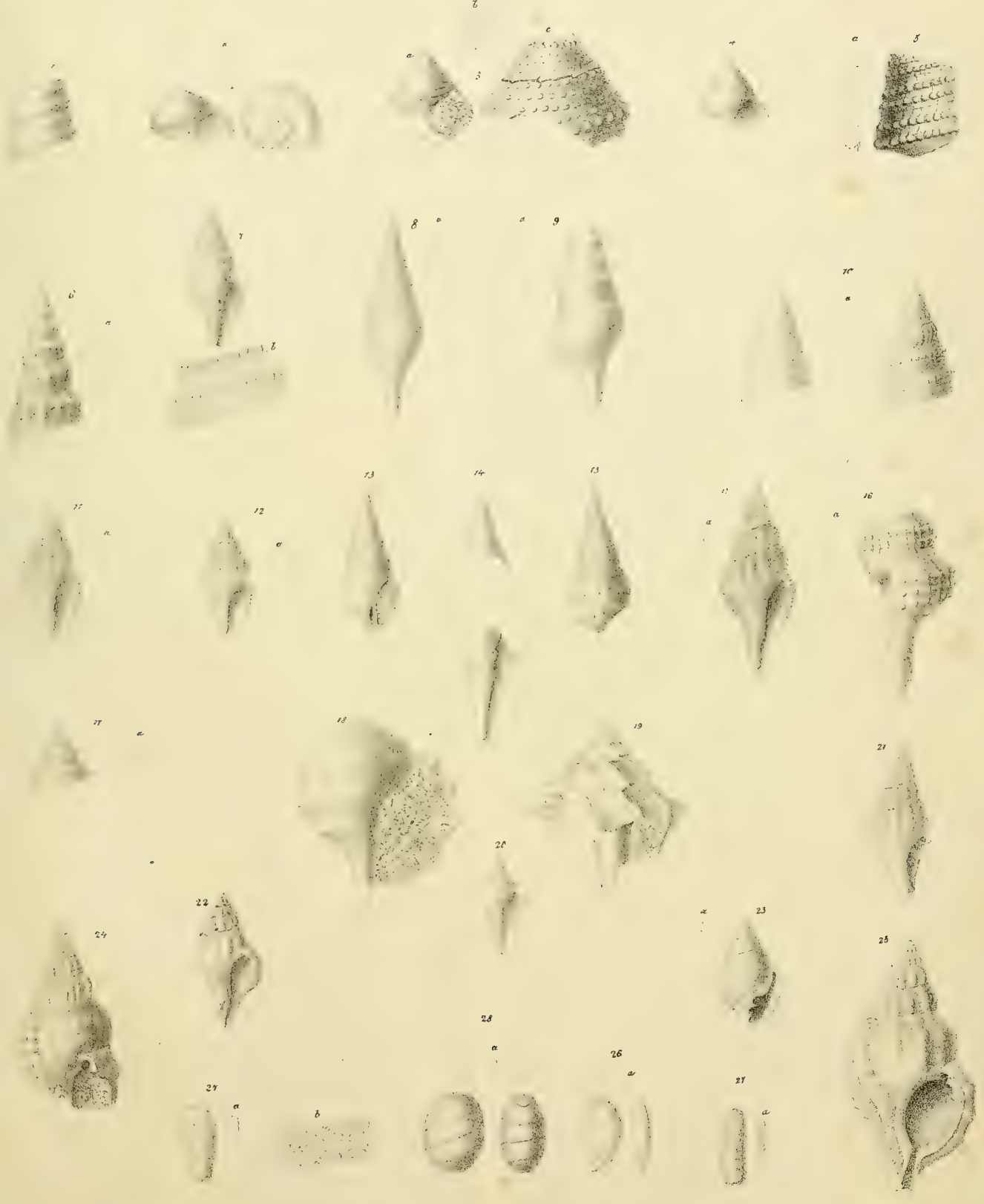

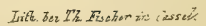





\section{Date Due}

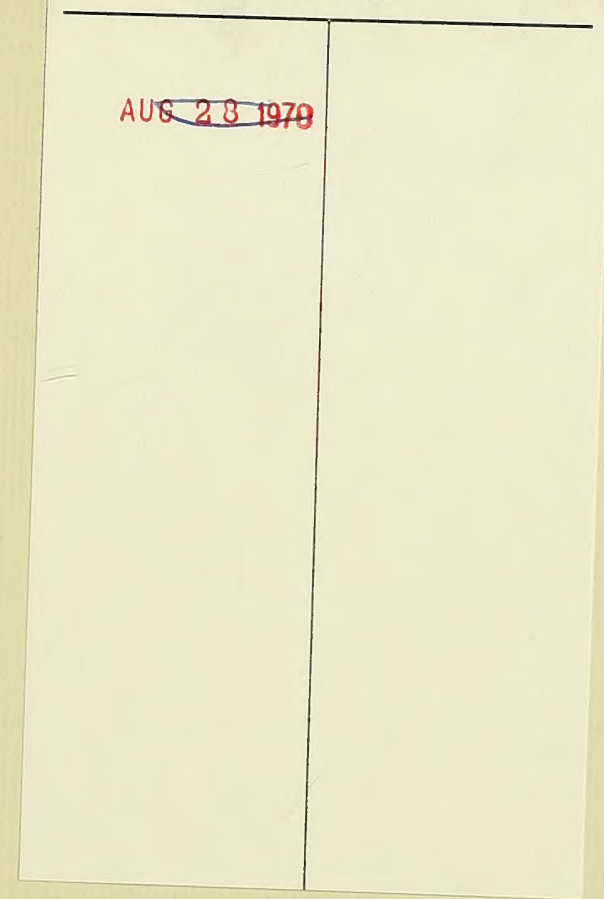




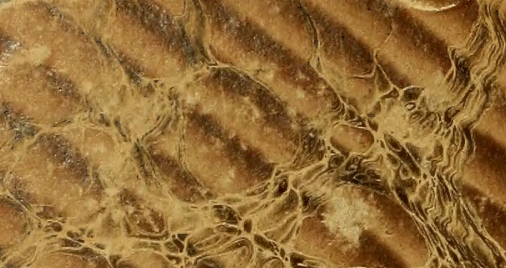

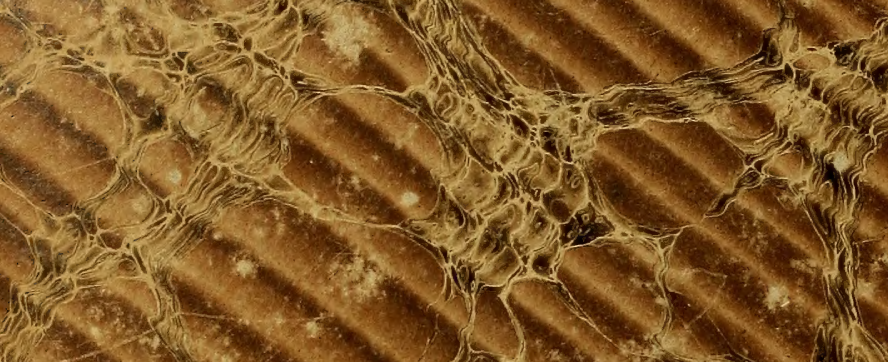
-3.

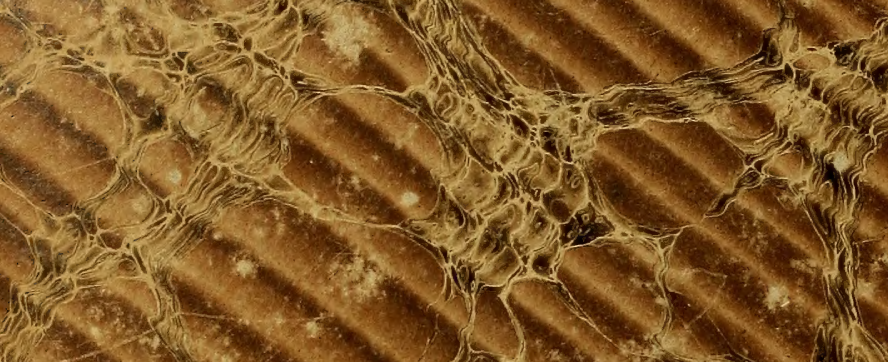
fitis 2 20.5.

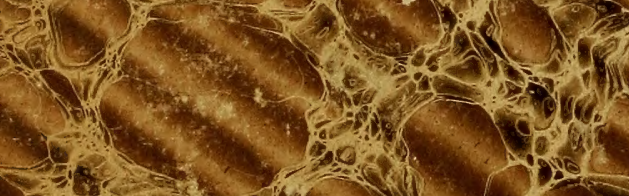

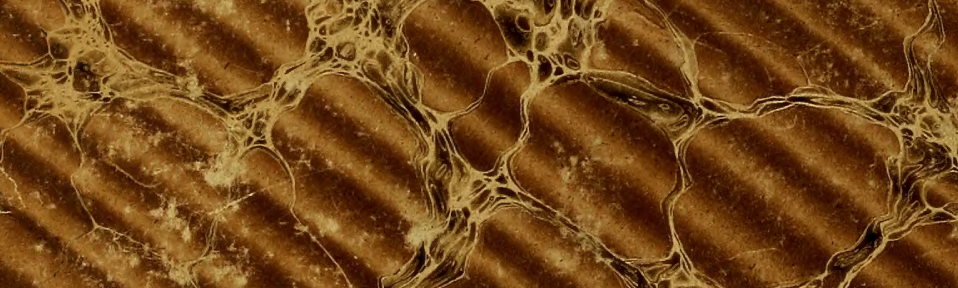
$3^{2} y^{2}+2$ - 25 mity $x+5$

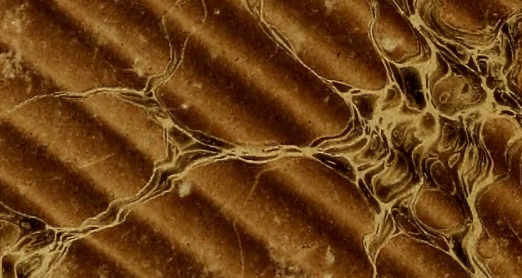
7. 15

)है . ivit 